\title{
Weitere Beiträge zur Histologie und Pathologie der Meningitis und Sinusthrombose.
}

\author{
Von \\ Privatdozent Dr. Hermann Streit. \\ (Mit Tafel VI-IX.)
}

In meiner Arbeit ,Histologische Fragen zur Pathologie der Meningitis und Sinusthrombose" habe ich die Frage offen gelassen, ob die ersten Stadien der Entzündung an der Durainnenfläche resp. den Leptomeningen stets durch direkte bakterielle resp. bakteriell toxische Wirkung durch die Dura selbst eingedrungener Bakterien erzeugt werden, oder ob unter Umständen eine rein toxische Fernwirkung von Bakterienmassen, die sich außerhalb der Intraduralräume befinden, zur Erklärung herangezogen werden kann. Außerdem sohien es mir wichtig, wenn es möglich ist, festzustellen, ob sich bei der bakteriell entstandenen Pachymeningitis interna Bakterien außerhalb der pachymeningitischen Plaques im Subduralraum selbst nachweisen lassen. Und schließlich interessierte mich die Frage, ob bei zirkumskripten, eventuell etwas ausgedehnteren bakteriellen pachy- resp. leptomeningitischen Prozessen Bakterien im Rückenmarkskanal vorhanden sind.

Wir werden in folgendem sehen, wie weit es mir gelungen ist, auf die erste und zweite der zur Diskussion stehenden Fragen eine befriedigende Antwort zu geben. Was das letzte der aufgeworfenen, einer Lösung noch harrenden Probleme betrifft, so möchte ich gleich von vornherein betonen, daß hierzu meine experimentell gewonnenen Erfahrungen nicht ausreichen. Es dürfte jedoch meinem Ermessen nach für jemand, der meine Versuche nachprüft und die von mir ge-

1) Streit, Histologische Fragen zur Pathologie der Meningitis und Sinusthrombose. Archiv f. Ohrenhk. 83. Heft 3 u. 4.

Auch in dieser zweiten Arbeit bin ich ebenso wie bei Teil I, was die Erlaubnis zum Halten der Versuchstiere usw, betrifft, vielfach auf die Hilfe und Unterstützung des hiesigen pathologisehen Instituts angewiesen gewesen. Ich bin dem Direktor desselben, Herrn Professor $\mathrm{H}$ e $\mathrm{n} \mathrm{k}$ deshalb zu großem Dank verpflichtet.

Archiv f. Ohrenheilkunde. Bd, 89. 
machten Fehlerquellen vermeidet, wohl möglich sein, auf dem geschaffenen Fundamente weiterzubauen und auch diese Aufgabe einwandsfrei $\mathrm{zu}$ lösen ${ }^{1}$ ). Ich komme hierauf noch am Schlusse meiner Ausführungen zu sprechen und gehe zunächst dazu über, die nähere technische Ausführung meiner Experimente zu schildern, und zwar natürlich nur, insofern dieselben von meiner ersten Versuchsreihe abweichen.

Da es sich für mich in dieser zweiten Arbeit, wie bereits erwähnt, darum handelte, die ersten Zeichen von Entzündung der Hirnhäute an einer größeren Versuchsreihe festzustellen, konnte' ich von einer längeren Beobachtungsdauer absehen. Ich habe mich deshalb darauf beschränkt, die Versuchstiere ein bis drei Tage zu beobachten; nur ein Tier habe ich fünf Tage lang am Leben gelassen. Dagegen kam es mir darauf an, möglichst kräftige Reaktionsäußerungen von seiten der Intraduralräume zu erzielen. Diese Absicht suchte ich dadurch zu erreichen, daß ich bei dem ersten Teil meiner Fälle zwar noch in ähnlicher Weise vorging, wie bei meiner zu Anfang erwähnten Arbeit, d. h. die Bakterienaufschwemmungen der freigelegten Duraaußenfläche einfach applizierte und einen gewöhnlichen Verband anlegte; jedoch brachte ich, soweit ich darüber verfügte, als ganz besonders virulent bekannte Stämme in Anwendung. Aus demselben Grunde benutzte ich bei einzelnen Beobachtungen Mischkulturen von Streptokokken resp., was mir besonders praktisch scheint, eine Mischkultur von Streptokokken und Kolibazillen. In dem zweiten Teil meiner Versuche habe ich, ebenfalls von der Absicht geleitet, möglichst ausgedehnte Entzündungserscheinungen zu erreichen, die von Ha y mann ${ }^{2}$ ) in seiner Arbeit ,Zur experimentellen Erzeugung der Sinusthrombose" inaugurierte Art der Infektion angewandt, d. h. es wurde ein mit Bakterien vollgesogener Gazetampon der Oberfläche der freigelegten Dura direkt angelegt und dort unter Druck befestigt. Ich möchte gleich hinzufügen, daß3 der gewünschte Effelkt von mir hierdurch bisweilen zwar erreicht wurde, bisweilen jedoch auch

1) Soweit mir die Literatur bekannt ist, existieren zum gleichen Thema auBer meinen experimentellen Versuchen nur einige Tierexperimente Uffenordes, über die ich der Arbeit des Autors: Beiträge zur otogenen Allgemeininfektion, Zeitschr. f. Ohrenhk. 60, folgendes entnehme: ,Nach Trepanation des Schädels wurden Kulturen verschiedener Bakterien vorsichtig zwischen Knochen und Dura eingestrichen. In fast allen Fällen trat eine foudroyante Sepsis ein." Weitere histologische Details habe ich an Ort und Stelle nicht finden können.

2) Haymann, Sinusthrombose und otogene Pyämie ixn Lichte experimenteller Untersuchungen. Archiv f. Ohrenhk. 83. Heft 1 u. 2. 
bei diesem Infektionsmodus die erzielten Reaktionserscheinungen das gewöhnliche Maß kaum überschritten.

In folgendem will ich zunächst die Beschreibung meiner experimentell gewonnenen Resultate in extenso geben.

Hund T. Infiziert mit einer für die gewöhnlichen Versuchstiere hochvirulenten Streptokokkenkultur, die aus dem hiesigen hygienischen Institut bezogen wurde (drei Tropfen einer eintägigen Bouillonkultur). Getötet nach einem Tage.

Sektionsprotokoll: An der DuraauBenfläche sieht man, entsprechend der Infektionsstelle, einige minimale Erhabenheiten. An der Durainnenfläche sind keine Besonderheiten nachweisbar. Das Gehirn erscheint normal.

Mikroskopischer Befund: Der Außenfläche der harten Hirnhaut läuft ein schmaler Exsudatstreifen parallel. Innerhalb des letzteren lassen sich reichliche gelapptkernige Leukocyten und Fibrin nachweisen. Von diesem entziündlichen Exsudat aus dringen Eiterzellen an einzelnen Stellen in ziemlicher Menge quer durch die Lamellen der Dura mater und erscheinen auf der Innenfläche derselben wieder. An der letzteren Stelle kann man in einzelnen Präparaten keine besonders hervortretenden entzündlichen Erscheinungen, vielleicht mit Ausnabme einer stellenweise sich bemerkbar machenden starken Zellvermehrung, feststellen. In anderen Schnitten treten, anscheinend isoliert voneinander, fibxinöse Plaques auf. Diese intraduralen pachymeningitischen Exsudate liegen allenthalben unterhalb des intakten, aber im übrigen bäufig entzündlich gewucherten Endothels. Neben und mit ihnen zusammen finden sich Haufen von gelapptkernigen Leukocyten. Man kann konstatieren, daß an einzelnen Punkten Bakterien die harte Hirnhaut durchwandern und auf der Innenfläche derselben wiedererscheinen. Im übrigen sind innerhalb der Dura selbst nur ziemlich spärliche Kokkenhäufchen nachweisbar. An den weichen Hirmhäuten fällt zwar ein relativ stark ausgeprägter Zellreichtum auf, im übrigen lassen sich jedoch irgendwie bedeutende Zeichen von Entzïndung hier nicht feststellen.

Hund. II. Tnfiziert mit derselben hochvirulenten Streptokokkenkultur wie Hund I (drei Tropfen einer eintägigen Bouillonkultur). Getötet nach zwei Tagen.

Sektionsprotokoll: Die Außenfläche der Dura mater erscheint durch ein kleines entzündliches Granulationsknöpfehen verdickt, die Innenfläche ist anscheinend normal. Am Gehirn und den Hirnhäuten lassen sich keine Besonderheiten nachweisen.

Mikroskopischer Befund: Die oberflächlichsten Zellschichten dex harten Hirnhaut sind ziemlich stark von gelapptkernigen Leukocyten durchsetzt, an einer Stelle findet sich ein Exsudatknöpfchen, das aus Fibrin und Eiterzellen zusammengesetzt ist.

Der Durainnenfläche verläuft stellenweise ein schmaler Saum von anscheinend entzïndlich veränderten Zellen parallel. In einigen Präparaten sieht man auf der Innenfläche der Dura ein ziemlich kleines Klümpchen von fibrinöser Struktur aufsitzen, welches von gelapptkernigen Leukocyten infiltriert ist. Bisweilen durchsetzen Eiterzellen quer die harte Hirnhaut. In anderen Schnitten wiederum kann man sowohl auf der Außen- wie Innenfläche der harten Hirnhaut geringere entzündliche Auflagerungen lzonstatieren, während die trennenden Duraschichten so gut wie frei sind von Veränderungen entzündlicher Art.

Überall sieht man die vorher erwähnten, im allgemeinen ziemlich wenig ausgeprägten Entzündungserscheinungen der Durainnenfläche durch ein gut erhaltenes Endothel vora Subduralraum sich abgrenzen. 
In einzelnen Präparaten lassen sich auf der Innenfläche der Dura nicht unbedeutende Fibrinanhäufungen, untermischt mit gelapptkernigen Leukocyten, nachweisen. Bisweilen durchdringen Bakterien, allerdings in geringer Menge, die ganze Dicke der harten Hirnhaut. Am Gehirn und den weichen Hirnhäuten fehlen Anzeichen von Entzündung sowie Bakterien.

Hund IIT. Geimpft mit einer Streptokokkenkultur (aus Osteomyelitis des Menschen gewonnen), Virulenz für weiße Mäuse: Ein ccm tötet eine weiBe Maus in 24 Stunden. Hund wird getötet drei Tage post infect.

Sektionsprotokoll: Úber der Infektionsstelle ist in der Muskulatur ein mächtiger Abszeß entstanden; in demselben finden sich Kolibazillen in Reinkulturen. Auf der Außenfläche der Dura mater kann man eine kleine Granulation konstatieren. Auf der Durainnenfläche ist zunächst bei der Obduktion nichts Pathologisches festzustellen. Auch bei genauem Hinsehen bleibt es zu Anfang ungewiB, ob auf der Innenfläche ein Belag ist oder nicht. Eirst bei genauester Untersuchung fällt eine recht schwer nachweisbare Linie ins Auge, die der Peripherie eines intraduralen Exsudats entspricht. Bei Einbettung in Formol wird diese Linie noch deutlicher (siehe $\mathrm{Abb}, 4$ ). Am Gehirn und an den Hirnhäuten werden makroskopisch keine Besonderheiten nachgewiesen.

Aus dem Intraduralraum der infizierten Seite werden Streptokokken und Kolibazillen gezüchtet.

Mikroskopischer Befund: Entsprechend der Infektionsstelle ist die DuraauBenfläche bedeckt durch ein Exsudat von unregelmäBiger Gestaltung. Dasselbe ist bald dicker, bald dünner und besteht zum gröBten Teil aus kleinen Rundzellen sowie gelapptkernigen Leukocyten. In seinen tieferen Partien treten besonders im AnschluB an die Dura selbst daneben auch Schwärme junger Fibroblasten auf, welche stellenweise bereits deutlich nachweisbare junge Bindegewebsfäserchen produziert haben. Bakterien, sowohl Stäbchen wie Kokken, lassen sich innerhalb dieses Exsudatbelags ganz außerordentlich reichlich nachweisen. Im allgemeinen nimmt ihre Anzahl von auBen nach innen $\mathrm{zu}$ in bemerkenswerter Weise ab. Die Duralamellen sieht man an verschiedenen Punkten stark aufgelockert, durch Rundzellen. und gelapptkernige Leukocyten auseinandergedrängt.

Mit diesen letateren gelangen Bakterien von der AuBenfläche der Dura in die Substanz der harten Hirnhaut hinein und durchdringen dieselbe in ihrer ganzen Dicke. Auf der Durainnenfläche hat sich ein ziemlich mächtiges Exsudat aufgelagert. Dasselbe besteht aus einem unregelmäBig geformten Maschenwerk von gröberen und feineren Fäden sowie kleinen knötchenförmigen Verdickungen. Daneben verläuft eine Anzahl derberer Fibrinstränge der Fläche der harten Hirnhaut parallel. Besonders nach den Rändern zu fällt mitunter eine eigentümliche Felderung dieses Exsudats auf, und zwar in der Weise, daß dasselbe an gewissen Punkten resp. Linien unterbrochen erscheint. DaB man es nicht etwa mit Kunstprodukten zu tun habe, dafür spricht der Umstand, daß die Grenzen dieser Exsudatfelder oftmals besonders stark tingiert sind und sich so von ihrer Umgebung: nicht selten recht deutlich abheben. Außerdem herrscht parallel diesen Grenzlamellen ein bemerkenswerter Zellreichtum. Bisweilen sieht man dieses Exsudat nach den Rändern zu direkt übergehen in ein feinfaseriges Gewebe, das seiner Struktur nach an lockeres Bindegewebe erianert. Das Studium dieses Gewebes, welches seinem ganzen Gefüge nach absolut als Fibrinausscheidang imponiert, ist dadurch ersehwert, daß nur in einzelnen Präparaten die Weigertsche Methode eine spezifische Färbung, und zwar auch hiex nux eben andeutungsweise markiert, erkennen läBt. In den meisten Präparaten ist dies 
Gewebe bei der Weigertschen Fibrinfärbung nicht resp. mit einem grauen bzw. ganz schwach bläulichgrauen Farbenton tingiert.

Mit Pikrokarmin färbt es sich rot; es zeigt gar keine Elektivfärbung gegenüber dem Bindegewebe. Bei starker Eosin-Überfärbung (Iämatoxylin-Eosin) nimmt es einen rotvioletten Farbenton an, ähnlich den neugebildeten Zelleibern des extraduralen Exsudates. Ubberhaupt erinnert es auch in gewöhnlichen Hämatoxylin-Eosin-, Gieson- und Methylenblaupräparaten in der Art seiner Färk ung am meisten an Zelleiber junger, eben sich streckender Fibroblasten. Wenn man dieses Exsudat nun nach den Rändern hin verfolgt, so schließt sich an dasselbe zunächst ein bei schwacher Vergrößerung strukturlos erscheinender Streifen, anscheinend gleichen Materials, an, der umringt ist von einer Anzahl epitheloider Zellen. Daß man es hier mit einem ähnlichen fibrinartigen Produkt, wie es vorher beschrieben ist, zu tun habe, dafür spricht einerseits der unmittelbare innige Zusammenhang mit dem letzteren, andererseits die gleiche Farbennuancierung sowohl bei Gieson-, Hämatoxylin-Eosin- oder Weigertscher Färbung, als auch schließlich ganz besonders die Struktur dieses Exsudatbelags. Bei Anwendung der Immersion kann man die feinfaserige Formation dieses Streifens deutlich erkennen. In manchen Präparaten geht derselbe direkt über in ein zellreiches Gewebe, das durchaus an ganz junges Bindegewebe erinnert, bei dem die Gestalt der einzelnen Fibroblasten noch ganz deutlich hervortritt.

Ganz nach den Rändern der Pachymeningitis interna zu sieht man, wohl als erstes Produkt der Entzündung, den Zusammenhang zwischen Endothel und Bindegewebe gelockert, indem es zu einer Zellvermehrung zwischen Endothel und Bindegewebe gekommen ist. Diese Zellen sind zum Teil sicher Abkömmlinge des Eindothels, zum Teil kann es sich um Zellelemente handeln, die ihrem Aussehen nach aus GefäBen stammen (mononukleäre Elemente resp. gelapptkernige Zollen). Rote Blutkörper fehlen anscheinend fast völlig.

Mitunter sieht man in demselben Schnitt mehriach Stellen miteinander abwechseln, in denen die Pachymeningitis interna rein zelliger Natur ist, mit solchen, an denen das vorher geschilderte fibrinartige Exsudat gänzlich dominiert. Zumal nach den Rändern des pachymeningitischen Exudats hin ist ein derartiges Bild keine Seltenheit. Die zelligen Partien setzen sich zusammen manchmal fast nur aus den vorher erwähnten, zum Teil wohl sicher als Endothelabkömmlinge $\mathrm{zu}$ bezeichnenden großkernigen Elementen resp. aus den letzteren und mehrkernigen Leukocyten. Mitunter tauchen inmitten der zelligen Partien Inseln auf, die reinen Fibrincharakter tragen.

Beim Verfolgen lückenloser Serien kann man mitunter diese fibrinartigen Inseln direkt ineinander übergehen sehen, und zwar auf Kosten der zuricktretenden Zellinfiltration. An den Stellen, wo die Entzündung eine stärkere ist, gegen die Mitte der Infektionsstelle hin, zeigen sich derartige Verhältnisse mit großer Regelmäßigkeit, so daß schließlich das fibrinartige Exsudat gegenüber dem Zellinfiltrat gänzlich prävaliert. Auch dort, wo das Exsudat an Dicke bedeutend zunimmt, verliert sich der zellige Charakter desselben mehr und mehr. Innerhalb der fädigen Fibrinlamellen treten ziemlich häufig knäuelartig zusammengeballte Klümpchen von Fäden auf.

Nach dem Zerebralraum zu ist das fibrinöse Exsudat durch ein gut markiertes Endothel abgegrenzt. Mithin kann es sich um kein Abscheidungsprodukt des Liquor cerebrospinalis, sondern nur um ein Erzeugnis der Dura selbst handeln. Bisweilen drängt sich dem Beobachter direkt die Auffassung auf, ob nicht die beschriebenen Zellen unterhalb des Endothels irgendwie mit der Entstehung dieses Exsudats in Zusammenhang zu bringen sind.

Gehirn und Hirnhäute weisen keinerlei Besonderheiten auf. Ins- 
besondere sieht man innerhalb der weichen Hirnhäute keine bemerkenswerten Anzeichen von Entziundung, mit Ausnahme einex allerdings auch hier vorhandenen starken GefäBfüllung. Fibrin und polynukleäreLeukocyten fehlen gänzlich.

Bakterien lassen sich sehr reichlich innerhalb der äuBersten Schichten des extraduralen Exsudats nachweicen. Sie durchdringen die ganze Dicke desselben, werden aber nach innen zu bedeutend spärlicher. Ferner sieht man vereinzelte Bakterien die Dura durchwandern, und zwar an den Stellen, wo die Duralamellen durch Exsudat auseinandergedrängt sind. Innerhalb der fibrinösen Pachymeningitis interna fehlen in den meisten Schnitten Bakterien völlig. Doch kann man in anderen Präparaten auch dort, besonders in den äuBeren Fibrinlamellen, allerdings mehr vereinzelte Bazillen nachweisen. Höchst selten treten sie hier etwas häufiger auf, so daß sie in kleineren Gruppen zusammenliegend gefunden werden. Vexeinzelte Stabchen und Kokken lassen sich bis in die innersten Schichten des Fibrinexsudats hin verfolgen.

Jedenfalls besteht ein sehr auffälliges Mißverhältnis zwischen der Ausdehnung der Pachymeningitis interna und der relativ spärlichen Menge der Bakterien.

Hund IV. Infiziert mit einer Mischkultur von Kolibazillen and Streptokokken über der rechten Hemisphäre (zwei Ôsen). Beide Bakterienarten waren aus einem HundeabszeB gezüchtet. Tier erkrankt schwer und wird zwei Tage post infektionem getötet.

Sektionsprotokoll: Muskulatur über der Infektionsstelle eitrig infiltriert. In der Dura ein kleines Loch, dasselbe ist tarnponiert durch ein spitzes Knochenstückchen, welches anscheinend die harte Hirnhaut während der Operation durchbohrt hatte ${ }^{1}$ ).

Die Durainnenfläche ist entsprechend der rechten Hemisphäre sehr stark eitrig belegt. Entsprechend der linken Hemisphäre exscheint die Dura normal. Die weichen Hirnhäute weisen bei oberflächlichem Betrachten zunächst auf beiden Seiten keine besonders bemerkbaren Unterschiede auf. Erst bei Herausnehmen des Kopfes kann man feststellen, daß über dem rechten Stirnhirm zwischen Dura und weichen Hirnhäuten sich ein recht bedeutender Eiterherd befindet. Ein kleinerer Herd im Subduralraum findet sich etwas seitlich von der freigelegten Stelle rechts, Beim Abziehen der harten Hirnhaut flieBt dieser anscheinend begrenzte subdurale AbszeB genau so aus, wie z. B. ein eröffneter HautabszeB.

Die Pachymeningitis interna endet rechts an der Hirnbasis; man kann ziemlich deutlich die Grenze festlegen. Nach dem Kleinhirn zu läßt sich eine scharfe Grenze nicht konstatieren. Im eröffneten Sinus longitudinalis liegt ein rotes Gerinnsel, das zum Teil adhärent zu sein scheint. Die Innenwand des Sinus sieht rechts stark gerötet und etwas uneben aus. Die Pachymeningitis interna scheint in ihrer Ausdehnung durchaus nicht der Leptomeningitis vollig zu entsprechen.

Aus dem Subduralraum der rechten Hemisphäre werden in einem Präparate Kolibazillen und Streptokokken, im anderen nur Kolibazillen gezüchter. Aus dem linken Subduralraum und aus dem Rückenmarkraum ergeben die angelegten Kulturen kein Wachstum.

Mikroskopischer Befund: Die Verletzungsstelle der harten Hirnhaut ist von zerfaserten und entzündlich veränderten Wundrändern umgeben. Inmitten des Defektes selbst liegen einzelne kleine von Eiterzellen durchsetzte Durafetzen.

Der Außenfläche der harten Hirnhaut verläuft ein verhältnis-

1) Diese Verletzung war übrigens während der Operation nicht bemerkt worden. 
mäBig schmaler, nicht immer gleich breiter Streifen entzündlichen Gewebes parallel. Derselbe besteht aus Fibrinklümpchen, gelapptkernigen Leukocyten und Zellen mit großem blassem Kern, die an junge Fibroblasten exinnern. Das Gewebe der eigentlichen Dura mater ist bald mehr, bald weniger stark von Eiterzellen quer durchzogen. Auch die bindegewebigen Elemente der letzteren befinden sich anscheinend selbst im Zustande der Proliferation. Parallel der harten Hirnhaut zieht auf der Innenfläche ein mächtiger der Dura an Dicke mindestens gleichkommender Streifen entzündlichen Exsudats. Dasselbe setzt sich zusammen aus Eiterzellen, Fibrinmassen und Zellen mit großem plasmareichem Kern. Nach der Mitte des Schädels, dem Sinus longitudinalis hin, erscheint die äuBere Schicht der harten Hirnhaut nicht mehr entzündlich verändert, so daß also hier die nach dem Knochen hin liegende Wand des Sinus selbst ziemlich normal ist. Dagegen hat sich die entzündliche Infiltration längs den Innenlamellen der Dura mater fortgepflanzt. Die innere zerebrale Wand des langen Hirnsinus ist demgemäß sehr stark entzündlich verdickt. Und zwar handelt es sich sowohl um gelapptkemige Leukocyten als um Zellen mit großen Kernen, bei denen es unbestimmt bleibt, ob man es mit Endothelabkömmlingen oder jungen Bindegewebszellen zu tun habe. Ein deutlich und sicher ausgesprochenes Grenzendothel fehlt hier nach dem Sinus zu entweder gänzlich oder man kann gerade noch Reste desselben feststellen. In der Sinuswand selbst verlaufen mehrere ziemlich große GefäBe mit gut erhaltenem Endothel. Sie sind prall mit roten Blutkörperchen vollgepfropft. An manchen Stellen erscheint das Endothel des Sinus wie aufgekippt. Schwärme von Leukocyten begleiten den aufgekippten und geborstenen Rand desselben und stellen so eine direkte Verbindung zwischen dem Lumen des Blutgefäßes und der Wand desselben her. Im Innern des langen Hirnblutleiters findet man ein ziemlich starkes Gerinnsel. Dasselbe besteht aus zusammengesinterten roten Blutkörperchen, Fibrinklümpchen und. gelapptkemigen Leukocyten. Letztere, und zwar sowohl die Fibrinniederschläge als die polynukleären Leukocyten, finden sich sowohl im Innern dieses Gerinnsels als besonders in den Randzonen desselben. Der ziemlich entwickelte und fast das ganze Lumen des Gefäßes ausfüllende Thrombus steht nur an einer Stelle, und zwar innerhalb einer schmalen zipfelartigen Fortsetzung des Sinuslumens mit der Wand des Gefäßes in direktem Zusammenhang. An allen übrigen Stellen besteht entweder überhaupt keine Verbindung zwischen ihm und der Wand des Sinus, oder aber es läbt sich immer noch ein beide trennender Endothelsaum nachweisen.

An einer anderen Stelle verläuit der GefäBwand anstatt des fehlenden Endothels ein dünner Fibrinsaum parallel. Mit demselben. in Verbindung steht ein mikroskopisch kleiner, aus Fibrin und Eiterzellen zusammengesetzter Thrombus. Auffallenderweise sind an dieser Stelle die entzündlichen Veränderungen in der Wand des Sinus selbst. gar nicht besonders stark ausgesprochen. Jedoch findet sich diese minimale thrombotische Auflagerung gerade an einer Ausbuchtung des Blutgefäßes, wo die Strömungsgeschwindigkeit augenscheinlich verringert ist.

Die Maschen der weichen Hirnhäute sind dicht ausgestopft von gelapptkernigen Leukocyten und Zellen mit größeren blassen Kernen, daneben finden sich hier und dort Fibrinanhäufungen. Die Pachymeningitis interna setzt sich nach innen vom Sinus longitudinalis auch auf die entsprechende Fläche der GroBhirnsichel fort. Doch erreichen die entzündlichen Veränderungen nicht den inneren Rand der Falx, sondern hören hier unweit vom Sinus longitudinalis auf. Auch innerhalb der weichen Hirnhäute kann man an der entsprechenden Stelle auf der betreffenden, also rechten GroBhirnhemisphäre ein 
vollkommenes Nachlassen der Entziundungserscheinungen konstatieren. Es ist also hier die Entzündungsgrenze der Pachymeningitis interna etwa dieselbe wie die der Leptomeningitis.

Die an die Falx cerebri anschlieBenden Partien der weichen Hirnhäute der linken Großhirnhemisphäre sind gleichfalls zirkumskript entzündet. Zwar ist die Entründung derselben an Ort und Stelle nicht unbeträchtlich, doch dehnt sie sich aach den Seiten sehr wenig über die linke Großhirnheraisphäre hin fort.

Nach vorne zu. bricht etwa entsprechend den hinteren Partien des rechten Stirnhirns der eitrige Belag der Pachymeningitis interna mit ziemlich scharfer Grenze ab. Nach hinten zu endet die Pachymeningitis interna über dem Tentorium cerebelli. Die Leptomeningen sind gleichfalls bis hierher entzündlich verändert. Doch hat es den Anschein, als ob die pachymeningitische Entzündungsgrenze sich etwas weiter hin ausdehnt als die leptomeningitische. Das Tentorium selbst ist von der Entzündung nicht durchbrochen. Die weichen Hirnhäute über dem Kleinhirn sind völlig frei von Entzündungserscheinungen. Auch an der unteren Fläche des Kleinhims am verlängerten Mark und innerhalb des IV. Ventrikels lassen sich entzündliche Veränderungen nicht nachweisen.

Bakterien finden sich sowohl innerhalb der äuBeren wie innerhalb der inneren pachymeningitischen Auflagerungen. Auch zwischen den Lamellen der Dura selbst lassen sie sich, allerdings an Zabl weniger reichlich, nachweisen. Am gehäuftesten sind dieselben in den internen pachymeningitischen Entziundungsherden zu konstatieren. Auch das leptomeningitische entzündliche Exsudat ist von Bakterien durchzogen, allerdings besonders die äuBeren Schichten desselben, während nach innen hin - nach dem Zerebrum - Bakterien stellenweise überhaupt fehlen, stellenweise nur ganz spärlich festzustellen sind. Die innere Wand des Sinus longitudinalis ist durch starke Bakterienmassen durchsetzt, besonders aber die nach dem Lumen zu gerichteten Partien derselben. Von hier aus treten Bakterien in ziemlicher Anzahl in das Blut über und finden sich in den wandständigen Thromben wieder; in den freien Gerinnseln sieht man Bakterien nur sehr selten auftreten, meistenteils fehlen hier Bakterien iuberhaupt.

Hund V. Infiziert mit der gleichen Mischkultur von Streptokokken and Kolibazillen wie Hund IV (zwei Ósen). Getötet nach drei Tagen.

Sektionsprotokoll: Muskulatur über der Infektionsstelle eitrig verfärbt.

Auf der DuraauBenfläche der rechten infizierten Hemisphäre findet sich eine kleine Granulation. Auf der Durainnenfläche läBt sich an entsprechender Stelle ein allerdings exst bei genaustem Hinsehen deutlicher eitriger Belag von Pfennigstückgröße feststellen.

Derselbe schneidet anscheinend nicht mit ganz scharfen Grenzen ab. Weiche Hirnhäute und Gehirn weisen keine Besonderheiten auf. Aus der verfärbten Muskulatur werden Kolibazillen und vereinzelte Streptokokken gezüchtet. Die Impfungen aus dem Rückenmarkramm, dem rechten und linken Subduralraum ergeben kein Wachstum.

Mikroskopischer Befund: Entsprechend der Infektionsstelle findet sich in dem ersten Teil der Serienschnitte eine augenscheinlich durch Verletzuag bei der Operation erzeugte Perforationsöffnung. Dieselbe wird zum Teil durch einen Pfropf entziindlichen Exsudats tamponiert. Sowohl im Innern dieses letzteren als auch zwischen den aufgefaserten durchrissenen Duraschichten sieht man Unmengen von Eiterzellen eingelagert. Inmitten der äuBeren pachymeningitischen Entzïndungsherde sind eine Anzahl abgesprengter Knochenstückchen, wohl KnochenmeiBel-Splitter, eingewachsen. Aber auch innerhalb des 
Intraduralraumes finden sich vereinzelte Knochenpartikelchen inmitten des internen pachymeningitischen Exsudats. Diese Knochensplitter sina augenscheinlich durch den versehentlich gesetzten Duradefekt in den Durainnenraum eingedrungen.

Die der Duraaußenfläche aufsitzenden Granulationsknöpfe bestehen zum. größten Teil aus gelapptkernigen Leukocyten. Daneben läßt sich ein mehr oder weniger gut ausgesprochenes Fibrinnetz nachweisen. Dieses letztere ist ohne einen ersichtlichen Grund in einem Teil der Präparate nach Weigert gut gefärbt, in einem anderen weist es keine spezifische Farbenreaktion auf. Dieser Unterschied in der Färbung besteht sogar in Präparaten, die nicht nur gleich lang mit der gleichen Flüssigkeit gefärbt sind, sondern bisweilen handelt es sich sogar um nebeneinanderliegende Schnitte desselben Objektträgers.

Ein ganz ähnliches Verhalten wie die AuBenfläche der Dura weisen auch die der Durainnenfläche parallel verlaufenden Fibrinanhäufungen auf. Auch hier kann man zuweilen in einem Schnitt desselben Objektträgers bei Weigertscher Färbung eine ganz charakteristische Farbenreaktion konstatieren, während der zweite Schnitt nach Weigert ungefärbt erscheint. Die internen pachymeningitischen Exsudate sind bald stärker, bald schwächer zellig durchsetzt, und zwar handelt es sich um Eiterzellen, kleine Rundzellen und Zellen epitheloider Art. Diese der Durainnenfläche parallel verlaufenden Entzündungsherde brechen nach ihren Rändern hin häufig mit ziemlich scharfer Grenze ab. Mitunter sieht man getrennt durch anscheinend normale Dura neue Plaques auftreten. Beim weiteren Verfolgen der Serien kann man dann häufig feststellen, daß diese scheinbar isolierten Plaques an einer Stelle miteinander zusammenhängen und es sich also um strangförmige Ausläufer eines gemeinsamen entzündlichen Herdes handelt. Eine typische Endothelgrenze nach dem Intraduralraum zu läßt sich über dem gut pfennigstïckgroßen Exsudat der Pachymeningitis interna nur stellenweise nachweisen. Häufig kann man feststellen, daß das Endothel durch die unter ihm liegenden entzündlichen Herde buckelartig emporgewölbt wird. Nicht selten gelingt es nicht mit Sicherheit, das Vorhandensein resp. Fehlen einer Endothelgrenze zu konstatieren.

Die weichen Hirahäute weisen gegenüber der Infektionsstelle in einer Anzahl von Präparaten einen relativ geringfügigen Grad von Entzündung auf. Man sieht nur ihr Endothel gewuchert. Hier und da treten, unabhängig voneinander, kleine Fibrinklümpchen auf, manchmal untermischt von gelapptkernigen Leukocyten und kleinen Rundzellen. An anderen Stellen ist es zu umschriebenen, doch ziemlich bedeutenden entzündlichen Ausscheidungen innerhalb der Maschen der weichen Hirnhäute gekommen, so daß die letzteren an derartigen Punkten knötchenförmig verdickt erscheinen. An solchen Punkten setzt sich das entzuindliche Exsudat aus Häufchen von Fiterzellen and Fibrinmassen zusammen. Mitunter herrscht mehr der eitrige, mitunter mehr der fibrinöseitrige, manchmal der rein fibrinöse Charakter vor. Diese zirkumskripten meningitischen Plaques gehen ohne scharfe Grenze in das wenig oder gar nicht veränderte Gewebe der angrenzenden Meningen über. Dieser Übergang ist oft kaum merkbar. Man sieht nur das eitrige Infiltrat geringer werden. Die Eiterzellen verschwinden ganz. Bisweilen macht sich noch eine Strecke hindurch eine Vermehrung des Endothels bemerkbar, bisweilen fehlt auch diese.

In ihrer Flächenausdehnung sind die entzündlichen Erscheinungen der weichen Hirnhäute innexhalb der rechten Hirnhälfte bedeutend weniger ausgebreitet als die ihnen entsprechende Pachymeningitis interna.

Bakterien finden sich in großen. Mengen innerhalb der äußersten 
Schichten der Paehymeningitis externa. Mehr nach innen zu werden sie seltener und fehlen fast völlig, doch sieht man an einzelnen Stellen Bakterien mit Eiterkörperchen zusammen die Dura quer durchdringen.

Die Pachymeningitis interna ist fast völlig bakterienfrei. Nur ganz vereinzelt lassen sich hier und da Bakterien nachweisen. An einer Stelle findet sich ein kleines Häufchen von ihnen. Jedenfalls steht die Größe der nachgewiesenen Pachymeningitis interna zu der Menge der Bakterien in durchaus keinem Verhältnis. Vereinzelte Bakterien kann man auch innerhalb der entzündlich veränderten weichen Hirnhäute konstatieren, doch ist hier ihre Zahl ganz verschwindend gering.

Hund VI. Der Hund ist infiziert mit einer Mischkultur von Kolibazillen and Streptokokken (je zwei Tropfen einer eintägigen Bouillonkultur), Bakterien ron Hund $V$ gezüchtet. Tier getötet 24 Stunden post infectum.

Sektionsprotokoll: Auf der Duraaußenfläche keine Besonderheiten, desgleichen auf der Innenfläche derselben. Meningen und Gehirn erscheinen frei von entzündlichen Veränderungen. Auf der verfärbten Muskulatur werden Streptokokken und Kolibazillen gezüchtet. Aus dem Subduralraum der rechten und linken Hemisphäre sowie dem Rückenmarkskanal ergibt die Abimpfung kein Wachstum.

Abstrichpräparate aus dem rechten und linken Subduralraum sowie dem Rückenmarkskanal zeigen nur formlosen Detritus.

Mikroskopischer Befund: Auf der DuraauBenfläche finden sich am Ort der Infektionsstelle teils zusammenhängende, mehr flache, teils knötchenförmige Exkreszenzen. Dieselben bestehen aus einem grobfaserigen Maschenwerk von fibrinöser Struktur und sind allenthalben von reichlichen Mengen gelapptkerniger Zellen durchsetat.

Die großen GefäBe der DuraauBenfläche sind zum Teil thrombosiert. Die Duralamellen selbst erscheinen an einzelnen Stellen von Scharen gelapptkerniger Leukocyten durchsetzt; an anderen ist die harte Hirnhaut anscheinend ziemlich frei von entziundlichen Erscheinungen.

Auf der Durainnenfläche ziehen parallel derselben gleichfalls entzündliche Lamellen von fibrinöser Struktur, untermischt von mehr oder weniger reichlichen Leukocyten. Diese letztere Zellgattung tritt hier mitunter ganz auffallend stark in Erscheinung. Mitunter herrscht mehr der rein fibrinöse Charakter des Fxsudats vor. Im übrigen ergeben weder die fibrinösen Lamellen auf der Duraaußenfläche noch auf der Innenseite derselben, trotzdem sie absolut fibrinöse Struktur besitzen, die typische Weigertsche Färbungsrealution, resp. die letztere ist nur stellenweise angedeutet. Wenn die Weigertsche Reaktion mehr ausgesprochen ist, so repräsentieren die blau gefärbten Fibrinfäden und Knotenpunkte ein recht zierliches Netzwerk. Gegen die Ränder dieser internen fibrinösen Auflagerungen hin sieht man häufig größere protoplasmareiche Zellen, und zwischen diesen letzteren manchmal faserige, strukturlose Streifen. Bisweilen liegen die vorher erwähnten großen Zellen selbst in zierlicher maschenförmiger Anordnung zusammen.

Die Plaques der Pachymeningitis interna finden sich oft genau vis-à-vis den extraduralen entzündlichen Veränderungen. Sie werden mitunter durch einen deutlich wahrnehmbaren, manchmal gewucherten, jedenfalls intakten Endothelsaum nach innen zu begrenzt. An anderen Stellen kann man eine. Endothelgrenze nicht mehr mit Sicherheit feststellen, da Endothel und entziundliches Infiltrat zusammen ein nicht sicher herausdifferenzierbares Zellinfiltrat darstellen.

Bakterien finden sich auf der Außenfläche der Dura in Unmenge. Sie dringen gewöhnlich nicht in die Duraschichten selbst weit hinein. 
Nur recht spärlich lassen sich Bakterien innerhalb der harten Hirnhaut nachweisen. Doch treten bisweilen auch im Innern der internen Pachymeningitis vereinzelte Exemplare von ihnen auf.

Zwischen den Lamellen der weichen Hirnhaut lassen sich gegenüber dem Ort der Infektionsstelle stellenweise nicht unbeträchtliche Fibrinausscheidungen konstatieren. Die Weigertsche Methode ergibt gleichfalls nur teilweise die typische Farbenreaktion. Daneben erscheinen Häufchen von gelapptkernigen Leukocyten, mitunter in nicht unbeträchtlichen Scharen. Auch die Endothelien der weichen Hirnhäute sind gewuchert. Die BlutgefäBe sind stark erweitert. Vereinzelt sieht man innerhalb der entzündlich veränderten weichen Hirnhäute kleine Häufchen von Bakterien, und zwar sowohl Streptokokken wie Stäbchen. Die Entzündungserscheinungen der weichen Hirnhäute wechseln ohne sichere Grenze ab und machen nach den Rändern hin Partien Platz, wo das Gefüge der Meningen anscheinend ziemlich normale Struktur aufweist. Mitunter kann man in den Grenzpartien eine deutliche Endothelvermehrung innerhalb der weichen Hirnhäute konstatieren. In manchen Präparaten treten noch abseits vom eigentlichen entzündlichen Herde, innerhalb einer anscheinend normalen Umgebung, kleine Fibrinkliumpchen auf.

Hund VII. Infiziert mit einer Mischkultux von Kolibatillen und Streptokokken. Gewonnen von Hund V (7 Tropfen einer eintägigen Kolibouillonkultur; 2 Tropfen einer eintägigen Streptokokkenbouillonkultur). Tier getötet 36 stunden post infectionem.

Sektionsprotokoll: Auf der DuraauBenfläche läßt sich eine rötliche Auflagerung feststellen. Auf der Innenfläche fehlen Besonderheiten.

Über der linken - also nicht infizierten - Hemisphäre verlaufen weiße, stark ausgeprägte Bindegewebsstreifen, den Gefäßen parallel (wohl Altersveränderung). Ferner finden sich hier an einzelnen Stellen Verwachsungen zwischen Dura und Meningen.

Gehirn und Hirnhäute erscheinen normal.

Das Deckglaspräparat ergibt aus rechtem und linkem Subduralraum nur formlosen Detritus, während innerhalb des aus dem Rückenmarkskanal gewonnenen Liquors eine nicht unbeträchtliche Ansammlung von gelapptkernigen Leukocyten konstatiert werden kann.

Aus der verfärbten Muskulatur werden Kolibazillen und Streptokokken gezüchtet. Die Abimpfung aus dem Subduralraum der rechten und linken Hemisphäre und dem Rückenmarkskanal ergibt kein Wachstum.

Auf der Duraaußenfläche liegen, entsprechend der Infektionsstelle, ziemlich bedentende Massen eines faserigen Exsudats von durchaus fibrinartiger Struktur. Zwischen den Maschen desselben sieht man die Schatten einer Unmenge von roten Blutkörperchen. Mituater kann man quer durch dieses extradurale Exsudat verlaufende breitere Streifen derselben faserigen Substanz nachweisen, oft in der Weise, daB diese breiteren Lamellen die vorher erwähnten Ansammlungen von roten Blutkörperchen in einer ganzen. Anzahl parallel verlaufender Giirtel umgeben. Innerhalb dieses Exsudates resp. demselben aufliegend lassen sich mehr oder weniger große Häufchen von gelapptkernigen Leukocyten nachweisen. Mitunter tritt der rein zellige Charakter des Exsudats mehr oder vollig in den Vordergrund, so dab das letztere bisweilen sogar einen rein eitrigen Charakter annehmen kann. Die eigentlichen Lamellen der harten Hirnhaut sind nur verhältnismäßig wenig zellig infiltriert; nur an einzelnen Stellen sieht man sie durch einzelne Exemplare oder kleine Gruppen von Wanderzellen durchsetzt.

Auf der Innenfläche dex harten Hirnhaut kann man ein ganz ähnlich gebautes fibrinartiges Exsudat wie auf der AuBenfläche der 
Dura mater nachweisen. Dasselbe hat eine verhältnismäßig nur geringfügige Ausdehnung. Es fehlt in einem gróßen Teil der Serienpräparate fast völlig. Sowohl das extradurale wie das intradurale durchaus fibrinartige Exsudat färbt sich nach der Weigertschen Methode entweder gar nicht oder nur ganz wenig. Doch läBt die vorher beschriebene so außerordentlich spezifische Struktur dieses Exsudats, sein charakteristisches Vorkommen auf der Duraaußenfläche zwischen und um die Schatten der roten Blutkörperchen herum keinen Zweifel darüber entstehen, daß man es mit Fibrin zu tun habe. Man muß eben annehmen, daß das Hundefibrin in frischen Stadien nach Weigert sich zum Teil gar nicht, zum Teil nur schlecht färbt. Innerhalb des intraduralen Exsudats resp. an dasselbe anschließend kann man manchmal Stellen beobachten, wo die Lamellen eigentümlich auseinandergezogen sind. Oder man hat mitunter den Eindruck, als ob an bestimmten Punkten das ganze Exsudat aus langgereckten, nur lose zusammengefügten, an Fibroblasten erinnernden Zellen bestehe. Innerhalb der zusammenhängenden Komplexe dieser letzteren sieht man dann wiederum bisweilen entfernt von den Hauptmassen des eigentlichen Exsudats kleine uruschriebene fibrinartige Klümpchen auftauchen.

Im allgemeinen ist das intradurale Exsudat ziemlich zellarm, nur spärlich lassen sich in demselben Elemente, die an junge Bindegewebszellen erinnern, resp. gelapptkernige Leukocyten nachweisen. An andern Stellen fällt die erstere Zellart mehr in den Vordergrund. In einer Reihe von Präparaten sieht man das intradurale Exsudat durch ein deutlich ausgeprägtes Endothel rom Zerebralraum abgeschieden. Bakterien finden sich besonders in den oberflächlichsten Schichten des extraduralen Exsudats, und hier in groBen Massen; doch durchdringen sie dieses letztere stellenweise vollständig. Immerhin ist ihre Zahl nach innen zu etwas geringer. Innerhalb der Lamellen der Dura selbst lassen sich nur relativ spärliche Bakterien nachweisen. Das intraduräle Exsudat schließlich scheint fast völlig bakterienfrei; in den meisten Schnitten ist keine Spur von Bakterien zu erkennen. Doch habe ich in einem der Schnitte, auch hier allerdings auBerordentlich spärlich, Bakterien - im ganzen drei bis vier - sicher nachweisen können.

Die weichen Eirnhäute sind gegenüber der Infektionsstelle bedeutend verdickt und zellreich, und zwar handelt es sich zum Teil um eine ausgesprochene Wucherung der Fndothelien, die zahlreich und dicht aneinandergedrängt exscheinen. Andererseits sieht man Elemente, die an junge Fibroblasten erinnern, sowie einzelne oder in kleinen Gruppen zusammenliegende gelapptkernige Leukocyten. An einzelnen Stellen erscheinen auch die oberflächlichsten Hirnpartien auffallend zellreich. Bakterien fehlen innerhalb der weichen Hirnhäute völlig.

Hund VIII. Infiziert mit einer Mischinfektion von Streptokokken. Es werden dazu vier Stämme benutzt. Dieselben wurden gewonnen aus Fällen menschlicher Meningitis, Ervsipel, Angina und Sepsis. Der erste der vier Stämme wurde durch Passage durch eine Mans, die drei anderen durch Kaninchenpassage virulenter gemacht. Miteiner Bouillonkultur dieser vier Stämme wird ein Tampon durchtränkt. Derselbe wird nach Freilegung der Dura derselben angelegt, darüber Muskulatur und Hant vernäht. Tier getötet 36 Stunden post infectionem.

Sektionsprotokoll: Jauchung der Muskulatur. Auf der äuBeren Durafläche liegt ein verfärbter Granulationsknopf auf. Auf der Durainmenfläche sind Besonderheiten nicht zu erkennen. Gehirn und Hirnhäute sind normal.

Aus dem Eiter der Muskulatur werden Kokken in Reinkulturen gezüchtet. Aus dem Subduralraum der rechten und linken Hemisphäre sowie der Lumballüissigkeit findet sich kein Wachstum. 
Mikroskopischer Befund: An der Infektionestelle findet sich auf der Anßenseite der Dura ein flach aufsitzendes, etwa stecknadelkopfgroßes Exsudat. In demsell en kann man große Mengen gelapptkerniger Leukocyten nachweisen. Die entzündliche Infiltration klingt in ziemlicher Nähe von dem eigentlichen Infektionsherd ab. Die angrenzenden Duralamellen sind relativ zellreich. Genau am Ort der Infektion dringen gelapptkemige Leukocyten in nicht unbedeutendem Maße quer durch die Dura hindurch. Als erstes Anzeichen entzündlicher Vorgänge auf der Durainnenfläche sieht man die Endothelzellen saftreicher werden. Zwischen dem eigentlichen Endothel und den bindegewebigen Lamellen der Dura hat sich eine zunächst nur wenig ausgesprochene Zwischenschicht von netzartiger Struktur gebildet. Die Knoten dieses Netzes werden repräsentiert durch große ziemlich blasse Zellkerne, das Maschenwerk durch zarte Fäserchen von durchaus fibrinartiger Beschaffenheit. Man hat bei Immersionsbetrachtung durcharus den Eindruck, als ob die zu den vorher beschriebenen Kermen gehörenden Zelleiber irgendwie an der Entwicklung dieser faserigen $\mathrm{Z}$ wischenmasse beteiligt sind.

Jedenfalls kann man die eigentlichen Grenzen dieser Zelleiber überhaupt nicht herausdifferenzieren. Weiter nach dem Infektionszentrum hin haben sich grobkörnige fibrinartige Massen entweder zwischen Endothel resp. die vorher geschilderte netzartig veränderte obersehicht und die Bindegewebslamellen der Dura geschoben, oder sie tauchen hier und da als Schollen zwischen den Fasern des feinmaschigen Fibrinnetzes selbst auf. Innerhalb dieser stärkeren Anhäufungen eines fibrinartigen Exsudats treten hier und da gröbere Häufchen ron gelapptkernigen Leukocyten auf. Manchmal sind dieselben in bedeutender Anzahl vorhanden.

An Ausdehnung übertreffen die entzündlichen Erscheinungen auf der Durainnenfläche ganz bedeutend diejenigen der AuBenfläche der harten Hirnhaut.

Die weichen Hirnhäute erscheinen zwax ziemlich zellreich, doch nicht verdickt. Bemerkenswertere entzïndliche Erscheinungen fehlen.

Zur Entscheidung der bakteriellen Frage ist ein Teil der untersuchten Präparate unbrauchbar, da sich aus nicht mehr zu ermittelnden und ganz unklaren Gründen Bakterien, und zwar diphtheroide Stäbchen, z. B. auch an den Schnitträndern und überhaupt an Stellen finden, wo ihr Vorhandensein absolut ausgeschlossen ist. Eine ganze Reihe von Sehnittserien erweist sich andererseits, mit Ausnahme der oberflächlichen Schichten der Pachymeningitis externa, wo stets Bakterien, und zwar derbe Stäbchen und Kokken, nachzuweisen sind, als völlig frei von Eitererregern.

Hund IX. Impfung mit denselben Bakterien in gleicher Menge und in derselben Weise über der linken Hemisphäre wie bei Hund VIII. Auch hier wird ein Tampon eingenäht (cf. Hund VIII). Tier getötet nach $21 / 2$ Tagen.

Sektionsprotokoll: Starke Jauchung der Muskulatur. Uber der Duraaußenfläche ein verfärbter Granulationsknopf. Die Durainnenfläche scheint an zirkumskripter Stelle vis-à-vis dem Ort der Infektion etwas verfärbt. Die Hirnhäute sind normal. Die Venen sind wehl etwas stark gefüllt.

Aus dem Eiter der Muskulatur werden Kokken in Reinkulturen gezuichtet. Aus dem Punktat des rechten und linken Subduralraums sowie dem Lumbalsack wachsen keine Bakterien.

Mikroskopischer Befund: An der Stelle der Infektion sitzt der Duraaußenfläche ein ziemlich beträchtliches Exsudat auf. Dasselbe besteht zum größten Teil aus Eiterzellen und Fibrin. Letzteres ergibt in einer Anzahl von Präparaten eine ziemlich ausgeprägte Weigertsche Reaktion. In anderen Präparaten ist die spezifische 
Färbung nur verhältnismäßig gering oder stellenweise überhaupt nicht ausgesprochen. In diesem extraduralen Exsudat finden sich ziemlich beträchtliche abgesprengte Knochenpartikelchen eingemauert.

Die Dura selbst wird von einer Anzahl gelapptkerniger Leukocyten durchwandert. Dieselben erscheinen auf der Innenfläche der harten Himhaut wieder, doch finden sie sich hier in verhältnismäßig nur ziemlich geringer Anzahl. Dagegen läßt sich ein der Innenfläche der Dura mater parallel verlaufendes fibrinöses Exsudat von stellenweise Duradicke feststellen. Die Fibrinfäserchen sind zum Teil stärker, zum Teil recht zierlich. Im allgemeinen ist die Weigertsche Farbenreaktion auf der Innenfläche der harten Hirnhaut bedeutend schlechter ausgesprochen als auf der Außenfläche derselben. Das innere Grenzendothel scheint erhalten zu sein, wenigstens kann man es an vielen Stellen mit Sicherheit nachweisen. An anderen Stellen ist dieser Nachweis nicht so ohne weiteres möglich. Im AnschluB an dieses Innenendothel kann man in einer ganzen Reihe von Präparaten eine ziemliche Anzahl blasser Zellkerne nachweisen. Man hat durchaus den Eindruck, als ob die dazugehörigen Zellen als Endothelankömmlinge anzusprechen sind.

An einer Stelle, wo eine alte Verwachsung zwischen Dura und Zerebrum besteht und der Arachnoidalraum mithin aufgehoben ist, tritt der fibrinöse Charakter der Pachymeningitis interna gegenüber den angrenzenden Partien mehr zurück, dagegen ist diese Verwachsungsstelle reichlich ron gelapptkernigen Leukocyten infiltriert. Die Entzündungserscheinungen gehen jedoch nicht auf die Zerebralsubstanz über.

Die weichen Hirnhäute sind verdickt und sehr zellreich, und zwar handelt es sich besonders um Zellformen mit großen blassen Kernen und kleine Rundzellen. Die Blutgefäße sind etwas erweitert. Fibrin fehlt völlig; gelapptkernige Leukocyten lassen sich nur in ganz vereinzelten Exemplaren nachweisen.

Bakterien finden sich in einem Teil der untersuchten Serienschnitte reichlich innerhalb der Pachymeningitis externa, besonders in ihren äuBeren Schichten. Sie dringen bis in die angrenzenden Duralamellen vor, allerdings nur in recht spärlicher Anzahl. Außerordentlich selten kann man Bakterien im Innera der fibrinösen Pachymeningitis interna nachweisen. Tedenfalls stehen die wenigen vorgefundenen Exemplare zu der Größe der Entzizndungserscheinungen in absolut keinem Vexhältnis. Im Innerm der weichen Hirnhäute and im Gehirn fehlen Bakterien.

In einem anderen Teil der zur Untersuchung gekommenen Gewebsschnitte kann main im intraduralen pachymeningitischen. Exsudat gleichfalls für gewöhnlich keine Bakterien nachweisen. An vereinzelten Stellen dagegen lassen sich hier spärliche Exemplare sowie kleine zusammenliegende Häufchen konstatieren. Ganz ähnlich ist der Befund innerhalb der Leptomeningen. Mit Ausnahme recht seltener Einzelindividuen fehlen hierselbst Bakterien.

In den oberflächlichen Schichten des Zerebrum gelingt es hier und dort ebenfalls, an besonderen Stellen kleine typische Kokkenhäufchen und Einzelbakterien festzustellen. Die Umgebung derartiger Partien ist bakterienfrei.

Was die Form der Bakterien betrifft, so sieht man im extraduralen Exsudat dünnere und dickere, manchmal reeht dexbe, meistens stäbchenartige Formen. Mitunter hat man allerdings den Eindruck, als ob diese Stäbchen zum Teil Pseudostäbchen sind, entstanden durch Zusammensetzung kokkenartiger Elemente. Daneben lassen sich auch vereinzelte zarte Kokkenketten nachweisen. 
Hund X. Impfung in derselben Weise wie vorher Hund VIII und Hund IX. Tötung nach drei Tagen.

Sektionsprotokoll: Jauchung der Muskulatur. Granulationen auf der Duraaußenfläche. Starke Pachymeningitis interna über der linken Hemisphäre sowie über den basalen Partien der Dura. Die Innenfläche der Dura der rechten Hemisphäre erscheint normal.

Starke Leptomeningitis über der linken Hemisphäre. Die Leptomeningen des Kleinhirns, der rechten Hemisphäre und der Medulla oblongata weisen keine Besonderheiten auf.

Aus der Muskulatur und dem Punktat des linken Subduralraums werden Koklzen in Reinkulturen gezüchtet, aus dem Punktat des rechten Subduralraums und dem Lumbalsack wachsen keine Bakterien.

Mikroskopischer Befund: Parallel der Duraaußenfläche verläuft, ebenso wie auf der Innenfläche derselben, ein breiter, größtenteils aus gelapptkernigen Leukocyten zusammengesetzter Saum. Besonders mächtig ist derselbe auf der Innenfläche ausgeprägt. Er hat hier etwa dieselbe Dicke wie die Dura selbst. Zwischen den Eiterkörperchen der Pachymeningitis externa lassen sich auch Fibrinanhäufungen nachweisen, die aber nur in vereinzelten Präparaten deutliche Weigert-Färbung aufweisen. Innerhalb der äußeren wie der inneren pachymeningitischen Auflagerungen finden sich Unmengen von Bakterien. Die Dura selbst ist stellenweise vollig frei von Eitererregern. An anderen Punkten sind ihre Lamellen etwas aufgelockert und durch Züge von gelapptkernigen Leukocyten infiltriert. Hier lassen sich hin und wieder Bakterienhäufchen nachweisen. Bisweilen sieht man in der Durawand ziemlich große Gefäßräume, dicht mit roten Blutkörperchen und spärlichen gelapptkernigen Leukocyten vollgestopft.

Die entzündliche Infiltration setzt sich besonders als Pachymeningitis interna, jedoch auch innerhalb der innersten Duralamellen bis in die Umgebung des Sinus longitudinalis hin fort, während die äußeren Schichten der harten Hirnhaut frei sind von entzündlichen Erscheinungen. Der Sinus selbst ist von einem deutlich entzündlichen Wall umgeben, der halbmondförmig die innere Zirkumferenz des Blutleiters umschließt, während die äußere, nach dem Knochen hin liegende Sinuswand mehr oder weniger frei von Entzündungserscheinungen ist. Das innere Endothel des Sinus selbst ist zum Teil noch gut erhalten.

An anderen Stellen läßt es sich nicht deutlich herausdifferenzieren, da die innere GefäBwand selbst durch eine Brücke von gewucherten großkernigen Zellen und gelapptkemigen Leukocyten mit einem im Sinuslumen befindlichen Thrombus in organisch fester Verbindung steht. Dieser Thrombus besteht aus Fibrinmassen und Leukocytenhäufchen. Auch lassen sich reichliche Bakterienanhäufungen in ihm nachweisen. Es läßt sich mit ziemlicher Sicherheit feststellen, daß die Bakterien von der inneren Wand des Gefäßes längs der vorther beschriebenen entzưndlichea Brücke ins Lamen eingewandert sind. Kleinere Fibrinfäden reichen bis in die vorher beschriebene, die Sinuswand mit dem Thrombus verbindende Brücke hinein. Im Lumen des eröffneten Gefäßes liegen noch mehrere Thrombenbröckel völlig frei. Auf Grund der pathologischen Befunde läßt sich die genaue Entstehung dieser letzteren nicht mit Sicherheit nachweisen, wahrscheinlich haben sie mit den vorher beschriebenen der Wand adhärenten Thrombenmassen an irgendeiner Stelle in Verbindung gestanden.

In einzehnen dieser freiliegenden Bröckelchen kann man noch die Silhouette zusammengesinterter roter Blutkörperchen mehr oder weniger deutlich erkennen, während innerhalb der wandständigen Auflagerungen die grobfibrinöse Natur derselben im Vordergrunde steht und nur Inseln schattenfömiger Erythrocyten sich eben noch erkennen lassen. 
Die weichen Hirnhäute sind, entsprechend der infizierten Hemisphäre, an der Konvexität stark entzündlich verändert. Thre Gefäße sind maximal erweitert, sie selbst ron gelapptkernigen Leukocyten, kleinen Rundzellen und Elementen, die wohl als gewucherte Endothelien aufgefaßt werden können, infiltriert.

Die Entzündungserscheinungen, und zwar sowohl Mengen von gelapptkernigen Leukocyten wie Bakterienhaufen, dringen parallel der Großhirnsichel nach innen zu vor. Sie erscheinen wieder auf der gegenüberliegenden Fläche der Falx cerebri. Die Falx selbst ist nur verhältnismäßig wenig entzündlich verändert.

Die weichén Hirnhäute der anderen Hemisphäre sind in der Umgebung der Falx stellenweise stark entzündlich infiltriert und mit Bakterien durchsetzt. Doch kann man nicht weit von der Mittellinie die Grenze der Entriundungserscheinungen konstatieren.

An der Hirnbasis der infjzierten Seite sind die Hirnhäute zum Teil frei von Entzïndungserscheinungen, zum Teil nur von geringfügigen Häufchen gelapptkerniger Leukocyten durchsetzt. An anderen Stellen jedoch kann man auch hier bereits starke Ansammlungen von Eiterzellen, untermischt von Bakterien, nachweisen. Der Seitenventrikel ist noch nicht von den entzündlichen Vorgängen erreicht.

In der Gegend des Hinterhauptlappens besteht gleichfalls noeh eine ausgesprochene eitrige Pachymeningitis interna. Die weichen Hirnhäute erscheinen hier mehr sprung- und etappenweise eitrig infiltriert. Mit Partiea, die stark entzündet sind, wechseln solche ab, die entweder gänzlich normal erscheinen oder bei denen man nur eine verhältnismäßig geringfügige Zellwucherung nachweisen kann. Bisweilen sieht man hier übrigens nicht unbeträchtliche Haufen von gelapptkernigen Leukocyten ins Gehirngewebe selbst vordringen. Sowohl innerhalb der pachymeningitischen als auch der leptomeningitischen Entzündungsherde finden sich Bakterien (Stäbchen), während die Dura und das Zerebrum bakterienfrei sind. An der Hinterfläche des verlängerten Marks, unterhalb des Kleinhirns, finden sich in der pialen Hülle kleine Bazillenanhäufungen. An diesen Stellen sieht man eine allerdings ziemlich geringfügige Zellvermehrung, hier und da kleine Gruppen von gelapptkemigen Leukocyten. Ganz vereinzelte Bakterienschwärme erstrecken sich längs der Medulla oblongata bis in die Gegend des IV. Ventrikels hinein fort. Die entzündlichen Erscheinungen von seiten der Hirmäute sind nur auBerordentlich gering: Die in den IV. Ventrikel hineinragenden Arachnoidalzotten sind frei von Bakterien und Entzündungserscheinungen: daselbst lassen sich zwischen den einzelnea Kleinhirngyri keine Bakterien oder Anzeichen von Entzündung nachweisen.

Auf der vorderen Fläche des verlängerten Marks kann man die Grenzen der Entziündung nach unten hin ziemlich bestimmt feststellen. Man findet nur in den oberen Partien kleine, allerdings ziemlich unbedeutende Häufchen von Eiterzellen, während mehr nach unten hin die weichen Hirnhäute ziemlich frei von entzïndlichen Vorgängen sind. Bazillen lassen sich hier gleichfalls noch, doch recht vereinzelt, nachweisen.

In anderen Präparaten fehlen die vorher geschilderten Entzündungsvorgänge an den besehriebenen Stellen bereits so gut wie völlig.

Was die Art der Bakterien betrifft, so herrschen überall ziemlich derbe stäbchenartige Formen vor, die manchmal zu recht bedeutender Länge ausgewachsen sind. Dagegen kann man daneben sowohl im extraduralen wie intraduralen leptomeningitischen. Exsudat als auch im Innern des Sinusthrombus noch vereinzelte zarte kokkenartige Elemente nachweisen, die manchmal zu kleinen Ketten ausgewachsen sind. Úberall ist die Form der Bakterien nicht sehr markant, da neben gut gefärbten Exemplaren sehr viele heller gefärbte oder nur stellen- 
weise gefärbte, augenscheinlich degenerierende Exemplare nachgewiesen werden können, die die Auffassung der vorherrschenden Bakterienform sehr erschweren.

Hund XI. Infiziert mit einer für die gewöhnlichen Versuchstiere hochvirulenten Streptokokkenkultur (bezogen aus dem hiesigen hygienischen Institut, denselbe Stamom wurde bereits bei Hund I und II benutzt). Der Infektionsmodus war derselbe wie bei Hund VIII, IX und $X$ (es wurde ein mit einer frischen Bouillonkultux durchtränkter Tampon nach Freilegung der Dura eingenäht). Tier getötet drei Tage post infectum.

Aus einem entstandenen HautabszeB werden Streptokokken in Reinkultur gezüchtet. Die Abimpfung aus dem rechten und linken Subduralraum sowie dem Rückenmarkskanal ergibt kein Wachstum.

Sektionsprotokoll: Auf der DuraauBenfläche findet sich entsprechend dem Orte der Infektion ein Granulationsknöpfchen. An der Durainnenfläche, den weichen Hirnhäuten, dem Zerebrum lassen sich keine Besonderheiten nachweisen.

Mikroskopischer Befund: Die AuBenfläche der harten Hirnhaut ist durch ein zirkumskriptes entzündliches, aus Fibrin- und Eiterzellen bestehendes Exsudat verdickt. Innerhalb desselben sieht man hier und dort abgesprengte Knochensplitter eingemauert. An einzelnen Stellen durchdringen gelapptkernige Leukocyten quer die Dura und erscheinen auf der Innenfläiche derselben wieder. Diese Pachymeningitis interna ist stellenweise recht deutlich ausgeprägt. Sie ist teils eitriger, teils fibrinöser Struktur. Sie findet sich nicht immer genau vis-à-vis der Pachymeningitis externa, sondern breitet sich weiter aus als die letztere. Manchmal sieht man auf der Innenfläche der harten Hirnhaut hier und dort vereinzelte mit den eigentlichen entzündlichen Plaques der Pachymeningitis interna anscheinend nicht in Zusammenhang stehende Häufchen von gelapptkernigen Leukocyten. In anderen Präparaten stellen mehr vereinzelte Eiterzellen den direkten Konnex her. Diese entzündlichen Veränderungen der Durainnenfläche finden sich, sobald sie einen gewissen Grad nicht überschreiten, unterhalb des erhaltenen Endothels. An den Stellen, wo die Entzündung eine stärkere ist, läBt sich der Endothelsaum nicht mit Sicherheit feststellen.

Die weichen Hirnhäute erweisen sich als zellig relativ stark infiltriert. Jedoch handelt es sich um Endothelzellen resp. junge Bindegewebszellen. Nur hin und wieder finden sich vereinzelte Eiterzellen.

Bakterien sieht man nur äußerst spärlich hier und dort in vereinzelten Exemplaren im Innern der äußeren pachymeningitischen Auflagerungen. Innerhalb der Pachymeningitis interna resp. in den weichen Himhäuten fehlen Bakterien.

Hund XII. Infiziert mit denselben Bakterien genau in der gleichen Weise wie Hund XY. Tier getötet fün Tage post infectionem.

Uber der freigelegten Dura war ein AbszeB entstanden. Aus dem AbszeBeiter werden Streptokoklien in Reinkultur gezüchtet. Aus dem rechten und linken Subduralraum sowie dem Rückenmarkskanal ergeben die angelegten Kulturen kein Wachstum.

Sektionsprotokoll: Unter der Kopfschwarte mäehtiger AbszeB. Außenfläche der Dura entsprechead der Infektionsstelle in ein Granulationspolster verwandelt. An der Innenfläche der harten Hirnhaut, den weichen Hirnhäuten sowie dem Zerebrum lassen sich Besonderheiten nicht nachweisen.

Mikroskopischex Befund: Die Duraaußenfläche ist bedeckt von einem ziemlich beträchtlichen Entzïndungssaum. Derselbe setzt sich zum größten Teil aus gelapptkernigen Leukocyten zusammen. Daneben sieht man jedoch aruch bereits als Zeichen der Regeneration

Archiv f. Ohrenheilkunde. Bd. 89. 
ziemlich beträchtliche Ansammlungen von jungen Bindegewebszellen. In den Van Gieson-Präparaten kann man hier und dort in den der Dura anschließenden Lagen ganz feine neugebildete Bindegewebsfäserchen nachweisen. Innerhalb dieses Exsudats sind kleine Knochensplitter eingebacken.

Die harte Hirnhaut selbst ist gegenüber der Infektionsstelle ziemlich beträchtlich von gelapptkernigen Leukocyten durchzogen. Ihre Lamellen erscheinen dadurch zum Teil aufgelockert und auseinandergedrängt.

Auf der Innenfläche der Dura mater findet sich ein gut ausgeprägter Entzündungssaum. Dieses intradurale Exsudat kommt mitunter der Dura an Breite nahe. Es ist zum Teil fast rein fibrinöser, zum Teil fibrinös-eitriger Natur. An seinen Rändern sieht man häufig größere, wohl als gewucherte Endothelien aufzufassende Zellen. Diese letzteren machen an einzelnen Stellen die Hauptmasse des Zellinfiltrates aus. Wenngleich man an allen stellen nicht mit Sicherheit ein das intradurale Exsudat nach den weichen Hirnhäuten hin abgrenzendes Endothel feststellen kann, läßt sich doch stellenweise auch dort noch, wo das Exsudat relativ mächtig ist, ein Endothelsaum konstatieren. An einer Stelle sieht man auf dem internen pachymeningitischen Exsudat einen unregelmäßig begrenzten, ziemlich beträchtlichen Knopf entzündlichen Gewebes aufsitzen. Derselbe dehnt sich zwar nach den an dieser Stelle kaum merkbar entzündlich veränderten weichen Hirnhäuten hin aus, scheint aber nicht mit ihnen in Verbindung zu stehen. Er setzt sich aus gelapptkernigen Leukocyten und gewucherten Endothelien zusammen. Hier und dort finden sich im Innern desselben Fibrinanhäufungen.

Innerhalb der weichen Hirnhäute, die stellenweise ein fast normales Aussehen bewahrt haben, sieht man hin und wieder kleine Zellanhäufungen eingesprengt. Dieselben bestehen aus gewucherten Endothelien und zwar nicht sehr zahlreichen, doch immerhin in bemerkenswerter Anzahl vorhandenen gelapptkernigen Leukocyten. Die Gefäße sind zum Teil prall gefüllt und. zeigen bedeutende wandständige Leukocytenanhäufungen.

Bakterien lassen sich nur äußerst spärlich nachweisen. Bisweilen sieht man kleine Kokkenhäufchen in den oberflächlichen Schichten des extraduralen Exsudats, an anderen Stellen konnte ich Bakterien nicht mit Sicherheit feststellen. In manchen Präparaten schienen Bakterien überhaupt zu fehlen.

Im Anschluß an die vorher geschilderten Resultate meiner Tierversuche füge ich gleich zwei Beobachtungen am Menschen an, die bezüglich der später zu ziehenden Folgerungen als zweckmäßige Parallele und Bestätigung dienen können.

Fall I. Friedrich E., 32 Jahre. Nephritis chronica, Otitis media sinistra acuta. Keine Labyrinthsymptome. Mastoiditis. Aufmeißelung. Diffuse eitrige Durchsetzung des Knochens. Freilegung von Sinus und Dura der mittleren Schädelgrube, da der Knochen soweit erkrankt ist. Erysipel über Hals, Brust und linkem Arm mit nachfolgender enorm àsgedehnter eitriger Einschmelzung des Unterhautzellgewebes. Inzision usw. Exitus zehn Tage post operationem.

Sektionsbefund: Phlegmon über Hals, Brust und Arm. Chronische Nephritis. Herzhypertrophie. Dura von gewöhnlicher Beschaffenheit, Innenfläche überall glatt. Weiche Hirnhäute normal aussehend. Hirnsubstanz ohne Besonderheiten. Hirnsinus frei von thrombotischen Auflagerungen.

Histologischer Befund: Auf der Duraaußenfläche der frei- 
gelegten mittleren Schädelgrube sieht man ein mächtiges Exsudat auflagern. Dasselbe setzt sich zusammen aus gelapptkernigen Leukocyten, einer Unmenge kleiner Rundzellen und einer nur schwach gefärbten klumpigen Zwischensubstanz. In einer Anzahl von Präparaten kann man an dem Gefüge dieser Zwischensubstanz sowie aus dem allerdings oft nur zum Teil positiven Resultate der Weigertfärbung erkennen, daB es sich, stellenweise wenigstens, teils um Fibrin handelt. Nach der eigentlichen Dura hin ist eine Anzahl von jüngen Bindegewebszellen aufgetreten, aus denen sich hier und dort junges Bindegewebe herausdifferenziert hat. Innerhalb dieser äußern pachymeningitischen Entzündungszone liegen eine ganze Reihe kleiner Knochenstiickchen eingebacken.

Im allgemeinen sind die äußern Lamellen der Dura mater ganz bedeutend mehr entzündlich infiltriert wie die innern. An verschiedenen Punkten sieht man jedoch auch polynukleäre Leukocyten vereinzelt oder in kleineren Häufchen quer die Dura bis nach innen hin durchsetzen. Das Innenendothel scheint vollständig erhalten zu sein. Eine wesentliche Vermehrung der Endothelzellen läßt sich nicht konstatieren. An vereinzelten Stellen sieht man auch als Anzeichen einer allerdings ziemlich geringfügigen Pachymeningitis interna schmale Fibrinsäume die Durainnenfläche begleiten. Bakterien kann man nur im Exsudat der Pachymeningitis externa, und auch hier nur in den äuBem Schichten, nachweisen.

Auf dex freigelegten Sinusoberfläche findet sich ein ziemlich beträchtliches unregelmäBig gestaltetes Exsudat, das zum größten Teil aus gelapptkernigen Leukocyten zusammengesetzt ist. Die Kerne desselben erscheinen zum Teil zerfallen und degeneriert. Von hier aus dringen Eiterzellen quer durch die aufgelockerten Duralamellen. Daneben findet man viele kleine Rundzellen und eine ganze Anzahl Zellfragmente, deren Provenienz sich nicht mit absoluter Sicherheit feststellen läßt. Ferner kann man allenthalben innerhalb der Sinuswand strotzend gefullte Gefäße mit zum Teil stark entzündlich veränderten Wänden konstatieren. Parallel der Sinusinnenfläche läBt sich eine ziemlich bedeutende zellig infiltrierte Zone nachweisen. Hier herrschen kleine Rundzellen, gelapptkernige Leukocyten und Zellen mit großem blaßem Kerne vor. Was diese letztere Zellgattung: betrifft, bleibt es manchmal zweifelhaft, ob man es mit jungen Bindegewebszellen oder Endothelabkömmlingen zu tun habe. Die innere pachymeningitische Entzündungszone breitet sich vom Orte der Entstehung aus parallel der Sinuswand zuweilen weiter fort als die entsprechende Entzündungszone auf der Aubenfläche des Blutleiters. Nach der Peripherie dieser Pachymeningitis interna zu wird dieselbe demnach bisweilen von anscheinend normalen Durapartien nach auben hin begrenzt. Das Innenendothel des Sinus scheint mit geringen Ausnahmen, auf die ich noch zu sprechen komme, erhalten zu sein. An manchen Stellen sieht man dicht an das Endothel anschlieBend, doch unter deraselben, kleine Klümpchen formlosen Exsudats. An andern Punkten kann man auch auBerhalb der internen pachymeningitischen Entzündungsgrenze entlang der inneren Sinuswand kleine Häufchen von Rundzellen und gelapptkernigen Leukocyten unterhalb des intakten Endothels feststellen. An einer Stelle findet man etwas abseits gelegen vom eigentlichen Entzïndungsherd eine starke Ansammlung der vorher erwähnten Zellen. Es läßt sich nicht mit Sicherheit bestimmen, ob das Endothel hier erhalten ist. In der Umgebung dieses kleinen Infiltrates fällt eine bemerkenswerte Randstellung der Erythrocyten auf.

Im Bereich der Pachymeningitis interna sitzt der entzündlich infiltrierten Sinuswand eine kleine knopfartige Exkreszenz auf, die sich aus einem formlosen Exsudat zusammensetzt. Innerhalb des 
letztern finden sich Gruppen von gelapptkernigen Leukocyten. Bei Immersion kann man feststellen, dap dieses kleine Klümpchen in direktem Konnex mit der Gefäßwand selbst steht. Ein eigentliches Endothel läßt sich hier nicht nachweisen. In einigen Präparaten sieht man innerhalb dieses Exsudats mehrere rote Blatkörperchen eingeschlossen. Der ganzen Struktur nach ist dasselbe am ehesten als Fibrin aufzufassen, trotzdem sich keine sichere Fibrinreaktion ergibt (conf. Abb. VIII).

Etwa in der Mitte der vorhandenen Pachymeningitis interna haften auf der Sinuswand zwei flach aufsitzende thrombotische Auflagerungen. Dieselben setzen sich aus Fibrin und gelapptkernigen Leukocyten zusammen, stehen zwar mit der Gefäßwand in innigem Konnex, doch nicht untereinander (conf. Abb. TX).

Auf der SinusauBenseite und innerhalb der Pachymeningitis externa liegen in ziemlich großen Häufchen Bakterien. Doch sieht man in einzelnen Präparaten nicht unbeträchtliche Bakterienmengen auch innerhalb der eigentlichen bindegewebigen Lamellen des Hirnblutleiters. Eine thrombosierte Vene inmitten der Sinuswand enthält recht viel Bakterien. Auch innerhalb der vorher beschriebenen Pachymeningitis interna der Sinuswand lassen sich in einer Reihe von Präparaten eine Anzahl Bakterienhäufchen nashweisen, desgleichen kann man rwar nicht in allen, jedoch in einzelnen Schnitten innerhalb der vorher beschriebenen kleinen Thromben ( $T$, Abb. IX) Bakterien konstatieren.

Fall II. Frieda K., 4 Jahre. Otitis media acuta dextra. Ohreiterung zunächst anscheinend ausgeheilt, dann Rezidjv. Keine Labyrinthsymptome. Aufmeibelung. Perisinuöser AbszeB. Weite Freilegung des Sinus und der mittleren Schädelgrube. In den nächsten Tagen treten schwere meningitische Symptome auf. Starke Bewaßtseinstrubbung usw. Lumbalpunktion negativ. Drei Tage nach der ersten Operation zweiter operativer Eingriff. Ausgedehnteste Freilegung der mittleren und hinteren Schädelgrube. Resektion der Pyramidenkante. Inzision des Sinus. In demselben läBt sich dicht neben der Inzisionsstelle ein nicht sehr bedeutender wandständiger Thrombus feststellen. Blutstrom völlig erhalten. Punktion des Kleinhirns hinter dem Sinus negativ. Mehrmalige Punktion des Großhirns über dem Tegmen tympani gleichfalls negativ. Hierbei kommt es zu einer mächtigen Bluturg, die nur schwer gestillt werden kann. Kochsalzinfusion usw. Kind kommt einige Stunden später ad exitum.

Sektionsbefund: Schädeldach mit der Dura an verschiedenen Stellen fest verwachsen. Utber dem rechten Scheitellappen ein Blutkoagulum, das sich bis ijber den rechten Stirnlappen fortsetzt. Die weichen Hirnhäute mäBig gerötet, nirgends getrübt. In der Dura der mittleren Schädelgrube finden sich mehrere Löcher (Punktionsstellen). Ein feiner schlitzförmiger Spalt liegt gerade über einem Sinus, der von dex Crista petrosa dextra bis zur Crista sphenoidalis dextra verläuft. Der Sinus ist nur im Beginn noch sondierbar, in den übrigen Teilen anscheinend obliteriert. Im rechten Sinus sigmoideus findet sich ein etwa bohnengroßer wandständiger rötlich-grauer Thrombus. Die Außenwand des Sinus zeigt entsprechend dem Thrombus ein Granulationspolster von ziemlicher Dicke. In der Substanz des Kleinhirns findet sich eine $2-3 \mathrm{~cm}$ tiefe strichförmige Hämorrhagie, in der Substanz des Schläfenlappens $3-4$ ähnliche Punktionskanäle. Uber dem rechten Schläfenlappen läßt sich auBerdem eine flache subpiale Suffusion nachweisen. Eine weite Vene an der Oberfläche des rechten Schläfenlappens zeigt einen stecknadelkopfgroßen Wanddefekt. Das rechte Hinterhorn ist an seinem äußersten Ende obliteriext. Über dem Unterwurm des Zerebellums zeigt sich eine cpake gelbe eitrige Infiltration der Meningen. 
Histologischer Befund: Der AuBenwand des Sinus sigmoideus verläuft ein breiter sehr zellreicher Saum parallel, und zwar handelt es sich fast durchschnittlich um starke Anhäufungen von jungen Bindegewebszellen und kleinen Rundzellen. Zwischen diesen Zellen sieht man allenthalben neu gebildete Bindegewebsfäserchen. Desgleichen findet sich hier eine ganze Anzahl junger Gefäße vor. Ganz nach auBen hin schlieBen sich an diese augenscheinlich in Regeneration begriffene etwas ältere Pachymeningitis externa Fibrinniederschläge an, die bald zarter, bald ziemlich ausgesprochen sind. Diese Fibrinanhäufungen sind augenseheinlich jüngeren Datums als die vorher beschriebene bereits in deutlicher Regeneration begriffene Zone.

Die Bindegewebslamellen der eigentlichen Sinuswand sind verhältnismäBig nur wenig entzündlich infiltriert. Bisweilen sieht man allerdings hier und dort mehr oder weniger groBe Anbäufungen von kleinen runden Zellen und jungen. Fibroblasten. Auch tauchen an versehiedenen Punkten vereinzelte oder zu kleinen Gruppen zusammenliegende gelapptkemige Leukocyten auf. Die innersten Partien der GefäBwand gehen ohne jede trennende Endothelschicht in einen wandständigen flach aufsitzenden Thrombus über (conf. Abb. V). Derselbe setzt sich zum größten Teil aus Fibxinlamellen zusammen. Inmitten des Thrombus sieht man einen sehr starken aus Unmengen von Eiterzellen bestehenden Herd. Desgleichen lassen sich an einzelnen Stellen größere Mengen von Erythrocyten im Thrombus nachweisen. Nach dem Gefäßlumen zu, das im übrigen völlig erhalten ist, wird der Thrombus durch eine zwar nicht ununterbrochene, jedoch zum Teil sehr gut nachweisbare Zellmembran begrenzt. Dieselbe besteht aus einer stellenweise $6-8$ Lagen breiten Schicht von langgestreckten zelligen Elementen. An den Rändern des Thrombus findet sich eine einfache Zellenlage, die in das Nachbarendothel der Sinusinnenwand direkt überzugehen scheint.

An einem Punkte sitzt der freien Fläche des Thrombus eine länglich geformte unregelmäBig gestaltete, schon makroskopisch sichtbare Exkreszenz auf. Dieselbe flottiert augenscheinlich frei im Gefäßlumen (conf. Abb. V). Diese Exkreszenz besteht zum Teil aus Fibrin, zum Teil aus starken Anhäufungen von Zellen, die meistens zerfallen und in Auflösung begriffen zu sein scheinen. Es ist deshalb schwer, die Art dieser Zellen genau festzustellen. Teilweise scheint es sich um gelapptkernige Leukocyten zu handeln. Sehr deutlich kann man konstatieren, daß sich die Fibrinmassen des eigentlichen Thrombus direkt in diese Exkreszenz herüberziehen.

An einer andern Stelle der GefäBwand sitzt auf dem Boden einer alten Pachymeningitis intera fibrinosa ein augenscheinlich ganz frisches Gerinnsel auf. Dasselbe steht durch Fibrinzüge, die direkt in die Pachymeningitis interna übergehen, in breiter Verbindung mit. der Wand des Sinus. Dieses Gerinnsel setzt sich zum größten Teil aus roten Blutkörpern zusammen; an einzelnen Stellen wird es durch dünnere fibrinöse Züge durchschnitten. Am Rande desselben findet sich eine stärkere Ringzone von Fibrin, welches den Kern von roten Blutkörperchen halbkreisförmig umgibt (conf. Abb. VI).

Die Pachymeningitis interna ist gröBtenteils bakterienfrei, nur in den innersten nach dem Lumen zu gerichteten Partien kann man hier und da inmitten eines formlosen Detritus sowie minimaler Fibrinfäserschen Anhäufungen von Bakterien konstatieren. Die unmittelbar nach außen zu anschließenden Teile der Gefäßwand enthalten keine Bakterein. Der vorher beschriebene rote Thrombus (Abb. VI) ist zum größern Teile bakterienfrei. Jedoch sieht man auch hier, am Rande des Thrombus sowie in den ganz innersten nach dem Lumen zu gerichteten fibrinösen Partien desselben bisweilen kleine Ansammlungen von Kokken. Man hat durchaus den Eindruck, als ob die Bak- 
terien an diesen speziellen Stellen nicht von außen nach innen, sondern von innen nach außen zu vorgedrungen sind. Die äußersten Schichten der Pachymeningitis externa des Sinus sind sehr stark bakteriell durchsetzt. Die Kokken liegen besonders in den vorher erwähnten frischen Fibrinniederschlägen bisweilen in gröBeren Klumpen zusammen. Im Innern der Bindegewebslamellen des Sinus selbst sieht man gleichfalls hier und dort vereinzelte Kolken; im allgemeinen jedoch ist die GefäBwand bakterienfrei.

Innerhalb des vorher beschriebenen wandständigen Thrombus ( $T$, Abb. V) kann man gleichfalls nur ganz vereinzelte Kokken nachweisen, hier und dort nahe der Oberfläche. Die meisten Partien des Thrombus enthalten keine Bakterien. Inmitten der zu Anfang geschilderten nach dem GefäBlumen zu sich ausbreitenden frei endigenden Exkreszenz (Abb. V a) lassen sich an beiden Enden sowie in der Mitte spärliche kleine Kokkenhäufchen feststellen.

Mit Ausnahme der vorher beschriebenen Veränderungen scheint die Sinuswand ziemlich frei zu sein von thrombotischen Auflagerungen. Nur findet man genau vis-à-vis dem wandständigen Thrombus auf der gegenüberliegenden Wand des Sinus an zirkumskripter Stelle augenscheinlich die ersten Anfänge der Thrombenbildung. Man sieht eine nur mikroskopisch nachweisbare rundliche Auflagerung, die anscheinend aus Blutplättchen besteht; die Grenzen derselben lassen sich nicht uiberall gegen das Innenendothel hin vollig präzis verfolgen (conf. Abb. VII), Innerhalb dieses Gerinnsels finden sich vereinzelte Kokken. Fibrin fehlt. Die Sinuswand selbst ist in der Umgebung dieser Stelle ziemlich frei von Entzündungserscheinungen, insbesondere kann man in derselben keine Bakterien nachweisen. An der Punktionsstelle der Kleinhirndura sind die Gewebslamellen der Hirnhaut zerrissen und unregelmäßig durcheinander gelagert. (conf. Abb. V). Besondexs in den oberflächlichen Schichten finden sich zwischen ibnen Unmengen von Eiterzellen und Fibrinmassen. Diese sehr manifesten Entzündungserscheinungen lassen sich etwa bis zur Mitte der Punktionsstelle nachweisen und klingen dort allmählich ab. Immerhin kann man geringere Ausläufer der entzündlichen Vorgänge bis an die Innenfläche der Dura hin verfolgen. Ebenso ist die weitere Umgebung der Punktionsstelle ziemlich stark entzündlich verändert. Hier läßt sich eine ausgesprochene Pachymeningitis externa sowie eine nicht unbedeutende Infiltration des eigentlichen Duragewebes konstatieren. Dicht am Stichkanal lagem auf der änBern Kleinhirndurafläche größere Bakterienmassen und folgen dem Kanal etwa bis zur Hälfte seines Verlaufes. Die Partien rings um das innere Ende der Stichöffnung sind im wesentlichen bakterienfrei, jedoch lassen sich rereinzelte Kokkenhäufchen unmittelbar auf der zerebralen. Fläche der Kleinhirndura nachweisen.

\section{Pachymeningitis interna.}

Wenn ich zunächst die Resultate meiner experimentellen Versuche zusammenfasse, so sind dieselben in Kürze folgende: Zunächst kann ich, und zwar ausnahmslos, eine der Erfahrungen meiner ersten Arbeit bestätigen. Fast stets entwickelte sich als Folge einer Durainfektion mit oder ohne Verletzung der harten Hirnhaut eine Pachymeningitis externa und interna geringerer oder stärkerer Art. Meine letzten experimentellen Versuche geben Gelegenheit, genau die Entwicklung und das Fort- 
schreiten von entzündlichen Veränderungen auf der Durainnenfläche $\mathrm{zu}$ studieren. Besonders kommen hierfür die Fälle 3, 6, 7, 8, 11 und 12 in Betracht. Es fällt zunächst auf, daß die Pachymeningitis interna nicht selten die Pachymeningitis externa ganz bedeutend an Mächtigkeit übertrifft. Ebenso wie bei meiner ersten Arbeit kann man auch hier die Tatsache konstatieren, daß die einzelnen entzündlichen Plaques auf der Innenfläche der harten Hirnhaut mitunter scheinbar in Keinem festen Zusammenhang miteinander stehen; erst bei Serienuntersuchung findet man dann bisweilen dünne zusammenhängende Brücken oder es lassen sich mehr vereinzelte die Verbindung herstellende Eiterzellen konstatieren.

Gewöhnlich breiten sich die entzündlichen Vorgänge unter dem erhaltenen resp. gewucherten Endothel aus, ja es können ganz gewaltige Entzündungsprodukte auf der Durainnenfläche vorhanden sein, und trotzdem ist die Endotheldecke völlig intakt. Die letztere kann durch die unter ihr liegenden Infiltrationszellen bisweilen ganz bedeutend aufgebuckelt und weit nach dem Intraduralraum vorgebuchtet werden. Andererseits kann man bisweilen an manchen Stellen keinen abgrenzenden Endothelsaum konstatieren, oder es muß in dubio bleiben, ob ein solcher vorhanden ist oder nicht. Hierzu möchte ich erwähnen, daß zunächst sehr wohl infolge technischer Fehler bei der Einbettung usw. hier und dort das Endothel ein- oder abgerissen sein kann und daß ferner bei einer sehr stark entzündlichen Infiltration Endothelzellen und Infiltrationszellen sich absolut nicht voneinander trennen lassen, so daß in diesem Punkte eine sichere Entscheidung zur Unmöglichkeit worden kann. Jedenfalls ist es ganz fraglos, daß das Innenendothel der Dura eine ganz enorme Widerstandsfähigkeit besitzt und als ein Schutzwall ersten Ranges gegenüber der fortschreitenden Infektion angesehen werden kann.

Sehr interessant war es für mich, die nähere Art der Entstehung der Pachymeningitis interna sowie ihre feinere Struktur zu studieren. Wenngleich ich zugeben muß, daß auch die histologischen Bilder, besonders was die Provenienz der einzelnen entzündlichen Elemente betrifft, mir nicht in allem volle Klarheit verschaffen konnten, möchte ich es doch nicht unterlassen, diesen Punkt zusammenfassend zu behandeln. Ich werde aus den vorher angedeuteten Gründen allerdings bisweilen genötigt sein, mich einer erläuternden Kritik zu enthalten. 
Die ersten entzündlichen Vorgänge bei der Entwicklung einer Pachymeningitis interna gehen zwischen dem Endothel und den oberflächlichen Lamellen der harten Hirnhaut vonstatten. Es entsteht hier eine eigentümliche Zwischenschicht von netzartiger Struktur. Die Knoten dieses Netzes werden repräsentiert durch große ziemlich blasse Zellkerne, das Maschenwerk durch zarte Fäserchen von durchaus fibrinartiger Beschaffenheit. Bei Immersionsbetrachtung hat man den Eindruck, als ob die zu den vorher beschriebenen Kernen gehörenden Zelleiber irgendwie an der Entwicklung dieser faserigen Zwischensubstanz beteiligt sind. Jedenfalls kann man die eigentlichen Grenzen der Zelleiber gegenüber der Zwischensubstanz häufig nicht deutlich herausdifferenzieren. Infolge derartiger Bilder, die sich als reaktive Folge eines auf die Duraaußenfläche einwirkenden bakteriellen Entzündungsreizes bereits $1 \frac{1}{2}$ Tage post infektionem zeigen, liegt der Gedanke nahe, daß es zu einer Exsudation zwischen die ganz äußersten, unmittelbar an das Endothel grenzenden Lamellen der Dura mater gekommen ist.

Es hält ziemlich schwer, den eigentlichen Charakter des: vorher geschilderten zwischen den Zellen auftretenden, bei Immersionsbetrachtung oft durchaus fibrinartig aussehenden Exsudates zu bestimmen. Dasselbe ergibt zwar bei spezifischer Färbung keine richtige Fibrinreaktion, geht jedoch nicht selten in typisches Fibrin derartig über, daß an der nahen Verwandtschaft dieses Exsudats mit Fibrin kaum gezweifelt werden kann. Der Zusammenhang dieses Exsudates mit den zelligen Elementen ist übrigens häufig ein derartig intimer, daß sich dem Beobachter bisweilen direkt die Auffassung aufdrängt, ob diese Zellen nicht irgendwie mit der Entstehung. des Exsudats in Zusammenhang zu bringen sind.

Manchmal besteht die sich als erste Folge des Entzündungsreizes entwickeInde Grenzschicht zwischen Endothel und den Bindegewebslamellen der harten Hirnhaut scheinbar nur aus lose zusammengefügten, ziemlich protoplasmareichen Zellen. Andererseits tauchen bisweilen hier und da $\mathrm{zw}$ ischen den Maschen dieser Grenzschicht grobkörnige Klümpchen. auf, die zwar noch nicht die Fibrinfärbung angeben, jedoch ihrer ganzen Struktur nach immer mehr dem typischen Fibrinbau nahekommen; oder es schieben sich gleiche Massen zwischen die netzartige Grenzschicht und die eigentlichen Lamellen der Dura mater ein.

Ist die reaktive Äußerung auf den Entzündungsreiz eine 
stärkere, so tritt der eigentliche Fibrincharakter immer deutlicher hervor. Es zeigt sich ein unregelmäBig geformtes Netzwerk von groben und feineren Fäden sowie kleinen knötchenförmigen Verdickungen. Daneben verlaufen bisweilen eine Anzahl derberer Fibrinstränge der harten Hirnhaut parallel. Besonders nach den Rändern zu fällt mitunter eine eigentümliche Felderung dieses Exsudates auf, und zwar in der Weise, daß dasselbe an gewissen Punkten resp. Linien unterbrochen erscheint. Parallel den Grenzlamellen dieser Felder herrscht bisweilen ein bemerkenswerter Zellreichtum. Da selbst bei derartigen ganz einwandfreien Bildern einer typischen Fibrinstruktur die spezifische Weigert-Reaktion nicht selten versagt oder nur strichweise angedeutet ist, wird hierdurch das Studium der feinen histologischen Übergänge des vorher geschilderten fibrinartigen Exsudats in das eigentliche Fibrin recht erschwert. Andererseits kommt es als weitere Folge des Entzündungsreizes bisweilen zu sicher nachweisbaren Wucherungen des Endothels selbst, und diese Endothelwucherungen ähneln derartig den zelligen Elementen innerhalb der vorher genauer beschriebenen Grenzschicht zwisehen Endothel und Bindegewebe, daß eine sichere Bestimmung der Herkunft dieser Zellen häufig genug zur Unmöglichkeit wird.

Je nach dẻm Grade der Entzündung treten ferner mononukleäre Elemente oder gelapptkernige Leukocyten in mehr oder weniger großen Haufen auf. Diese letzteren können bisweilen derartig prävalieren, daß stellenweise hinter denselben der Fibrincharakter der Pachymeningitis interna zurücktritt.

In fast sämtlichen der von mir erzeugten Pachymeningitiden auf der Durainnenfläche konnte ich Bakterien nachweisen. Eine Ausnahme bilden nur die beiden Fälle Hund 11 und 12. Was zunächst die letztere Beobachtung betrifft, so habe ich bei derselben allerdings auch auf der Duraaußenfläche in einzelnen Schnitten überhaupt keine Bakterien gefunden, in anderen Präparaten waren hier nur relativ spärliche Bakterienhäufchen konstatierbar. Es liegt deshalb der Gedanke sehr nahe, daß die Bakterein in dem zur Diskussion stehenden Falle (Hund 12) fünf Tage nach der Infektion bereits wieder geschwunden sein können. Jedenfalls scheint derselbe keine prinzipielle Bedeutung zu haben.

Wie man aus meiner ersten Arbeit ${ }^{1}$ ) ersehen kann, setzten die regressiven Prozesse im allgemeinen etwa am fünften Tage

1) Conf. Streit 1. c. 
ein. Mit ihrem Beginn verschwanden gewöhnlich ganz prompt die Bakterien. Man hatte im allgemeinen den Eindruck, als ob die durch die Dura eingedrungenen Bakterien sich gegenüber den antibakteriellen Kräften der Intraduralräume als wenig widerstandsfähig erwiesen. Eine Ausnahme zu diesem außerordentlich regelmäßig beobachteten Gesetz bildete eigentlich, wenn man davon absieht, daß man in einem Falle Bakterien noch nach sieben Tagen post infectionem nachweisen konnte — nur ein Fall. Bei dieser Beobachtung waren kleine Knochenmeißelsplitter durch die Inzisionswunde der Dura in den SubduraIraum eingedrungen. In der Umgebung dieser Knochenpartikel, die wohl in ihrer Fremdkörpereigenschaft als fortdauerndes Reizmoment anzusehen sind, fanden sich noch sechs Wochen post operationem starke Ansammlungen von Rundzellen, gelapptkernigen Leukocyten und Kokkenhäufchen.

Was den Fall betrifft, bei dem man noch nach sieben Tagen Bakterien zwar innerhalb der Pachymeningitis externa, nicht jedoch im Innern der internen pachymeningitischen Auflagerungen konstatieren konnte, so habe ich in meiner ersten Arbeit betont, daß die Auffassung naheliegt, für die Entstehung der Pachymeningitis interna bei dieser Beobachtung (Hund C) eine toxische Fernwirkung als erklärendes Moment heranzuziehen. Allerdings habe ich damals gleich hinzugefügt, da $B$ gegenüber diesem Erklärungsversuch doch noch ein Einwand möglich ist, nämlich der, daß die Bakterien außerhalb der harten Hirnhaut weniger hemmende Einflüsse für ihr Fortbestehen vorfanden, als auf der Innenfläche derselben und infolgedessen an der ersten Stelle sieben Tage post infectionem bereits wieder geschwunden sein können. Immerhin - so betonte ich bereits in meiner ersten Arbeit bei dem vorher erwähnten Falle Hund C - ist der Gegensatz zwischen dem massenhaften Auftreten von Bakterien innerhalb der epiduralen Granulationen und dem gänzlichen Fehlen in den tiefen Schichten der Dura zum mindesten etwas auffällig.

Aus diesen Gründen habe ich bei Besprechung des Falles Hund $\mathrm{C}$ die Entstehung der Pachymeningitis interna durch toxische Fernwirkung für wahrscheinlich gehalten. Die gleiche Auffassung ist wohl auch für Hund XI die naheliegendste, wenngleich hier ebenso wie bei Hund XII auch auf der Duraaußenfläche nur recht spärliche Bakterien nachgewiesen werden konnten, während dieselben innerhalb der Pachymeningitis interna überhaupt zu fehlen schienen. Toh habe mit Absicht gesagt, ,zu fehlen schienen", denn es 
liegt ja auf der Hand, daß man bei derartigen Untersuchungen, selbst wenn man noch so minutiös zu Werke geht, außerordentlich leicht vereinzelte Bakterien übersehen kann, zumal dort, wo Fibrinanhäufungen vorhanden sind.

Eine fernere Stütze der Auffassung, daß unter Umständen toxische Momente für das Zustandekommen von Entzündungserscheinungen auf der inneren Fläche der Dura teilweise wenigstens verantwortlich zu machen sind, bieten die nicht selten von mir gemachten Beobachtungen, bei denen sich innerhalb der internen pachymeningitischen Auflagerungen zwar Bakterien vorfanden, ihre Menge jedoch zur Größe der nachgewiesenen Pachy resp. Leptomeningitiden in keinem richtigen Verhältnis stand. $O b$ nun hier die toxische Wirkung von den intradural sich vorfindenden recht spärlichen Bakterien oder der großen Menge der extraduralen ausgeht, muß dahingestellt bleiben.

Resümiere ich kurz meine diesbezüglichen am Tierversuch gemachten Erfahrungen, so ist das gewonnene Resultat folgendes:

Fast stets treten als Reaktion auf einen von der Duraaußenfläche her einwirkenden bakteriellen Reiz entzündliche Veränderungen auf der Innenseite der harten Hirnhaut auf. Manchmal handelt es sich allerdings nur um kleine Fibrinanhäufungen resp. geringe Infiltrationen, in anderen Fällen jedoch kommt es zu mächtigen Exsudaten, die die Dura selbst bei weitem an Dicke übertreffen können. Diese internen Pachymeningitiden sind gewöhnlich bakterieller resp. bakteriell-toxischer Provenienz, ziemlich selten können sie jedoch anscheinend infolge toxischer Fernwirkung extraduraler Bakterienanhäufungen zustande kommen.

Es ist ja wohl sicher recht auffällig, ein wie gewaltiger Kontrast anscheinend in der Häufigkeit der von mir experimentell erzeugten internen Pachymeningitiden beim Versuchstiere und dem gleichen Krankheitsbilde beim Menschen besteht, soweit hierfür die einschlägigen Publikationen in Betracht kommen. Ich habe dieses Moment schon in meiner ersten Arbeit betont und will deshalb nur kurz, um Wiederholungen zu vermeiden, die Gründe zusammenfassen, weshalb ich glaube annehmen zu dürfen, daß die bisherigen Publikationen kein richtiges Bild für die Häufigkeit der menschlichen Pachymeningitis interna erbringen. Es sind dies folgende: 
Die menschliche Pachymeningitis interna heilt gewöhnlich prompt aus und kann schon deshalb nicht diagnostiziert werden, weil Obduktionen fehlen. Wenn es trotzdem durch $\mathrm{Zu}$ fall in späteren Stadien zum Tode und zur Sektion kommt, sind die hinterlassenen Residuen der Pachymeningitis interna, da sie meist nur in einer Duraverdickung bestehen, recht wenig markant. Die meisten frischen Fälle werden bei einer $\mathrm{Ob}$ duktion übersehen, weil sie die Neigung haben, lokalisiert zu bleiben und deshalb wenig ins Auge fallen. Wie aus meinen Obduktionsberichten hervorgeht, habe ich selbst bei meinen Versuchstieren, trotzdem ich ja ganz besonders auf die in Frage kommenden Stellen mein Augenmerk richtete, ziemlich häufig erst histologisch nicht unbedeutende innere Pachymeningitiden feststellen können. Solange das Innenendothel der Dura erhalten ist, fällt eine Verdickung der harten Hirnhaut absolut nicht auf (conf. Abb. IV).

Aus diesem Grunde glaube ich, daß die menschliche Pachymeningitis interna ganz bedeutend häufiger ist, als allgemein angenommen wird. In dieser Auffassung finde ich mich in Übereinstimmung mit Blegvad ${ }^{1}$ ), der erst kürzlich eine größere Anzahl von Beobachtungen menschlicher interner Pachymeningitiden zusammengestellt hat. Einzelne dieser letzteren gleichen fast absolut makroskopisch und mikroskopisch den am Tierversuch gemachten Beobachtungen. Auch in der Art der Entstehung der von Blegvad gesammelten Fälle besteht insofern eine gewisse Parallele zu meinen experimentellen Beobachtungen, als die Infektion bei der menschlichen Pachymeningitis interna fast stets direkt per continuitatem und nicht durch das Labyrinth hindurch erfolgte. Wenn Blegvad sagt: ,,Viele Fälle von sogenannter zirkumskripter Meningitis stellen sicher eine Pachymeningitis interna vor", so unterschreibe ich seine Ansicht vollkommen.

II. Entzündungen i m Subduralraum.

Der von Blegvad selbst veröffentlichte Fall I gleicht übrigens in seinem pathologischen Befund ganz außerordentlich meinen experimentellen Beobachtungen Hund IV und Hund X. Hund IV ist der einzige Fall, bei dem ich zirkumskripte Eiterungen im Subduralraum nachweisen konnte. Dieselben flossen nach Abhebung der Dura genau so aus, wie

1) Blegrad, Ưber die otogene Pachymeningitis interna purulenta. Archiv für Ohrenh. 83, Heft 3 u. 4 . 
etwa ein HautabszeB nach breiter Inzision. Es hatten sich also innerhalb des Subduralraums Verwachsungen gebildet, die durch Abhebung der Dura gelöst wurden. Bei dieser Beobachtung haben wir demnach die zweite allerdings selten in so klassischer Form auftretende Etappe in dem Fortschreiten der Infektion nach dem Schädelinnern vor uns. Diese Etappe wird, wie wir in meiner ersten Arbeit gesehen haben und wie ich im folgenden noch genauer ausführen werde, gewöhnlich übersprungen. Unter besonders günstigen Umständen kann sie sich jedoch geradezu klassisch, wie z. B. bei den Fällen von Heine $e^{1}$, Manasse ${ }^{2}$ ), Chavasse ${ }^{3}$ ), Blegvad ${ }^{4}$ ) und anderer ausbilden. Ich stimme der vielfach geäußerten Ansicht durchaus bei, daß in derartigen Fällen eine gewisse Gutartigkeit des Prozesses vorhanden sein dürfte. Natürlich ist in diesem Stadium eine vollkommene Heilung der Erkrankung sehr gut möglich und auch bereits mehrfach beobachtet. Mir scheint der spezielle Grund dafür, daß diese subduralen Eiterungen unter Umständen nicht ohne weiteres in ausgedehntem Maße auf die weichen Hirnhäute übergehen, ebenso wie bei der Pachymeningitis interna auch hier in der beträchtlichen Widerstandsfähigkeit des Endothels, dieses Mal des Außenendothels der Arachnoidea, zu liegen ${ }^{5}$ ). An der hervorragenden Widerstandsfähigkeit desselben Endothels liegt es wenigstens zum Teil, weshalb bei ausgesprochenen eitrigen Meningitiden der Subduralraum gewöhnlich frei von Exsudat ist. Im allgemeinen halte ich es jedoch für wahrscheinlich, und fast alle einschlägigen Beobachtungen geben mir recht -, daß in den Fällen, in welchen die Arachnoidea selbst längere Zeit von Eiter bedeckt ist, sich Entzündungserscheinungen an den weichen Hirnhäuten wenigstens histologisch werden nachweisen lassen. Allerdings dürften dieselben ebenso wie bei manchen meiner experimentellen Beobachtungen infolge gleichzeitiger Pachymeningitis interna bisweilen nur relativ wenig ausgesprochen oder auch eigentümlich sprungförmig sein, indem mit anscheinend normalen entzündlich veränderte Partien abwechseln. Dieser letztere Befund kann dann oft

1) Heine, Zur Kenntnis der intraduralen Eiterungen. Beiträge zur Ohrenheilk., Lucae, Festschrift, S. 339 .

2) Manasse, Über die operative Behandlung der otitischen Meningitis, Zeitschrift f. klin. Medizin, 55.

a) Chavasse, Sitzungsbericht des 7. internationalen Otologenkongresses zu Bordeaux, 7. August 1904.

4) Blegvad, 1. c.

5) Auf einen weiteren Grund komme ich weiter unten zu sprechen. 
zu Täuschungen Veranlassung geben, sofern nicht größere Oberflächengebiete zur Untersuchung kommen. Leider sind die hierfür ganz besonders interessanten histologischen Befunde von Blegvad so kurz gehalten, dab sie in dieser Hinsicht keine genügende Aufklärung geben. Blegvad scheidet übrigens den Begriff der Pachymeningitis interna nicht strikt von dem der subduralen Eiterungen - eine Trennung, die mir nicht nur theoretisch, sondern auch praktisch durchaus von Bedeutung zu sein scheint. Was speziell den Fall II von Blegvad betrifft, so ist derselbe, soweit die rechte Seite des. Schädels in Betracht kommt, wohl mehr als Pachymeningitis interna zu bezeichnen. Es ist mir doch etwas fraglich, ob in demselben die Arachnoidea lange Zeit direkt von Eiter umspült war.

Was die Körnersehe Ansicht betrifft' ${ }^{1}$ ), daß die Leptomeningen bisweilen durch eine ihnen außen ansitzende Granulationsschicht vor der Propagierung einer subduralen Eiterung geschützt sein können, so ist demgegenüber einzuwenden, da $B$ diese sogenannten Granulationen der Ausdruck einer entzündlichen Reaktion der weichen Hirnhaut selbst sind, daß also in solchen Fällen eine konsekutive zirkumskripte Meningitis besteht.

Allem Anschein nach bildet übrigens gerade der Subduralraum ein ganz besonders ungünstiges Terrain für die Fortentwicklung bakterieller Herde. So kommt es also, daß diese zweite Etappe im Fortschreiten der Infektion von der Duraaußenseite gegen die Meningen für gewöhnlich ganz übersprungen wird. Es resultiert als nächste Folge einer Duraentzündung mit oder ohne ausgesprochener Pachymeningitis interna im gegebenen Falle ohne weiteres die Leptomeningitis. Wie ich mich durch meine Tierversuche überzeugen konnte, lassen sich aus dem subduralen Raume trotz unweit gelegener zirkumskripter pachy- oder leptomeningitischer bakterieller Herde gewöhnlich keine Bakterien züchten (conf. Hund $V$, VI, VII, VIII, IX). In den beiden Fällen (Hund $\mathrm{X}$ und Hund IV), wo man wegen der großen Ausdehnung des Prozesses zwecks Abimpfung direkt durch die infizierte Dura hindurchgehen mußte, wurden zwar aus dem Subduralraum der besonders affizierten Seite anscheinend Bakterienkulturen gewonnen, jedoch dürfte es wohl niemals gelingen, bei derartig ausgedehnten Prozessen nachzuweisen, ob die Bakterien nun

1) Körner, Otitische Erkrankungen, 1902, S. 36. 
wirklich frei im subduralen Raum vorhanden gewesen sind oder den pachymeningitischen resp. leptomeningitischen Herden entstammen. Die Abimpfung fand nämlich in der Weise statt, daß bei uneröffneter Dura mit stark erhitzter Platinöse zunächst ein Loch in die harte Hirnhaut eingebrannt and sodann durch dasselbe in den subduralen Raum vorgedrungen wurde. Es ist natürlich unmöglich, wenn man zwischen zwei bakteriell infizierten Wänden hindurchgeht, zu bestimmen, $o b$ die gezüchteten Bakterien aus den Wänden selbst oder aus dem Raum zwischen ihnen stammen.

Wichtig dagegen ist der Gegensatz, daß man in derartigen Fällen prompt den" positiven Bakteriennachweis erbringen konnte, bei zirkumskripten Herden dagegen anscheinend die angelegten Kulturen fast ebenso prompt kein Wachstum ergaben. Gerade die beiden Beobachtungen Hund IV und Hund $\mathrm{X}$ geben hierfür ein besonders illustratives Bild, indem man, wie gesagt, bei ihnen zwar aus dem Subduralraum der besonders stark affizierten Seite Bakterien züchten konnte, nicht jedoch aus der anderen Seite, trotzdem auch hier zirkumskripte pachy- und leptomeningitische Plaques vorhanden waren. Eine einzige Ausnahme zu dem vorher Gesagten bildet nur ein Fall, Hund III. Hier konnte man bei einer zirkumskripten Pachymeningitis interna zwar Bakterien aus dem Subduralraum züchten, vielleicht ist man jedoch mit der Öse bis in die unmittelbare Nähe der pachymeningitischen Plaques vorgedrungen.

\section{Eitrige Leptomeningitis.}

Wenn es mir in keinem Falle, auch nicht bei den ausgedehnteren leptomeningitischen Prozessen, gelang, Bakterien aus dem Rückenmarkskanal zu züchten, so kann dies vielleicht auch daran liegen, daß es zweckmäßig ist, direkt aus dem strömenden Liquor abzuimpfen, nicht jedoch erst, wie ich es getan habe, nach der Tötung der Versuchstiere. Jedenfalls lege ich in dieser Hinsicht meinen Versuchen keine Bedeutung bei.

Wenn ich nun schließlich zu der Beschreibung der letzten Etappe komme, die eine von der Duraaußenfläche gegen das Zerebrum zu gerichtete Infektion nehmen kann, der Leptomeningitis, so scheint es mir zweckmäßig zu sein, auch hier die feineren Details, soweit ich sie am Tierversuche beobachten konnte, etwas ausführlich zu schildern.

In seinem Referat für den XXI. Otologenkongreß zu 
Hannover: "Über die Heilbarkeit der otogenen Meningitis" betont Preysing, daß man vorläufig infolge mangelnder histologischer Befunde bei otogener Meningitis genötigt ist, die Befunde bei anderen Meningitiden heranzuziehen. Preysing gibt selbst $\mathrm{zu}$, daß bereits die beiden hauptsächlich als Parallele in Betracht kommenden Meningitisformen, die epidemische und tuberkulöse Meningitis, sich ganz wesentlich in ihrer histologischen Struktur voneinander unterscheiden. Die gleiche Differenz dürfte man wohl auch zwischen diesen Formen and der otogenen eitrigen Form erwarten; und wenn meine Tierversuche ein einigermaßen brauchbares Bild ergeben, trifft dieses auch durchaus zu. Jedenfalls scheinen mir die Resultate des Tierexperiments in dieser Beziehung immerhin noch brauchbarer zu sein, als ein Zurückgreifen auf verwandte Meningitisformen beim Menschen.

Zunächst kann man auch bei der Leptomeningitis ebenso wie vorher bei der Pachymeningitis interna zwischen de $\mathbf{n}$ Reaktionserscheinungen unterscheiden, welche durch direkte bakterielle resp. bakteriell toxisehe Wirkung erzeugt sind, und de $n$ jenigen, bei welchen man infolge des Fehlens von Bakterien rein toxische Einflüsse entfernterer Bakterienhaufen anzunehmen gezwungen ist. Was zunächst die letzte Gruppe betrifft, so sind die Veränderungen an den weichen Hirnhäuten hier nicht nur gewöhnlich bedeutend weniger ins Auge springend, sondern auch in ihrem feineren histologischen Bau im allgemeinen etwas anders geartet.

Als erstes Anzeichen einer reaktiven Äußerung auf den von der Duraaußenfläche her einwirkenden Reiz sieht man an den weichen Hirnhäuten eine starke Gefäßfüllung; in manchen Fällen fällt eine ausgesprochene Randstellung der gelapptkernigen Leukocyten innerhalb der Gefäße auf. Sodann tritt ein gewisser unverkennbarer Zellreichtum ein, und zwar handelt es sich um Zellformen mit großem blassem Kern sowie mononukleäre Leukocyten. Was die erstere Zellgattung betrifft, so läßt sich mitunter nicht mit Sicherheit

1) Interessant ist in dieser Beziehung der Befund von Blegvad, da dieser Fall in der Tat eine natürlich in ganz geringem Maße histologisch untersuchte ausgeheilte otogene Leptomeningitis repräsentiert. Blegvad macht folgende Angaben: ,Auch aus den Teptomeningen wird (bei der Operation) ein Stiick exzidiert, das bei der Mikroskopie zeigt, daß die Leptomeningen verdickt und stark mit Rundzellen infiltriert sind. Einige Stellen im Präparat sind mit einer Schicht Fibrin bedeckt, in der sich eine Anzahl Leukocyten und zahlreiche rote Blutkörperchen befinden. Im Hirngewebe keine Zellvermehrung." 
bestimmen, ob man es mit jungen Bindegewebszellen oder mit gewucherten Endothelien zu tun habe. Jedenfalls scheint mir in einzelnen Fällen eine sichere Endothelvermehrung vorhanden gewesen zu sein, trotzdem man bei der Konstatierung einer Endothelwucherung genau berücksichtigen muß, daß sowohl Schrägschnitte, wie bekannt. täuschende Bilder geben können, als auch eine gewisse Vermehrung der Endothelien hier und da normalerweise vorkommen mag.

Gelapptkernige Leukocyten fehlen zunächst völlig oder treten jedenfalls, wenn sie vorhanden sind, im Bilde ganz zurück. Ist die entzündliche Reaktion eine stärkere, so zeigen sich Bilder, wie ich sie bei Hund V beschrieben habe. Gegenüber der Infektionsstelle weisen die Leptomeningen in einer Anzahl von Präparaten einen relativ geringfügigen Grad von Entzündung auf. Man sieht nur ihr Endothel gewuchert. Hier und da treten unabhängig voneinander kleine Fibrinklümpchen auf, manchmal untermischt mit gelapptkernigen Leukocyten und kleinen runden Zellen. An anderen Stellen ist es zu umschriebenen, doch ziemlich bedeutenden entzündlichen Ausscheidungen innerhalb der Máschen der weichen Hirnhäute gekommen, so daß die letzteren an derartigen Stellen knötchenförmig verdickt erscheinen. An solchen Punkten setzt sich das entzündliche Exsudat aus Häufohen von Eiterzellen und Fibrinmassen zusammen. Mitunter herrscht mehr der eitrige, mitunter mehr der fibrinös-eitrige manchmal der rein fibrinöse Charakter vor. Diese zirkumskripten meningitischen Plaques gehen ohne scharfe Grenzen in das wenig oder gar nicht veränderte Gewebe der angrenzenden Meningen über. Dieser Übergang ist oft kaum merkbar. Man sieht nur das eitrige Infiltrat geringer werden. Die Eiterzellen verschwinden ganz. Bisweilen macht sich noch eine Strecke hindurch eine Vermehrung des Endothels bemerkbar, bisweilen fehlt auch diese. Dieser Befund illustriert sehr gut einen etwas höheren Grad von Entzündung, der an einzelnen Stellen durchaus an das ausgesprochene Bild der Leptomeningitis erinnert, in anderen in unmittelbarer Nähe befindlichen dagegen nur wenig oder gar nicht von der Norm abweicht. $\mathrm{Zu}$ diesem sprungförmigen und ungleichmäßigen Bilde paßt die Menge und Verteilung der Bakterien sehr gut, indem sich nur hier und da vereinzelte von ihnen nachweisen lassen.

Wird der Grad der Entzündung in den weichen Hirnhäuten ein noch größerer, so wird das entzündliche Infiltrat Archiv f. Ohrenhellkunde, Bd. 89. 
stärker und ist gleichmäßiger über die Oberfläche und in die Sulci hinein verteilt. Immerhin sieht man bei den Übergangsfällen noch hier und da an den Grenzpartien anscheinend isolierte kleine Fibrinklümpchen resp. einen ins Auge springenden Wechsel von entzündeten und normalen Stellen, und zwar letztere oft ohne sicher gezogene Grenze. Eine derartig sprung- oder etappenförmige Ausbreitung der Entzündung läßt sich selbst bei den stärkeren Graden derselben, allerdings fern von dem ursprünglichen Herde, hier und da nach den Rändern hin nachweisen.

Ist schließlich das Bild der Leptomeningitis ein völlig ausgesprochenes, so sind die Maschen der weichen Hirnhäute vollgepfropft mit gelapptkernigen Leukocyten, Fibrinmassen, kleinen Rundzellen und Zellen mit großem blassem Kern (Endothelabkömmlingen resp. jungen Bindegewebszellen). Die Gefäße sind strotzend mit Blut überfüllt. In einzelnen Fällen erstrecken sich die entzündlichen Veränderungen bis in die oberflächlichen Hirnschichten hinein. Die Gefäße der Hirnrinde sind stark gefüllt, hier und dort sieht man Ausläufer von polynukleären Leukocyten von der Oberfläche aus mehr oder weniger weit in die Tiefe des Zerebrums hineindringen.

Was nun das Zusammentreffen resp. die Abhängigkeit der lepto- und pachymeningitischen Entzündungsherde voneinander betrifft, so habe ich schon betont, $\mathrm{da} B$ in einem großen Teil der Fälle trotz bedeutender entzündlicher Vorgänge an der Durainnenfläche die weichen Hirnhäute völlig intakt bleiben; eventuell kommt es zu einer an sich kaum bedeutungsvollen Zellvermehrung innerhalb der letzteren. Andererseits kann jede pachymeningitische Plaque, sei es nun, daß sie scheinbar isoliert vorhanden ist oder mit dem Hauptherde in direktem sichtbaren Konnex steht, mehr oder weniger entfernt von der eigentlichen Infektionsstelle den Anlaß zu einer Leptomeningitis geben, die ihrerseits wieder zirkumskript bleiben kann oder sich generalisiert. Außer meinen Tierversuchen sprechen hierfür auch die am Menschen gemachten Erfahrungen, z. B. von Blegvad ${ }^{1}$ ) und Alexander ${ }^{2}$. Ich verweise ferner an dieser Stelle auf meine Ansichten, die ich über die Entstehung der Briegerschen ${ }^{3}$ ) intermittierenden

1) Blegvad l. c.

2) Alexander, Klinische Studien zur Chirurgie der otogenen Meningitis, Archiv f. Ohrenheilk., Bd. LXXV u. LXXVI.

3) Brieger, Zur Pathologie der otogenen Meningitis. Deutsche otolog. Gesellschaft, Hamburg, 1899. 
Meningitis in meiner ersten Arbeit geäußert habe und die z. B. von Preysing geteilt werden.

Im allgemeinen sind die Entzündungserscheinungen auf der Durainnenfläche, also die Pachymeningitis interma, stärker ausgesprochen als auf der AuBenfläche derselben. Der ProzeB hat eben - und das ist, wenigstens für die Tierversuche, ganz charakteristisch - besondere Tendenz, parallel der Innenfläche der harten Hirnhaut nach allen Richtungen hin sich auszudehnen. Er ergreift von einer Hemisphäre die andere, indem er quer durch die Hirnsichel hindurchdringt und auf der anderen Seite genau so wie auf der zuerst ergriffenen, also als Pachymeningitis interna, fortschreitet. Auf diesem. Wege kann auch die innere Wand des großen Längsblutleiters durchdrungen werden und sich eventuell eine Sinusthrombose als Folge anschließen. Ich komme auf diesen Punkt noch später zurück.

Im allgemeinen sind die entzündlichen Veränderungen innerhalb der weichen Hirnhäute etwas weniger ausgedehnt als die entsprechende Pachymeningitis interna. Dieses Verhalten kann man bisweilen bereits makroskopisch feststellen, bisweilen erst im mikroskopischen Bilde. Während bei Hund X über dem Hinterhauptlappen noch eine ausgesprochene mächtige zusammenhängende Pachymeningitis interna bestand, erwiesen sich an den gleichen Stellen die weichen Hirnhäute scheinbar mehr etappen- resp. sprungweise infiltriert. Wir haben es hier an der Grenze der leptomeningitischen Entzündung mit Ausläufern derselben zu tun, die mit dem Grundstock etwa ebenso in Verbindung stehen wie die Gletscherzungen mit der Hauptmasse des eigentlichen Eismassives.

Die Regenerationsvorgänge an der Durainnenfläche sowie innerhalb der Leptomeningen setzten bereits nach einigen Tagen deutlich ein, mit ihrem Auftreten verschwanden gewöhnlich prompt die Bakterien. Um mich nicht zu wiederholen, verweise ich in dieser Beziehung auf meine erste Arbeit und möchte nur an dieser Stelle nochmals betonen, daß sich als Folge einer vorhanden gewesenen Pachymeningitis interna gewöhnlich unregelmäßig gestaltete, mehr oder weniger dicke, manchmal die Durabreite übertreffende Bindegewebszüge nachweisen ließen (conf. Abb. I). Innerhalb der weichen Hirnhäute war es gleichfalls stellenweise $\mathrm{zu}$ bedeutenden bindegewebigen Veränderungen gekommen. Die Infiltrationszellen hatten sich dann sowohl in ihrer Anzahl ganz bedeutend verringert, als auch im Charakter wesentlich geändert. Wäh- 
rend zunächst vorwiegend gelapptkernige Leukocyten vorhanden gewesen waren, trat diese Zellform jetzt im Bilde mehr zurück, dagegen prädominierten kleine Rundzellen und junge Bindegewebszellen. Auf einen Punkt möchte ich noch an dieser Stelle hinweisen. Preysing ist in seinem vorher erwähnten Referat der Ansicht, daß ich häufiger grobe Verlötungen und Verwachsungen der Hirnhäute untereinander als Folge einer vorangegangenen Entzündung derselben erzielt hätte, wenn ich, wie Miodowski ${ }^{1}$ ) und Haymann, imprägnierte Tampons verwendet hätte. Fs ist ja wohl sicher, daß die Art der Haymannschen Versuchsanordnung, einen besonders, wenn ich mich so ausdrücken kann, chronisch wirkenden Reiz repräsentiert, der sich in seinen Wirkungen am besten mit denen eines abgeschlossenen, unter Druck stehenden Epiduralabszesses dürfte vergleichen lassen, natürlich mit der Ausnahme, daß die Natur bei der Anlegung des Eiterdepots nicht so brüsk arbeitet wie der Operateur. Nun habe ich, wie aus meiner vorausgegangenen letzten Arbeit hervorgeht, um die Wirkungen eines kräftig einsetzenden Reizes mit denen eines chronisch wirkenden zu kombinieren, in einer Anzahl von Fällen (fünf) erstens einmal möglichst virulente Stämme benutzt und zweitens die Haymannsche Versuchsanordnung angewandt. Die Folge hat eigentlich den Erwartungen nicht entsprochen. Die erzielten Reaktionen waren im Grunde genommen, wenn man von Fall 10 absieht, nicht größer, als ich sie sonst erreicht habe. Es ist eben nicht so leicht, stets das richtige Verhältnis zwischen Infektiosität der benutzten Bakterienstämme und Widerstandsfähigkeit des einzelnen Tierorganismus, durch welches allein die beabsichtigte Reaktion erzielt werden kann, herauszubekommen. Auch beim Versuchstiere ist die Widerstandsfähigkeit des einzelnen Individuums eine sehr variable Größe, wie z. B. die in ihrer Stärke sehr differierenden Resultate der unter ganz gleichen Bedingungen angestellten Versuche 9 and 10 illustrieren.

Aus diesem Grunde nehme ich an, daß ich auch bei ständiger Anwendung der Haymannschen Versuchsanordnung wohl etwas, doch kaum wesentlich häufiger grobe Verwachsungen würde erzielt haben. Denn man muß sich doch folgende Frage klarlegen: Wann sind eigentlich derbere

1) Miodowski hat übrigens trotz kräftigster chemischer Reizung nur zweimal bei seinen experimentellen Fällen Verwachsungen von Dura und weichen Hirnhäuten erzielt (Archiv f. Ohrenheilk., 77, S. 239 ). 
Verklebungen zu erwarten? Doch nur dann, wenn der Subduralraum im engeren Sinne, d. h. der Raum zwischen Dura und Arachnoidea, in stärkerer Weise mit in den Entzündungsprozeß $B$ hineingezogen ist. Dies ist jedoch nach meinen vorhergegangenen Ausführungen und nach den Erfahrungen, die wir aus der menschlichen Pathologie haben, gewöhnlich bei der eitrigen Meningitis nicht der Fall. So nehme ich auch an, daß bei meinen 12 letzten Fällen nur in einem einzigen Verwachsungen der Hirnhäute untereinander aufgetreten wären, nämlich bei Hund IV, wo es zu richtigen subduralen Abszessen gekommen war. Eigentlich müßte man doch meinen, daß die Abimpfung direkt in den Subduralraum ${ }^{1}$ ) nach Verletzung resp. Inzision der Dura - wie ich es zum Teil getan habe für den letzteren den kräftigsten Entzündungsreiz repräsentiert und hiernach die mächtigsten Reaktionserscheinungen zu erwarten wären. Doch selbst dann fehlen, wie aus meinen experimentellen Versuchen hervorgeht, in der größeren Menge der Fälle grobe Verwachsungen. Wenn ich demnach in meiner ersten Arbeit gesagt habe: „Es fand sich, daß die Heilungstendenz innerhalb des Subduralraums ${ }^{1}$ ) anscheinend eine ganz hervorragende war, und zwar manifestierte sich dieselbe gewöhnlich nicht etwa durch Bildung grober anatomischer Verwachsungen und Abkapselungen - doch kamen in seltenen Fällen auch diese vor -, sondern einfach dadurch, dab der zunächst rein eitrige resp. fibrinös-eitrige Charakter der Entzündung allmählich durch Abnahme der Eiterzellen und Zunahme kleiner Rundzellen sich umwandelte," so muß ich diese Ansicht durchaus aufrechterhalten.

Ich weise zunächst darauf hin, daß ein wesentlich stärkeres resp. ganz überwiegendes Hervortreten der kleinen mononukleären Rundzellen gegenüber den polynukleären Elementen' ganz allgemein für eine gewisse Abschwächung des Prozesses spricht. Ein derartig besonders auffallendes Mißverhältnis beider Zellgruppen existiert nicht nur bei dem Milderwerden vorher virulenter eitriger Prozesse, sondern auch bei gewissen an sich langsam verlaufenden Meningitisformen, wie z. B. der tuberkulösen Meningitis, oder es wird - was besonders interessant ist - in den chronisch verlaufenden Fällen von epidemischer Meningitis im Gegensatz zu den akuten, die einen

1) Ich habe sowohl hier als an anderen Stellen meiner ersten Arbeit unter "Subdurairaum" alle unter der Dura befindlichen Räume verstanden. Ich gestehe ein, daß der Ausdruck hätte präziser gewählt werden können. 
ähnlichen Befund zeigen wie die eitrige Meningitis, beobachtet $\left.(\operatorname{Or} t h)^{1}\right)$.

Relativ selten sah ich ein Überwiegen der Lymphocyten gegenüber den gelapptkernigen Leukocyten auch bei meinen experimentell erzeugten eitrigen Meningitiden, z. B. bei Hund IX. Es handelte sich hier um eine Leptomeningitis, die wohl schon infolge des fast gänzlichen Fehlens von Bakterien von vornherein in sich die Tendenz trug, zirkumskript. zu bleiben. Auch Blegvad fand bei seiner vorher erwähnten histologisch untersuchten Beobachtung von ausgeheilter menschlicher Leptomeningitis vorwiegend Rundzellen. Ebenso. gibt Miodowskiª) an, daß er verdickte Gefäße und kleinzellige Infiltration als Zeichen abgelaufener oder schleichend sich hinziehender meningitischer Prozesse beim Menschen ansehen müsse.

Darin, daß Verwachsungen, Abkapselungen etwas grob ins Auge Springendes sind, liegt der Grund, daß sie bisher ziemlich als einzige Folge überstandener Entzündungsvorgänge an den Hirnhäuten bekanntgeworden sind. Die feineren Heilungsprozesse, wie ich sie z. B. vorher, allerdings nur in bescheidenem Maße, zu schildern versucht habe, die einen weit tieferen Einblick in die Werkstatt der Natur gewähren, sind aus demselben Grunde, weil sie eben nur wenig sichtbare Folgen hinterlassen, weit weniger bekanntgeworden. Hieran liegt es auch, weshalb bisher so wenig über histologische $\mathrm{Zufallsbefunde} \mathrm{von} \mathrm{ausgeheilten} \mathrm{Meningitiden,} \mathrm{die} \mathrm{ja} \mathrm{allein}$ in Betracht kommen, bekannt ist. Und doch sind meiner Ansicht nach ausgeheilte Meningitiden - allerdings dürfte es sich meistens wohl um mehr oder weniger zirkumskripte Formen handeln - durchaus nicht etwas Seltenes. Sie sind jedenfalls viel häufiger, als bisher angenommen wird.

Ich bin überzeugt, daß innerhalb der Intraduralräume (Subdural- und Pia-Arachnoidalraum) kräftige antibakterielle Kräfte walten, die sich unter Umständen durch überraschend schnelle Vernichtung großer Mengen infektiösen Materials kundtun. Für einen Teil dieser Räume, besonders den Subduralraum, liegt auch nach dieser Richtung hin ein Vergleich mit den serösen Räumen des Körpers, Pleuralraum usw., nahe. Welcher Art diese natürlichen Schutzvorrichtungen der Schädelinnẹnräume im einzelnen sind, ist. allerdings schwer zurzeit mit absoluter Bestimmtheit zu sagen. Ich vermute, daß 3

I) Orth, Deutsche med. Wochenschr., 1906.

2) Miodowski, Archiv f. Ohrenheilk., 77, S. 285. 
hier mehrere Faktoren sich unterstützen und bedeutungsvoll zusammenarbeiten. Es dürften dies zunächst wohl folgende sein: der Liquor cerebrospinalis, die Endothelien der weichen Hirnhäute, sowie die als Folge des Reizes aufzufassende sehr häufig nachweisbare Gefäßfüllung innerhalb der Meningen. Ob nun durchaus jeder der vorher angedeuteten Faktoren für sich allein bakterizide Wirkungen zu entfalten vermag, oder der Erfolg nur durch gemeinsame Arbeit mehrerer von ihnen denkbar ist, lasse ich dahingestellt.

\section{Seröse Meningitis.}

Wie aus meinen Tierversuchen hervorgeht, ist es mir niemals gelungen, eine bemerkenswerte Liquorvermehrung zu erzielen; auch Haymann kann in seiner Arbeit ,Zur Erzeugung der experimentellen Sinusthrombose" über keinen positiven Erfolg berichten. Zwar pflegt ein großer Teil der Autoren vorläufig noch jede abnorme pathologische Vermehrung des Liquors als seröse Meningitis zu bezeichnen, doch möchte ich mich diesem Standpunkt, der wohl in der Zukunft nicht aufrechtzuhalten ist, nicht anschließen. Ich habe deshalb zunächst im vorausgegangenen nur von einer ,Liquorvermehrung" gesprochen und stelle diesen Begriff wohlbewußt, wie es z. B. auch Preysing tut, in einen gewissen Gegensatz zur "serösen Meningitis". Wenn Quincke bei der Migräne sich den periodischen Kopfschmerz durch rasch entstandene und ebenso rasch verschwindende Ergüsse in die Ventrikel zu erklären versucht, liegt es doch viel näher, bei entzündlichen Reizmomenten an den Meningen oder in der Nähe derselben ähnliche Ergüsse in die Ventrikel oder zwischen die Arachnoidealmaschen anzunehmen, die hier je nach der Fortdauer des Reizes längere oder kürzere Zeit anhalten können. Die Vermehrung der Hirnflüssigkeit wäre in diesem Sinne ein völlig passageres Moment; für sie wäre der Ausdruck einer Meningitis serosa absolut unangebracht, da sie mit einer Meningitis (entzündlichen Veränderung der Meningen) durchaus nicht identisch wäre.

Mein experimenteller Mißerfolg - wenn ich mich so ausdrücken darf - nach der vorher diskutierten Richtung bin läßt natürlich absolut keine sicheren Schlüsse zu, da ja gerade in dieser Beziehung beim Tierversuch wesentlich andere Verhältnisse walten können als in der menschlichen Pathologie. Immerhin ist der große Gegensatz zwischen den außerordentlich häufig erzeugten zirkumskripten Entzündungsherden àn 
Dura und Meningen und dem gänzlichen Fehlen einer Liquorstauung beim Tierversuch zum mindesten etwas auffällig. Trotzdem halte ich es wohl für möglich, daß eine Li quorvermehrung (ein Liquor auctus Preysing) infolge, toxischer Einflüsse beim Menschen eventuell eintreten kann ${ }^{1}$ ). Was dagegen die sogenannte seröse Meningitis des Menschen betrifft, so will ich in folgendem weder etwas gegen die ziemlich häufigen klinischen Beobachtungen dieser Krankheitsform noch ihre Berechtigung am Krankenbette gesagt haben. Doch möchte ich betonen, daß einzelne Autoren in ihrer Heranziehung viel zu weit gehen, und daß häufig eine andere Erklärung, wie ich später zeigen werde, viel näher liegt.

Es ist wohl ganz sicher, daß die Vermehrung des Liquor cerebrospinalis unter Umständen gewisse Symptome, natürlich in erster Reihe Kopfschmerzen, zeitigen dürfte, und daß, sobald diese Liquorstauung durch Lumbalpunktion nachgewiesen ist, ein Teil der Symptome der sogenannten meningitischen Reizung durch sie erklärt werden kann. Dies sagt aber noch gar nichts, denn erstens einmal sind die näheren Gründe nach der Entstehung dieser pathologisehen Vermehrung der Hirnflüssigkeit zurzeit noch völlig ins Dunkel gehüllt und zweitens glaube ich, daß dieselbe weder das Primäre noch gewöhnlich — Ausnahmen mögen vorkommen - im Sinne der Prognose und Therapie das Wesentliche ist.

Ich bin vielmehr der Ansicht, daß, um das Zustandekommen der akuten serösen Meningitis zu ermöglichen, mehrere Bedingungen erfüllt sein müssen. Erstens müssen Entzündungserscheinungen an der Dura, gewöhnlich an der Innenfläche derselben resp. an den weichen Hirnhäuten, vorhanden sein. Manchmal sind dieselben allerdings nur geringerer Art. Ferner kommen wahrscheinlich einige zurzeit freilich noch nicht völlig geklärte Momente hinzu, die entweder auf eigentümlichen, nicht in jedem Falle vorhandenen anatomischen Verhältnissen oder auch auf einer spezifischen Reaktion des Organismus auf besondere Bakterien oder Bakterientoxine, resp., was das Wahrscheinlichste ist, auf der Kombinierung beider Momente beruhen. Was den ersten dieser zuletzt erwähnten Punkte betrifft, so möchte ich als Parallele auf den Umstand hinweisen, daß die chronische Liquor-

1) Für das von Preysing gewissermaßen als zweite Form der serösen Meningitis anerkannte Vorstadium besonders foudroyanter Meningitiden treffen diese letztern Ausführungen nicht zu. 
vermehrung, der Hydrocephalus internus, auf einer gewissen kongenitalen Anlage basiert, die ihren Ausdruck in einer abnormen Größe und Gestalt des Schädels findet (Oppenheim $\left.{ }^{1}\right)$. Natürlich nehme ich für die Meningitis serosa nicht etwa ganz ähnliche VerhäItnisse an. Die Anführung der vorher gemachten Parallele berechtigt vorläufig überhaupt nicht zu bestimmten Folgerungen. Den äußeren Anlaß zur Entwicklung einer derartigen chronischen Liquorvermehrung bieten oftmals Traumen; und hierin geht die Parallele noch weiter: Entstehung der Meningitis serosa nach operativen Eingriffen $^{2}$ ). Bei der Voraussetzung derartiger Verhältnisse erscheint es durchaus plausibel, warum ein bakterieller resp. bakteriell-toxischer Reiz in einem Falle eine bedeutende Vermehrung des Liquor cerebrospinalis zeitigt, in einem anderen nicht.

Es scheint mir angebracht zu sein, an dieser Stelle näher auf eine neu erschienene Arbeit von Wagener ${ }^{3}$ ) zurückzukommen, welcher an der Hand eines größeren Materials die zurzeit sehr in der Diskussion stehende Frage nach der Entstehung der otogenen serösen Meningitis in längern Ausführungen behandelt. Wagener geht von folgender Voraussetzung aus: ,Ist eine Ohreiterung nach Zerstörung des Knochens bis an die Dura fortgeschritten, so ist in leichteren Fällen der entzündliche Reiz so gering, daß die Reaktion sich nur an der Außenseite der Dura bemerkbar macht; die intraduralen Teile - Hirn und weiche Hirnhäute - werden also in diesen Fällen auch nicht auf die rein extradurale Eiterung reagieren. Bei weiterem Fortschreiten der Entzündung kommt es zu einer entzündlichen Durchtränkung, einer Auflockerung und Infiltration der Dura und schließlich zu einer entzündlichen Reaktion von Hirn und Hirnhäuten. Je nach der Art des Prozesses, die vor allem wohl durch Art und Virulenz der Bakterien bedingt ist, überwiegt seröses Exsudat oder Eiterbildung." Es wären demnach, wenn ich mich so ausdrücken darf, seröse und eitrige Meningitis Kinder einer Mutter, die sich nicht nur in der gleichen Art

1) Oppenheim, Lehrbuch der Nervenkrankheiten, 1908.

2) Vielleicht ist der Gang der Handlung bei der Entstehung der sogenannten traumatischen serösen Meningitis folgender: 1. Trauma; 2. Propagation ursprünglich vorhandener oder Entstehung neuer Plaques an der Durainnenfläche resp. innerhalb der Leptomeningen;

3. von letzterer ausgehende Reizwirkung führt zu Liquorvermehrung;

4. Symptomenbild der sogenannten serösen Meningitis.

s) Wagener, Passow-Schäfersche Beiträge, IV, 1911. 
ihrer Entstehung, sondern auch in ihren Charaktereigenschaften außerordentlich gleichen. Hierin stimme ich durchaus mit Wagener überein. Leider geht aus den folgenden Ausführungen Wa geners nicht mit absoluter Sicherheit hervor, wie weit Wagener sich dies, weitere Fortschreiten“" der primären Entzündung vorstellt, in den Fällen, in welchen als Folge eine sogenannte seröse Meningitis resultiert. Ich glaubte zunächst aus der Arbeit des Autors schließen zu können, daß im wesentlichen die Ansicht $W$ a geners folgende sei: Die seröse Meningitis entsteht durch toxische Fernwirkung außerhalb, vielleicht auch zum Teil innerhalb der Duralamellen befindlicher Bakterien, jedenfalls durch die geschädigte Dura hindurch. Plastisch entzündliche Veränderungen innerhalb des Intraduralraums sind nicht als Beding ung für die Entstehung dieser Form von Meningitis anzusehen.

Durch persönliche Rücksprache mit Wagener bin ich jedoch zu der Überzeugung gekommen, daß auch $W$ a ge ner annimmt, daß zum mindesten dort, wo die primären Herde an die Dura grenzen, innerhalb der Subduralräume sich gewöhnlich plastisch entzündliche Reaktionen(Leukocytenanhäufungen usw.) entwickeln dürften, natürlich nur dann, sobald die Subduralräume auf den Reiz überhaupt, also in unserem Falle durch Liquorvermehrung reagieren. Diese Ansicht ist durchaus die meinige. Ich bin überzeugt, daß niemals größere Mengen von Toxinen eine bestimmte Zeit lang durch die Dura diffundieren können, ohne daß der Intraduralraum hierauf plastisch entzündlich reagiert. Ich verweise hierbei zunächst als Parallele auf die Versuche von Miodowski ${ }^{1}$ ), der bei chemischer Reizung der Dura nicht unbedeutende plastisch entzündliche Veränderungen an Gehirn und Hirnhäuten nachweisen konnte, ferner auf meine eigenen Tierversuche. Aus ihnen geht, mit Sicherheit hervor, daß ein gegen die Duraaußenfläche gerichteter bakterieller Reiz viel häufiger als man es annimmt, geringere oder auch bedeutendere plastische Entzündungserscheinungen innerhalb der Dura zu erzeugen imstande ist. Dieselben, sei es nun, daß sie in Form einer Pachymeningitis interna oder als Leptomeningitis auftreten, haben eine nicht geringe Tendenz zur Ausheilung und können fast in allen Stadien nach Eliminierung des extraduralen Entzündungsherdes wieder verschwinden. Nicht selten, meinem Ermessen nach jedenfalls häufiger als angenommen

1) Miodowski 1. c. 
wird, gelangen auch Bakterien durch die Dura hindurch, und der eigentliche intradurale Raum als solcher spielt häufig genug, viel häufiger als wir annehmen, eine recht bedeutsame Rolle bei der Bekämpfung und Vernichtung dieser Infektionserreger. Oft werden wir in vivo dies kaum vermuten können, da auch die Lumbalpunktion bei derartigen zirkumskripten Prozessen gewöhnlich negativ ausfallen dürfte. Wie aus meinen experimentellen Versuchen hervorgeht, war ferner für gewöhnlich die Lebensdauer der in den eigentlichen Intraduralraum eingedrungenen Bakterien eine nur recht geringe. Nicht selten wird es vorgekommen sein, daß die Infektionserreger s of or t oder doch in der allernächsten Zeit nach ihrem Vordringen durch die Dura abgetötet wurden. In solchen Fällen können sie selbst resp. ihre Produkte sehr wohl bereits deutliche Reaktionen im Intraduralraum, z. B, eine bedeutende Vermehrung des Liquors usw. erzeugt haben, die bei der Diagnose dann allein berücksichtigt werden. Die Folge wäre notwendigerweise der Trugschluß, daß in einem derartigen Falle durch die Dura filtrierte Bakterientoxine die Ursache der sich vorfindenden Erscheinungen gewesen sind.

Diese auf pathologisch-anatomischer Basis begründete Ansicht - . vorläufig wird man sich allerdings mit den Resultaten des Tierversuchs zufriedengeben müssen, da gleiche Befunde beim Menschen wegen der ausgesprochenen Tendenz zur Ausheilung nur Zufallsbefunde bleiben dürften - erklärt zur Genüge das Symptombild der meningitischen Reizung von seinen ersten Anfängen bis zu der ausgeprägtesten Form. $\mathrm{Ob}$ in dem einen Falle der Liquor etwas mehr, in dem andern etwas weniger vermehrt ist, ist meinem Ermessen nach im Grunde genommen, pathologisch-anatomisch gedacht, gar nicht von einer solchen Bedeutung, daß man berechtigt ist, derartige Fälle als seröse Meningitis zu bezeichnen, selbst wenn die Liquorvermehrung zufälligerweise das bei weitem wichtigste klinische Symptom ist.

Was andrerseits die toxische Theorie betrifft, wie sie z. B. Wagener vertritt, so muß ich sagen, daß ich durch sie nach mancher Richtung hin bedeutend weniger als durch den vorausgegangenen Erklärungsversuch befriedigt bin So kann ich es mir z. B. absolut nicht vorstellen, daß bisweilen die angenommenen in die Zerebrospinalflüssigkeit gelangten Toxine ihre Wirkung erst nach der Operation ausüben können. 
Die Zerebrospinalflüssigkeit ist doch einer ständigen Erneuerung und Auffrischung ausgesetzt, so daß man wohl annehmen kann, daß in ihr vorhandene Toxine, sobald keine neuen Nachschübe erfolgen, schnellstens aufgesogen werden. Ganz anders liegen die Verhältnisse, wenn man zirkumskripte pachy- oder leptomeningitische Herde annimmt und dieselben resp. von diesen letzteren ausgehende Reizwirkungen für die Entstehung später eintretender nervöser Störungen, Neuritis optica, Abduzenslähmungen verantwortlich macht. Gerade das Auftreten derartiger Störungen im Anschluß an die Operation ist dann besonders verständlich, es ist z. B. in Parallele zu setzen mit der plötzlichen Ausbreitung bis dahin latenter oder zirkumskripter Labyrinthitiden infolge des Operationstraumas.

Etwas näher muß ich auf das zweite Hauptsymptom der sog. serösen Meningitis, die Veränderungen am Augenhintergrund eingehen. Sofern in der Tat, wie Wagener voraussetzt, das toxische Moment für die Entstehung der Neuritis optica bei seröser Meningitis das maßgebende ist, so müßte man die Neuritis optica bedeutend häufiger bei der eitrigen als bei der serösen Form der Meningitis vorfinden. Denn gerade bei der eitrigen Form dürften entsprechend der Schwere der Infektion besonders virulente toxische Produkte erzeugt werden. In der Tat sind es jedoch die serösen Meningitiden, zu deren Hauptcharakteristikum Veränderungen am Augenhintergrund gehören. Dafür, daß, bisweilen wenigstens, bei der serösen Meningitis die Erkrankung des Sehnerven sicher durch Drucksteigerung hervorgerufen wird, spricht nach Oppenheim ${ }^{1}$ ) schon die Tatsache, daß nicht selten der Typus der Hemianopsia bitemporalis besteht. „Dies erklärt sich aus dem Umstande, daß der blasig ausgehöhlte Boden des III. Ventrikels besonders das Mittelstïck des Chiasma opticum komprimiert. Ich fand es in einem Falle so reduziert, daß nur zwei dünne fadenförmige Fortsätze den Verlauf des Sehnerven anzeigten." (Oppenheim) ${ }^{1}$ ). Utberhaupt ist eine reine Toxintheorie zur Erklärung der entzündlichen Veränderungen am Sehnervenkopf zurzeit von ophthalmologischer Seite absolut nicht anerkannt. Sie wird auch in der erst neuerdings erschienenen Monographie von Schieck ${ }^{2}$ ) durchaus verworfen. Schieck ist der Ansicht, daß die Stauungspapille nicht durch Toxine, sondern durch den Druck im Zwischenscheidenraum ausgelöst wird. Alle Gefahren für den Sehnerven schwinden, sobald die

1) Oppenheim, Lehrbuch der Nervenkrankheiten, 1908.

2) Schieck, Die Genese der Stauungspapille. Wiesbaden, 1910. 
Lymphgefäße im Axialstrang wieder abschwellen und die aus dem hinteren Glaskörperabschnitt abzuführende Lymphe den natürlichen Weg in den Zwischenscheidenraum wiedergewinnt.

Jedenfalls scheint die Tatsache kaum zu bezweifeln zu sein, daß sich Veränderungen am Augenhintergrund bei den intrazerebralen Prozessen am häufigsten dort entwickeln, wo relativ schnell eine bedeutende Drucksteigerung eintritt. Dieses Faktum spricht naturgemäB mehr für mechanische resp. entzündlich-mechanische als für toxische Momente.

Auch der Umstand, daß bisweilen trotz bedeutender entzündlicher Veränderungen am Sehnervenkopf keine Vermehrung des Drucks der Zerebrospinalflüssigkeit nachgewiesen werden konnte, berechtigt nicht, zu rein toxischen Ursachen zu rekurrieren. Die Zerebrospinalflüssigkeit kann trotzdem sehr wohl eine gewisse Zeit lang vermehrt gewesen und ihr erhöhter Druck die Ursache der Veränderungen am Optikus sein, während man zur Zeit der Beobachtung nur noch die stabileren Veränderungen am Sehnerven, jedoch nicht die mehr passagere Druckerhöhung der Lumbalflüssigkeit, nachweisen konnte.

In betreff der Veränderungen am Augenhintergrunde stehen meine vorausgegangenen Ausführungen in gutem Einklang zur Ansicht Uthoff ${ }^{1}$ ). Uthoff meint, daß die bei extraduralen Prozessen seiner Ansicht nach relativ. selten vorkommenden Erkrankungen des Sehnervenkopfes in der Weise zu deuten sind, daß in solchen Fällen zirkumskripte entzündliche Veränderungen an der Durainnenfläche und in den angrenzenden weichen Hirnhäuten vorhanden sein dürften. Durch Fernwirkung kann seiner Ansicht nach die Neuritis optica resp. die Stauungspapille bei eitrigen Ohrprozessen ohne Komplikation wohl niemals entstehen.

Das Bild der serösen Meningitis hat ja an sich zweifellos zurzeit noch viel Schemenhaftes, da es sich zum gröBten Teil auf keiner soliden pathologisch-anatomischen Basis aufbaut. Da außerdem das klinische Hauptsymptom der serösen Meningitis, die Erhöhung des Druckes der Zerebrospinalflüssigkeit mit ihren Folgen, sich nicht nur bei seröser Meningitis sowie anderen zerebralen Krankheiten, sondern bisweilen auch bei Allgemeinerkrankungen, wie z. B. Chlorose,

1) Uthoff, Gräfe-Sämisch, Handbuch der gesamten Augenheilkunde. Leipzig, 1911. Bd. XI, Abt. 2 A. 
Delirium tremens, vorfinden $\operatorname{kann}^{1}$ ), so ist es wohl möglich, daß unter Umständen dieser oder jener derartige Fall, bei dem eine gleichzeitig bestehende Ohreiterung nur eine relativ unwesentliche Begleiterscheinung ist, nach dieser Richtung hin falsch gedeutet werden könnte. Immerhin dürfte eine Fehldiagnose in dieser Beziehung ein an sich ziemlich seltenes Ereignis sein.

Zurzeit muß man sich, sobald man keine bessern pathologisch-anatomischen Fundamente wie bisher hat, wohl oder übel mit dem zufrieden geben, was man erreicht hat, und ich habe gar nichts dagegen, wenn man ein Krankheitsbild, das die berühmte Trias der Symptome aufweist, Erhöhung des Drucks der Lumbalflüssigkeit, Veränderungen am Augenhintergrund, Heilbarkeit bei der klinischen Beoachtung als seröse Meningitis bezeichnet. Ich halte die Bezeichnung ,seröse Meningitis" für derartige Krankheitsformen zurzeit aus klinischen Gründen auch als praktisch, wenngleich ich mir immer vorstelle, pathologisch-anatomisch kann ganz was andres dahinter stecken. Deshalb bin ich auch, solange keine pathologiseh - anatomischen Gegengründe vorhanden sind und die vorher besprochene Trias von Symptomen in klarer Form sich zeigt, durchaus für Beibehaltung des Begriffs , seröse Meningitis“.

Nimmt man andrerseits der serösen Meningitis nun noch eins oder gar beide ihrer Hauptfundamente, nämlich die Erhöhung des Druckes der Zerebrospinalflüssigkeit sowie die Heilbarkeit, was bleibt dann von ihr übrig? Nichts als ein bequemer Lückenbüßer, der für alle diejenigen, die sich gern und leicht befriedigen lassen, in der Zukunft oftmals dann, wenn sie sonst gezweifelt und geforscht hätten, eine bequeme Befriedigung geben wird.

Es fragt sich nun, ob Wagener die vorher erwähnten wichtigen pathologiseh-anatomischen Gegengründe gegeben hat. Ioh glaube, nein. Aus diesen Gründen kann ich Wagener trotz voller Anerkennung seiner interessanten Arbeit, die u. a., was die Häufigkeit der Augenhintergrundveränderungen betrifft, viel neues bietet und sicher die Anregung zu weiteren Forschungen auf diesem Gebiet bringen dürfte, nicht beistimmen, wenn derselbe in konsequentem Ausbau seiner Toxinlehre sich folgendermaßen ausspricht: „Faßt man den Begriff der

2) Oppenheim 1. c. 
Meningitis serosa so weit, wie ich es eben getan habe, so ist es klar, daß die Diagnose auch dann gestellt werden kann, wenn die Lumbalflüssigkeit keinen besonders erhöhten Druck anzeigt. Auch die vielfach gestellte Forderung auf unmittelbaren therapeutischen Erfolg bei einer druckentlastenden Therapie ist unberechtigt. Nehmen wir doch an, daß durch die Toxinwirkung z. B. ein umsehriebenes Ödem, eine lokalisierte Schädigung der Hirnrinde hervorgerufen werden kann. Daß hier eine Restitutio ad integrum als unmittelbare Folge einor Lumbalpunktion nicht erwartet werden kann, liegt auf der Hand."

Fasse ich an dieser Stelle meine Ansicht nochmals kurz zusammen, so ist dieselbe folgende: Die seröse und die eitrige Form der Meningitis stehen sich prinzipiell außerordentlich nahe. Es besteht sicher meistenteils nur ein gradueller Unterschied zwischen beiden. Die eitrige Form ist in einem großen Prozentsatz der Fälle eine seröse, was sich durch die Erhöhung des Druckes der Lumbalflüssigkeit kundgibt. Ferner kann sich ein seröser Ventrikelerguß einer eitrigen Meningitis als Nachkrankheit anschließen.

Die seröse otogene Meningitis ist andererseits, wie ich vorher auseinandergesetzt habe, in gewissem Sinne fast stets eine eitrige, insofern als es irgendwo im Intraduralraum oft schwer nachweisbare Entzündungsherde gibt, die sie veranlaßt haben, seien es nun umschriebene leptomeningitische Plaques oder mehr oder weniger ausgesprochene interne Pachymeningitiden am Sinus, der Groß- resp. Kleinhirndura oder, was besonders häufig ist, an der Überleitungsstelle des Labyrinths zum Intrazerebralraum. Das nicht selten beobachtete Übergehen der serösen in die eitrige Form ist hierdurch zur Genüge erklärt.

Es liegt ja in der Natur der Sache, daß Krankheitsbilder, die in der Mitte der Diskussion stehen, auf einmal überall auftauchen und von jedem beobachtet werden. Solange praktische Momente nicht in den Vordergrund treten, kann man sich damit abfinden. Auch die vorher des näheren ventilierte Frage, ob allein infolge toxischer Fernwirkung eine seröse Meningitis mit allen ihren Symptomen resp. eine Vermehrung der Lumbalflüssigkeit (ein Liquor auctus Preysing) auftreten kann, oder ob diesen Vorgängen stets Entzündungserscheinungen im Innern des Intraduralraums vorausgehen müssen, bliebe, sofern sich unter gewissen Umständen hieran nicht weitere Folgerungen anschließen könnten, interessant, aber praktisch unwichtig. 
Ganz anders würde sich die Sachlage verhalten, wenn operative Eingriffe einer falschen theoretischen Auffassung: zuliebe unter Umständen zu häufig oder, was ebenso schlimm ist, nicht häufig genug gemacht werden. Beides scheint mir, wenn man unser Thema berücksichtigt, z. B. für die letzten von $\mathrm{Muck}{ }^{1}$ ) publizierten Fälle zuzutreffen. Ich will mit einigen Worten auf die Besprechung derselben eingehen, und zwar einzig und allein deshalb, weil sie mir so recht ein illustratives. Paradigma für eine Auffassung, die ich nicht anerkenne und deren Konsequenzen ich für gefährlich halte, zu sein scheinen.

Hätte Muck bei seinem Fall 4 (Kind K. F., schwere Mastoiditis nach Scharlach, Sinus blaurot, nicht pulsierend, Pyämie, Exitus) nicht von vornherein das Bild der selbständigen serösen Meningitis im Auge gehabt und angenommen, daB dieses letztere das von ihm beobachtete Krankheitsbild. zur Genüge erkläre, so hätte er unbedingt den zwar nicht verfärbten, aber pulslosen Sinus unter allen Umständen explorieren müssen. Die Auffassung ist nicht von der Hand zu weisen, daß in diesem Falle die nachgewiesene Meningitis serosa die Folge einer gleichzeitig bestehenden Sinusthrombose gewesen sein $\operatorname{kann}$, ebenso wie der zum Tode führende pyämische Zustand.

In seinem Fall I (Frau E., Knochen wenig erkrankt, Dura, Sinus sich vorwölbend, pulslos) hätte es meiner Ansicht. nach genügt, wenn Muck Dura und Sinus freigelegt und dann die Lumbalpunktion angeschlossen hätte. Weshalb Muck die Dura zweimal inzidierte, ist mir unverständlich. Ich kann mir nur vorstellen, daß Muck bei diesem augenscheinlich recht. schwer liegenden Falle die Lumbalpunktion als nicht radikal genug ansah. Und doch ist es anseheinend auch bei Beurteilung dieser Beobachtung viel wahrscheinlicher, daß die nachgewiesene Meningitis serosa nicht als primäre intrazerebrale Erkrankung, wohl überhaupt nicht als eine otogene Folgeerscheinung aufzufassen ist. (Es bestand eine gleichzeitige floride Lues.)

Überhaupt möchte es mir scheinen, als ob die Durainzision, wie sie z. B. Muck auch in seinen beiden letzten Fällen zum Teil wiederholt gemacht hat, im allgemeinen kein Eingriff ist, der therapeutisch für die seröse Meningitis in Betracht kommt. Bei der Therapie der Meningitis serosa muß.

1) Muck, Beitrag zur Kenntnis der otogenen Meningitis serosa. Zeitschr. f. Ohrenheilk., 1911, Bd. 62. 
man, wie schon Haslauer ${ }^{1}$ ) betont, stets schrittweise vorgehen. Die Hauptsache bleibt die Ausräumung des ursprünglichen Eiterherdes, sodann kommt die Lumbalpunktion zu ihrem Recht, und zwar die wiederholte Lumbalpunktion.

Man könnte sich allerdings ja wohl vorstellen, daß in dem einen oder anderen Falle, wo die Lumbalpunktion versagt, nachträglich eine Durainzision resp. unter ganz besondern Umständen eine Ventrikelpunktion notwendig werden dürfte. Doch müßten derartige Fälle so seltene Ausnahmen bleiben, daß sie praktisch kaum in Betracht kommen.

Bei der zirkumskripten Pachymeningitis interna genügt meiner Ansicht nach gleichfalls gewöhnlich die Freilegung der harten Hirnhaut. Es läßt sich darüber diskutieren, ob die Blegvadsche Ansicht zu Recht besteht: ,Da aber die Pachymeningitis keine präzisen Symptome gibt, ist man genötigt, schon allein auf den bloßen Verdacht hin zu inzidieren. Einen so großen Eingriff nimmt man natürlich nur dann vor, wenn man vor oder während der Operation einen starken Verdacht erhalten hat, daß ein subdurales Leiden vorhanden ist." Ich habe mancherlei Bedenken gegen diese Auffassung. Der Fall müßte doch ganz besonders schwer liegen, wenn ich mich aus diesen Gründen allein, ohne gleichzeitige Berücksichtigung des Lumbalpunktates, zur Durainzision entsohließen würde (conf. auch Wittma ack) ${ }^{2}$ ). Sehr häufig dürften nicht nur eine inkomplizierte Pachymeningitis interna, sondern auch Entzündungen im subduralen Raum, sowie mehr oder weniger zirkumskripte Leptomeningitiden nach breiter Freilegung der harten Hirnhaut ausheilen.

Was die Inzision der Dura betrifft, so habe ich den Eindruck, als ob dieser Eingriff, nachdem man sich an einer großen Reihe von Fällen davon überzeugt hat, daß derselbe ziemlich häufig keine weiteren Komplikationen im Gefolge hat, von einzelnen Autoren allzuoft vorgenommen wird, und daß infolgedessen, ganz allgemein genommen, nicht wenige Operateure zurzeit mehr Schaden durch zaviel vorgenommene Durainzisionen, als durch eventuelle Unterlassung dieses Eingritfs trotz bestehender Indikation anrichten dürften. So kann ich z. B. absolut nicht die Notwendigkeit einsehen, warum naoh einer unabsichtlichen Verletzung der harten

1) Haslauer, Ủber Meningitis serosa. Zentralbl. f. Ohrenheilk., Bd. IV, Heft 8.

$\left.{ }^{2}\right)$ W it t $\mathrm{m}$ a a c $\mathrm{k}$, Die operative Behandlung der eitrigen Meningitis bei Labyrintheiterungen. Münchn. med. Wochenschr. 1908.

Archiv f. Ohrenheilkunde. Bd. 89. 
Hirnhaut dieselbe breit gespalten werden soll, wie von einzelnen empfohlen wird. Die meisten Verletzungen der harten Hirnhaut - sie werden jedem Operateur vorgekommen sein heilen doch ohne weiteres prompt. Anders würden vielleicht die Verhältnisse liegen, wenn man genau wüßte, daß die Verletzung direkt mit einem stark infizierten Instrument stattgefunden hat, in der Weise, daß bestimmt virulente Keime in den Intraduralraum weit hinein verschleppt sind. Der Einwurf, daß man ja gewöhnlich an infiziertem Terrain operiert, und daß demnach diese Wahrscheinlichkeit wenigstens immer besteht, scheint mir nicht stichhaltig, da im allgemeinen die Erfahrung, natürlich mit sehr wichtigen Ausnahmen - ich komme darauf noch zurück -, bei Hirnpunktion usw. gegen diese Auffassung spricht. Schließlich erscheint es mir immerhin noch fraglich, worin die größere Gefahr besteht, breit den Durainnenraum mit einem infizierten Terrain in Verbindung zu setzen, oder nach Verletzung. der Dura abzuwarten, ob der Blut- resp. Lymphstrom nicht etwa eingedrungene Infektionserreger sofort wieder herausspült. Da derartige kleine Kontinuitätstrennungen der harten Hirnhaut fast stets sehr schnell prompt ausheilen, kommt für sie, meinem Ermessen nach, die Gefahr der Spätinfektion des Intraduralraums viel weniger häufig in Betracht als bei breiter Inzision der Dura. Ganz abgesehen davon, besteht ja bei ausgedehnter Spaltung der harten Hirnhaut außerdem noch die Möglichkeit eines sekundären Hirnprolapses.

Was die Hauptgefahren der Hirnpunktion betrifft es sind besonders Blutungen resp. eine konsekutive Infektion zu fürchten -, so sind dieselben ja zur Genüge bekannt und erst unlängst von Reinking ${ }^{1}$ ) in soiner zusammenstellenden Arbeit behandelt.

Ich selbst habe vor einigen Jahren eine Beobachtung gemacht, die in selten klassischer Form nach beiden Richtungen hin eine Mllustration zu meinen vorausgegangenen Andeutungen über die eventuellen Gefahren der Hirnpunktion bietet. Wie aus der vorstehenden Publikation dieses Falles F. K. hervorgeht, war ich genötigt, zum Zweck der Differentialdiagnose zwischen Meningitis und Hirnabszeß bei demselben mehrmals. sowohl Großhirn wie Kleinhirn zu punktieren. Ich tat dies von der Operationshöhle aus und explorierte den Schläfenlappen vom Tegmen tympani her, das Kleinhirn von einer unmittelbar

1) Reinking, Ủber die Gefahren der Himpunktion. Zeitschr. f. Ohrenheilk. 60 . 
hinter dem freigelegten Sinus gelegenen Stelle. Über dem Tegmen tympani inzidierte ich vorher die Dura mater. Bei der Durainzision verletzte ich einen hier verlaufenden nicht unbeträchtlichen Sinus, der allerdings obliteriert war. Dieser Sinus lag an Ort und Stelle des inkonstanten Sinus petrososquamosos ${ }^{1}$ ), hatte jedoch eine Verbindung mit dem Gebiet der Augenvenen. Bei der Hirnpunktion kam es zu einer mächtigen Blutung aus einer Hirnvene. Die Folge hiervon war ein ausgedehnter Bluterguß über Scheitel- und Stirnlappen sowie eine subpiale Suffusion. Es ist mir durchaus nicht unwahrscheinlich, daß dieser ganz bedeutende intradurale Bluterguß, der durch Tamponade nur sehr schwer gestillt werden konnte, den Tod des allerdings schon verlorenen Kindes sohneller herbeigeführt hat, als es sonst der Fall gewesen wäre.

Bei der Obduktion wurde der Sinus mitsamt der Punktionsstelle über der Kleinhirndura zwecks genauer histologischer Untersuchung herausgenommen. Das Resultat war nach mehreren Richtungen hin interessant. Zunächst einmal konnte man entlang dem Punktionskanal bis etwa zur Mitte desselben eine mächtige entzündliche Infiltration nachweisen (conf. Abb. V). Innerhalb derselben fanden sich beträchtliche Bakterienmassen. Jedoch waren einzelne Bakterien bereits bis an die Durainnenfläche vorgedrungen. Da man diesen Bakteriennachweis schon einige Stunden nach der Punktion erbringen konnte, ist es gar nicht ausgeschlossen, daß, sofern in unserem Falle der Patient am Leben geblieben wäre, schwere Folgen sich an die Kleinhirnpunktion später hätten anschließen können. Da ich außerdem während meiner Assistentenzeit einen Fall beobachtet hatte, bei dem sich an eine ohne positives Resultat ausgeführte Großhirnpunktion eine diffuse Encephalitis des Schläfenlappens anschloB, welcher der Patient erlag, bin ich persönlich geneigt, die Indikation zu exploratorischen Eingriffen am Zerebrum schwerer zu stellen, als ich es vielleicht ohne diese Erfahrungen tun würde.

Sinusthrombose.

Zum Schlusse meiner Ausführungen komme ich auf einige für die Entstehung der Sinusthrombose wichtige Momente zu sprechen. Wie aus dem zweiten Teil meiner experimentellen Versuche hervorgeht, fanden sich in zwei Fällen (Hund IV und $X$ ) Thrombosen innerhalb des langen Blutleiters, die auf

1) Conf. Streit, Ưber otologisch wichtige Anomalien der Hirnsinus usw. Archiv f. Ohrenheilk. 58. 
eine andere Art entstanden waren, als es z. B. Haymann in seiner zusammenfassenden Arbeit beobachten konnte. Der Infektionsmodus war, wie aus meinen Obduktionsprotokollen hervorgeht, folgender: Es hatte sich an der Infektionsstelle eine Pachymeningitis interna gebildet, welche entlang der Innenfläche der Dura fortgeschritten und auf die zerebrale Wand des Sinus übergegangen war. Die äußeren Duralamellen waren unmittelbar am Sinus gar nicht oder nur wenig zellig infiltriert. Dementsprechend wies auch die kranielle Zirkumferenz des Sinus gar keine resp. nur unbedeutende Entzündungserscheinungen auf. Die Hauptbedeutung der vorher geschilderten experimentellen Beobachtung scheint mir darin zu liegen, daß sie eine gute Erklärung für den Infektionsmodus im Falle von Sinusthrombosen bietet, in welchen der Knochen des Processus mastoideus nicht bis an den Sinus heran erkrankt ist. Körner ${ }^{1}$ ) nimmt an, daß bei derartigen Beobachtungen die Thromben kleiner Blutgefäße in den Sinus hineingewachsen sein können und auf diese Weise zu einer Thrombose des queren Hirnblutleiters Veranlassung gegeben haben. Ich will mich an dieser Stelle über die viel diskutierte Frage des Fortschreitens derartiger angenommener Thromben nicht näher einlassen, da ich eine Erörterung dieses Punktes - soweit der spezielle Fall in Frage kommt - für nicht so dringend halte. Meiner Ansicht nach kann bei derartigen Beobachtungen die Sinusthrombose beim Menschen in gleicher Weise entstehen, wie ich sie experimentell beim Tier erzeugt habe, also infolge Fortschreitens einer Pachymeningitis interna auf die innere Sinuswand. Soweit mir die Fachliteratur bekannt ist, ist auf diese durchaus naheliegende Möglichkeit bisher noch nicht von anderer Seite hingewiesen worden. In solchen Fällen können eventuell nach einfacher Aufmeißelung des Warzenfortsatzes ohne Sinusfreilegung durch Entfernung des primären Herdes die pyämischen Symptome etwa in gleicher Weise aufhören, wie es nach der Aufdeckung perisinöser Herde nicht selten beobachtet wird.

Kehre ich nun nach dieser Exkursion zur weiteren Beschreibung der Befunde in den beiden experimentellen Beobachtungen Hund IV und $\mathrm{X}$ zurück, so fehlte an den entzündlich veränderten Stellen nach dem Lumen des Gefäßes zu das Grenzendothel entweder vollkommen, oder man konnte nur

1) Körner, Die otitischen Erkrankungen des Gehirns usw. 1902 und Nachtrag 1908. 
Reste desselben konstatieren. An einzelnen Punkten erschien das Endothel eigentümlich aufgekippt, als ob es durch den Druck der unter ihm liegenden Infiltrationszellen geborsten sei. Schwärme von Leukocyten stellten die direkte Verbindung zwischen der Wand des Gefäßes und dem Lumen desselben her. - Im zweiten Falle war das Endothel noch ziemlich gut erhalten; nur an d e n Stellen, wo thrombotische Auflagerungen aufsaBen, ließ es sich nicht deutlich herausdifferenzieren. Die Thromben selbst setzten sich aus Fibrin, Leukocyten und roten Blutkörperchen zusammen. In beiden Fällen fanden sich neben den adhärenten, den eigentlichen Ursprung der Thrombenbildung darstellenden Parietalthromben innerhalb des Gefäßlumens freie Thrombenmassen, die allem Anscheine nach zunächst wohl an irgendeiner Stelle mit dem wandständigen Thrombus in Verbindung gestanden haben. In einem der beiden Fälle bestand zwischen den recht bedeutenden, fast das ganze Lumen des GefäBes ausfüllenden Thrombenmassen und der Wand des Gefäßes nur an einer scharf ur.grenzten Stelle, und zwar innerhalb einer schmalen zipfelartigen Fortsetzung des Sinuslumens, ein direkter Zusammenhang. Außerdem fand sich noch an einem anderen Punkte der Gefäßwand ein zweiter, mikroskopisch kleiner Thrombus. Hier schien das Endothel zu fehlen; an Stelle desselben verlief der Wand des Sinus ein dünner Fibrinsaum parallel. Diese minimale thrombotische Auflagerung ließ sich gerade an einer Ausbuchtung des Gefäßes nachweisen, wo augenscheinlich eine verminderte Stromgeschwindigkeit bestand. In beiden Fällen konnte man Bakterien sowohl in der entzündeten Gefäßwand als innerhalb der vorhandenen Thromben nachweisen. Ferner konnte man genau die Straße bestimmen, welche die Infektionserreger durch die zerebrale Wand des Sinus bis in das Innere desselben hinein genommen hatten.

Beide vorher skizzierten Momente, Endothelschädigung und Herabsetzung der Stromgeschwindigkeit des Blutes, haben sicher bei der Entstehung der Thrombenbildung in diesem Falle eine nicht geringe Bedeutung. In ähnlicher Weise, wie das Innenendothel der Dura einen Wall gegenüber einer nach dem Zerebrum zu fortschreitenden Infektion darstellt, schützt das Endothel des Hirnsinus recht bedeutsam den Körper gegenüber einer pyämischen Allgemeininfektion. Wie ich in einem Falle (Hund III) meiner ersten Arbeit beobachten konnte, kann es mitunter infolge entzündlicher Infiltration 
zu Ausbuchtungen und Aufbuckelungen der Gefäßwand kommen, die zwar das Gefäßlumen verengen, jedoch keineswegs, sobald das Endothel erhalten ist, zur Thrombenbildung führen. Gleiche Beobachtungen hat auch Haymann gemacht. Im übrigen ist es mitunter gar nicht so leicht, mit Bestimmtheit zu sagen, ob wandständige entzündliche Veränderungen an der Sinuswand zum Teil wenigstens unterhalb des Endothels entstanden sind, ob also eine typische zirkumskripte Pachymeningitis interna der Sinuswand vorhanden ist, oder ob es sich um Ausscheidungsprodukte des Blutes selbst, eine richtige wandständige Thrombose handelt. Ein illustratives Beispiel hierzu bietet mein Fall F. K. In demselben verlief der äußeren Wand des Sinus sigmoideus ein zweifacher, wohl entzündlich entstandener Saum parallel, und zwar erstens ein älterer, bereits in bindegewebiger Organisation befindlicher Streifen und zweitens nach außen von demselben eine typische fibrinöse Pachymeningitis externa jüngeren Datums. Die Wand des Gefäßes selbst war nur in mäßigem Grade entzündlich infiltriert. Nach dem Lumen zu saß derselben eine aus Fibrinmassen, roten Blutkörperchen und Leukocyten bestehende Auflagerung von der Form einer flachen Kalotte auf. Wie ersichtlich, hatte diese letztere durchaus die Gestalt und Zusammensetzung eines parietalen gemischten Thrombus (conf. Abb. V). Auffällig war nur der Umstand, daß über die Randpartien dieser Auflagerung sich das Grenzendothel der anschließenden Sinuswand noch ein Stückchen herüberzog. Mehr nach der Mitte der Auflagerung zu fanden sich an einzelnen Stellen mehrfache parallel verlaufende, das Sinuslumen abgrenzende Zellenlagen. Aus dem Bilde allein zu entscheiden, $o b$ es sich um gewucherte Endothelien oder um junge Bindegewebszellen handelte, machte gewisse Schwierigkeiten. Die sich der Oberfläche parallel streckende langgezogene Gestalt dieser Zellen, sowie ihr Verhältnis zum angrenzenden Gewebe sprach allerdings mehr dafür, daß man es mit Fibroblasten zu tun habe. Es handelt sich also in unserem Falle um eine Auflagerung an der Sinuswand, welche ihrer ganzen Struktur nach wohl als parietaler Thrombus aufzufassen ist, deren Ränder sich jedoch ein Stück unter das Endothel der Sinuswand herunterschoben. Die Frage liegt nahe, ob diese Randpartien des Thrombus unter dem Endothel selbst entstanden sind, oder ob der Thrombus sich zwischen Endothel und Sinuswand gewissermaßen von der Seite her hereingebohrt hat, oder ob sich ein neugebildetes Endothel über die Randpartien 
des Thrombus herübergezogen hat. Es dürfte schwer sein, hierüber ein entscheidendes Urteil zu fällen.

Wie aus der beigefügten Zeichnung des Falles (conf. Abb. V) hervorgeht, hängt mit der Oberfläche des Parietalthrombus nur an einer umschriebenen Stelle ein frei im GefäBlumen flottierendes Gerinnsel zusammen, dessen Lösung und Verschleppung durch den Blutstrom nach Lage der Situation vielleicht nahe bevorstand.

Man muß annehmen, daß der soeben beschriebene parietale Thrombus seiner ganzen Struktur nach relativ jüngeren Datums war. Jedenfalls ist er bereits zur Zeit der zweiten Operation vorhanden gewesen, da man ihn nach Spaltung des Sinusrohrs vollkommen sicher makroskopisch nachgewiesen hatte. Außerdem fand man bei dem gleichen Falle an einem anderen Punkte der Gefäßwand, auf dem Boden einer älteren Pachymeningitis interna aufsitzend, einen etwa stecknadelkopfgroßen fast rein roten Thrombus (conf. Abb. VI), sowie ganz abliegend von der Stelle der Thrombosierung an der gegenüberliegenden Wand des Sinus ein minimales, nur mikroskopisch nachweisbares aus Blutplättchen sich zusammensetzendes Gerinnsel. Dieses letztere thrombotische Bröckelchen sa $B$ ebenfalls in fester organischer Verbindung mit der Gefäßwand. Das Innenendothel des Sinus erschien hier eigentümlich aufgekippt (conf. Abb. VII).

Die Sinuswand selbst enthielt nur relativ spärliche Bakterien, desgleichen der zuerst beschriebene wandständige Thrombus. In letzterem fanden sich Bakterien, besonders in den jüngsten an das Sinuslumen grenzenden Partien. Wichtig ist ferner, daß die vorher geschilderte frei flottierende Exkreszenz dieses Thrombus gleichfalls bakteriell infiziert war. Im allgemeinen konnte man die Bakterien fast stets in den dem Lumen zunächst liegenden Teilen der Thromben nachweisen. Diese ganze Anordnung der Infektionserreger, besonders ihr Vorkommen frei im Gefäßlumen innerhalb eines feinen der Gefäßwand aufsitzenden Detritus (vielleicht zum Teil Blutplättchen), ließ den Gedanken diskutabel erscheinen, daß die Bakterien bei der Eröffnung des Gefäßrohrs in dasselbe gelangt sind. Allerdings ist es mir sehr wohl bekannt, daß man anch sonst ohne Erôffnung des Sinus häufig die meisten Bakterien in den jüngsten thrombotischen Auflagerungen vorfindet [conf. Haymann, Uffenorde $e^{x}$ ].

1) Uffenorde, Beiträge zur otogenen Allgemeininfektion. Zeitschr. f. Ohrenheilk. 60. 
Wenngleich man, wie schon Haymann betont, über das Alter eines Thrombus kaum jemals wird genaue Auskunft geben können, scheint es mir ferner wohl möglich, daß sowohl der rote als der Blutplättchenthrombus erst bei resp. infolge des Operationstraumas entstanden sind. In meinem Falle hätte also die Gefäßeröffnung unter gewissen Umständen mehr Schaden als Nutzen bringen können.

Wenngleich der vorher besprochene Fall also, allerdings mit Ausnahme der Bildung des bereits vor der Eröffnung des Sinus vorhanden gewesenen größeren wandständigen Thrombus, nicht notgedrungenerweise die Vorgänge widerspiegeln muß, die sich bei der natürlichen Thrombenbildung abspielen, da infolge der Spaltung des Sinus durchaus andere Infektionsverhältnisse gegeben waren, so illustriert er doch deutlich, welche pathologisch-anatomischen Ereignisse nach der Eröffnung des Sinus resp. infolge derselben bereits in wenigen Stunden innerhalb des Gefäßrohres eintreten können.

Ein wohl besseres einwandfreies Bild für die natürlichen Vorgänge bei der Thrombenbildung, und zwar ihre allerersten Anfänge, gibt Fall F. E. Bei der Operation hatte man den Knochen bis an den Sinus heran erkrankt gefunden, der Patient war zehn Tage post operationem an einer schweren Hals- und Brustphlegmose ad exitum gekommen. Bei der histologischen Untersuchung fand man nur eine starke Pachymeningitis externa, eine entzündliche Infiltration der Sinuswand selbst sowie eine ausgesprochene Pachymeningitis interna. Diese letztere setzte sich aus gelapptkernigen Leukoeyten, mononukleären Elementen und Zellen mit großen blassen Kernen zusammen und übertraf in ihrer seitlichen Ausdehnung die Pachymeningitis externa. Das Innenendothel war fast überall erhalten; mit einer Ausnahme allerdings. An mehreren Stellen, und zwar miteinander nicht in direkter Verbindung stehend (conf. Abb. IX), saßen der Gefäßinnenwand mikroskopisch kleine Exkreszenzen auf, die sich aus einem formlosen Detritus mit eingestreuten gelapptkernigen Leukocyten zusammensetzten.

Trotzdem eine sichere Fibrinreaktion nicht bei sämtlichen dieser Auflagerungen vorhanden, bei andern nur in einzelnen Schnitten angedeutet war, muß man doch annehmen, daß diese Exkreszenzen, und zwar ihrem ganzen Aufbau und ihrer Struktur nach, sich zum Teil aus Fibrin zusammensetzten. Thre Basis stand in unmittelbarem innigstem Gewebskonnex zur Gefäßwand, ein sicheres Endothel ließ sich hier nicht 
nachweisen. Bakterien fanden sich sowohl innerhalb der Pachymeningitis externa als auch in der Gefäßwand und im Innern der Pachymeningitis interna. Wenngleich es nicht gelang, innerhalb sämtlicher dieser kleinsten thrombotischen Auflagerungen Bakterien nachzuweisen, so will dieses negative Ergebnis nicht viel sagen. In einzelnen dieser kleinen Thromben fanden sich jedenfalls mit absoluter Sicherheit Bakterien vor.

Wir haben es also im vorher beschriebenen Falle mit den allerersten Stadien der Thrombenbildung beim Menschen zu tun.

Ich habe ferner nachgewiesen, daß auch diese mikroskopisch kleinsten Thromben bereits infiziert sein können. Natürlich darf man daraus nicht mit Sicherheit folgern, daß sie es in allen Fällen sein müssen.

So viel ist sicher, daß nur die allerersten Stadien der Thrombenbildung zur Entscheidung der vorher berührten wichtigen Frage in Betracht kommen können. Wenn Mahler ${ }^{1}$ ) bei einem Falle von Thrombose, bei dem die ursprünglichen Thrombenmassen zum großen Teil bereits durch Granulationsgewebe ersetzt waren, infolge negativen Bakterienbefundes sich zur Annahme berechtigt glaubt, einen toxischen Ursprung des nachgewiesenen Thrombus anzunehmen, so kann dies meiner Ansicht nach sehr wohl ein Trugschluß sein. Ein derartiger Thrombus ist sicher nicht mehr ganz jungen Datums, aus ihm können die ursprünglich vorhandenen Bakterien bereits wieder verschwunden sein. Die Verhältnisse liegen hier anscheinend ähnlich wie bei der Entstehung der Pachymeningitis interna resp. Leptomeningitis; ich verweise auf meine an dieser Stelle gemachten Äußerungen

Ebenso wie bei den zuletzt erwähnten Erkrankungen werden vereinzelte Bakterien innerhalb der thrombotischen Auflagerungen nicht selten übersehen werden; zumal bei gleichzeitiger Anwesenheit von Fibrinbalken dürfte ein Irrtum nach dieser Richtung hin naturgemäß kein seltenes Ereignis sein. Dazu kommen noch technische Färbefehler usw., so daß alle diese Fehlerquellen bei dem oft winzigen $\mathrm{zu}$ inspizierenden Terrain wohl genügen dürften, zuweilen eine falsche Vorstellung von der Entstehung derartiger kleiner Thromben zu erwecken.

Wenn man sich die Ha y mann schen Fälle unter Anlegung

1) Mahler, Kasuistischer Beitrag zur Pathologie und Klinik der otogenen aseptischen Sinusthrombose. Monatsschr. f. Ohrenheilk. XLV. Heft 11 . 
dieses Maßstabes ansieht, so fällt auf, daß Haymann in der überwiegenden Mehrzahl seiner Beobachtungen Bakterien gefunden hat. Berücksichtigt man aus den vorher diskutierten Gründen nur die frischeren experimentell erzeugten Niederschläge an der Sinuswand, so bleiben überhaupt nur drei von den 26 Haymannschen Fällen übrig, Hund 19, Hund 2 und Hund 5. Was zunächst Hund 19 betrifft, so ist erstens einmal auffällig, daß, trotzdem durch die Sinusinzisionswunde Knochenstückchen in das Lumen des Gefäßes eingedrungen waren, Bakterien nicht an dieser Stelle nachgewiesen werden konnten. Bei Hund 5 handelte es sich um einen wohl sehr kleinen Blutplättchenthrombus. Das die Verletzungsstelle verschließende rotbraune Gerinnsel bei Hund 2 kann man wohl kaum einen Thrombus nennen. Man sieht also, daß auch durch die in dieser Hinsicht so außerordentlich wichtige Arbeit Haymanns die Lehre, daß der entstandene Thrombus unter Umständen p r i m ä r nicht infiziert ist, meiner Ansicht nach keineswegs mit absoluter Beweiskraft gestützt wird. Trotzdem will ich andrerseits diese letztere Auffassung nicht für unmöglich halten mit Rücksicht auf die Versuche Talkes ${ }^{1}$ ), Haymanns und die Bondysche Arbeit ${ }^{2}$ ).

Infolge dieser Erwägungen fasse ich meine Ansicht dahin zusammen, die meisten Thromben sind bereits primär infiziert (Leutert). Unter Umständen, allerdings seltenermag es vorkommen, daß thrombotische Auflagerungen sich auch infolge toxischer Einflüsse bilden.

Wie aus der beigefügten Abbildung IX hervorgeht, können die kleinsten thrombotischen Auflagerungen augenscheinlich ziemlich gleichzeitig diskontinuierlich entștehen. Diese Beobachtung bietet also èin schönes Paradigma für das Vorkommen mehrerer Thromben im selben Falle. Weshalb gerade an den betreffenden Stellen der ThrombosierungsprozeB vonstatten ging und nicht in der Zone zwischen ihnen, lag wohl in lokalen Gründen, und zwar in besonders starker Schädigung des Endothels. Wenigsfens ließ sich das Endothel sowohl vor als hinter als auch zwischen den beiden Thromben als deutlicher Saum nachweisen, fehlte jedoch an der Stelle, wo die Thromben selbst aufsaßen. Die Substanz der Thromben stand in organisch fester Verbindung

1) Talke, Bruns' Beiträge zur klinischen Chirurgie, Bd. 36.

2) Bondy, Zur Klinik und Pathologie der otitischen Sinusthrombose. Monatsschr. f. Ohrenheilk. XLII, 9. 
mit dem daruntergelegenen entzündlich veränderten Gewebe der Gefäßwand, ohne Spur einer abgrenzenden Endothelmembran. Eine lokale zirkumskripte, besonders stark entzündliche Schwellung der Wand am direkten Sitze des Thrombus (im Sinne Uchermanns) habe ich nicht nachweisen können. Haymann fand bei seinen experimentellen Beobachtungen sechs diskontinuierliche Thromben. Drei waren der Ansicht des Autors nach angeschwemmt. In den übrigen Fällen fand sich der zweite Thrombus in der Nähe einer thrombosierten Duravene.

Haymann ist der Ansicht, daß ein solcher ins freie Sinuslumen vorspringender Venenpfropf zu einer frischen, von der primären Pfropfbildung abliegenden Gerinnselbildung Veranlassung geben kann. Diese Auffassung hat natürlich viel Bestechendes an sich. Ich teile sie durchaus. Doch alle diese Ursachen sind für gewisse Fälle von diskontinuierlicher Thrombenbildung nicht notwendig. Bedingung hierfür ist dagegen eine entzündliche Veränderung der Sinuswand sowie eine lokale verschieden weit vorgeschrittene Schädigung des Endothels. Diese beiden Gründe, Wandveränderung und Endothelschädigung, genügen vollkommen als Erklärung für die Entstehung der wandständigen Thromben, demnach also des ersten Stadiums fast sämtlicher Thromben am Sinus überhaupt; denn die alte Leutertsche Ansicht, dab - ich füge hinzu "fast" - sämtliche Thromben zunächst wandständig entstehen, besteht meiner Ansicht nach mit der vorher gemachten Einschränkung auch jetzt noch zu Recht. Daß natürlich lokale Thrombosierungsprozesse lokal bleiben und ausheilen können, leuchtet ohne weiteres ein; überhaupt besteht eine Ausheilungsmöglichkeit, und zwar sicher keine geringe, für jedes Stadium der Thrombenbildung vom wandständigen Thrombus an bis zur obturierenden Thrombose.

Andererseits ist es - allerdings wohl sehr selten - denkbar, daß unter besonderen Umständen bei nur geringfügiger Wandveränderung eine plötzliche, gewissermaßen apoplektiforme Thrombosierung größerer Teile der Blutsäule (Haymann) ${ }^{1}$ auftreten kann. Auch halte ich es wohl für möglich, daß mitunter durch Vermittelung des Sinusrohrs größere Mengen von Bakterientoxinen infolge plötzlicher Resorption ein foudroyant einsetzendes, pyämisch-septisches, gewöhnlich

1) Haymann, Úber experimentelle Sinusthrombose. Münch. Laryngol.-otolog. Gesellschaft, 23. Januar 1911. 
schnell zum Tode führendes Krankheitsbild ohne jede Thrombenbildung hervorrufen können (conf. Haymann). Ich selbst habe während meiner Assistentenzeit einen einschlägigen Fall beobachtet, den ich mir in dieser Weise erklären muß. Es handelte sich um einen kräftigen Mann, der wegen einer völlig unkomplizierten akuten Mastoiditis aufgemeißelt wurde. Während der Operation wurde der Sinus freigelegt. Er sah normal aus. Dieses freigelegte Sinusstück verfärbte sich unter meinen Augen am Operationstage derartig, daß es wie eine gangränöse Hernie aussah. Der Mann bekam einen sehr schwappenden Puls, zunächst ohne Temperaturerhöhung. Am nächsten Tage trat Fieber ein und nach noch nicht zweimal 24 Stunden post operationem erfolgte der Exitus. Die Obduktion ergab nirgends eine Spur von Thrombenbildung, im übrigen das typische Bild der Sepsis. Das verfärbte Sinusstück war grüngelb, bot jedoch auf seiner Innenfläche normalen Glanz, es fehlte jede Spur von Rauhigkeit. Leider hielt der obduzierende pathologische Anatom eine histologische Untersuchung des verfärbten Sinusabschnittes nicht für notwendig, da ihm der Fall absolut klar war. Schließlich hätte ja auch der eventuelle Nachweis mikroskopisch kleiner thrombotischer Auflagerungen zur Klärung dieser Beobachtung selbst nicht viel beitragen können, da derartige minimale Gerinnsel unmöglich eine genügende Begründung für die Schwere des Falles abgegeben hätten. Histologisch interessant wäre natürlich dieser Nachweis trotzdem gewesen.

Jedentalls sind die letzterwähnten Beobachtungen alles mehr oder weniger Ausnahmen, die praktisch nur relativ wenig in Betracht kommen.

Gewöhnlich entsteht der Thrombus parietal infolge einer entzündlichen Veränderung resp. Infektion der Sinuswand. Doch genügt diese erstere wichtige Ursache allein niemals zur Thrombenbildung. Die Infiltrierung der Gefäßwand kann beliebige Stärke annehmen, ja beinahe zum Verschluß des Lumens führen; es entsteht kein Thrombus, sobald nicht die zweite Grundbedingung, ein Verlust des Endothels, hinzukommt.

Als wichtiges prädisponierendes Moment zur Thrombenbildung kommen unter gewissen Umständen Veränderungen in den normalen Strömungsverhältnissen des Blutes (Wirbelbildungen, Einengungen resp. lokale Ausbuchtungen des Gefäßrohrs) in Betracht. 
Archiv f. Ohrenheilkunde. 89. Bd.
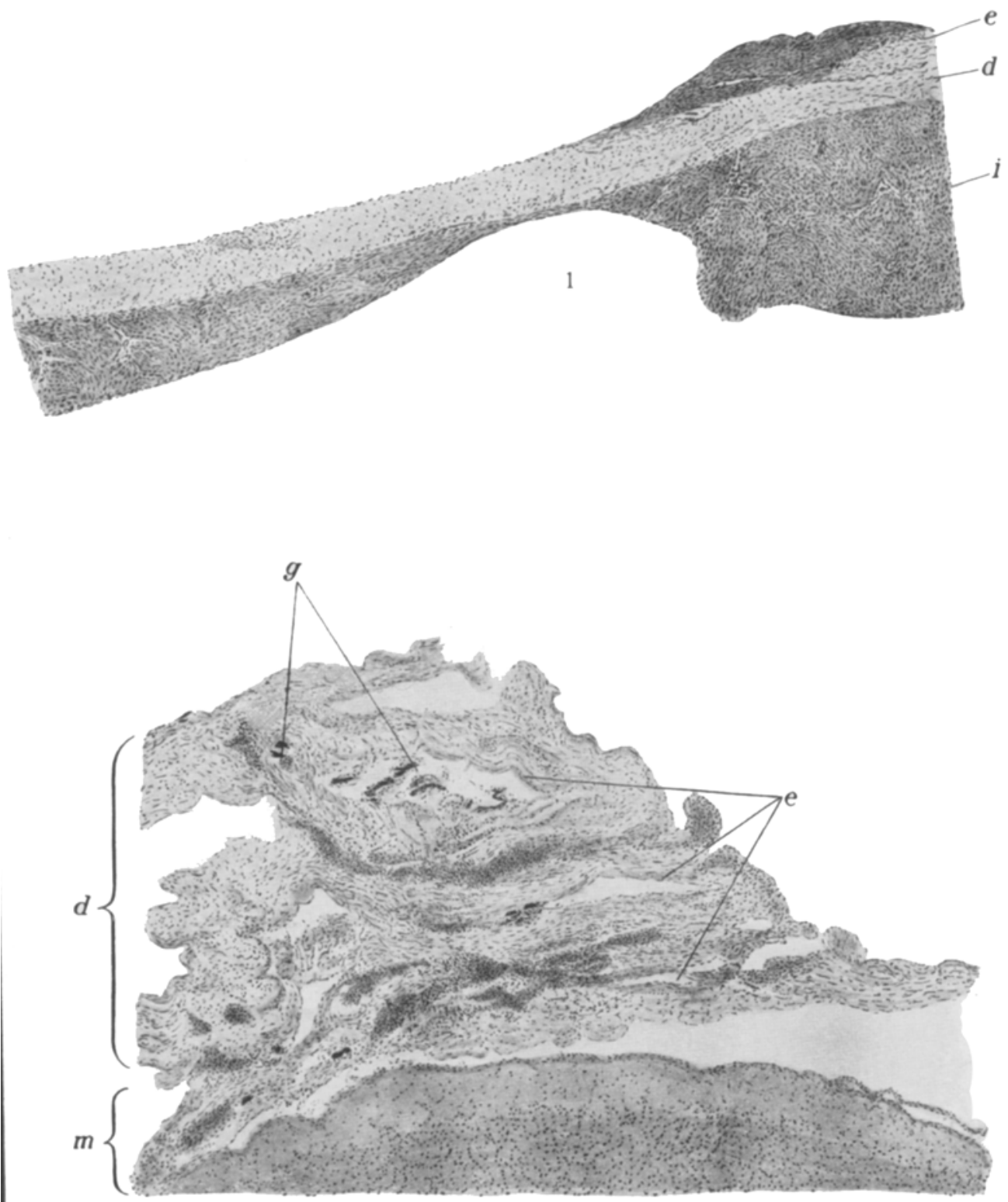
Tafel VI. VII.
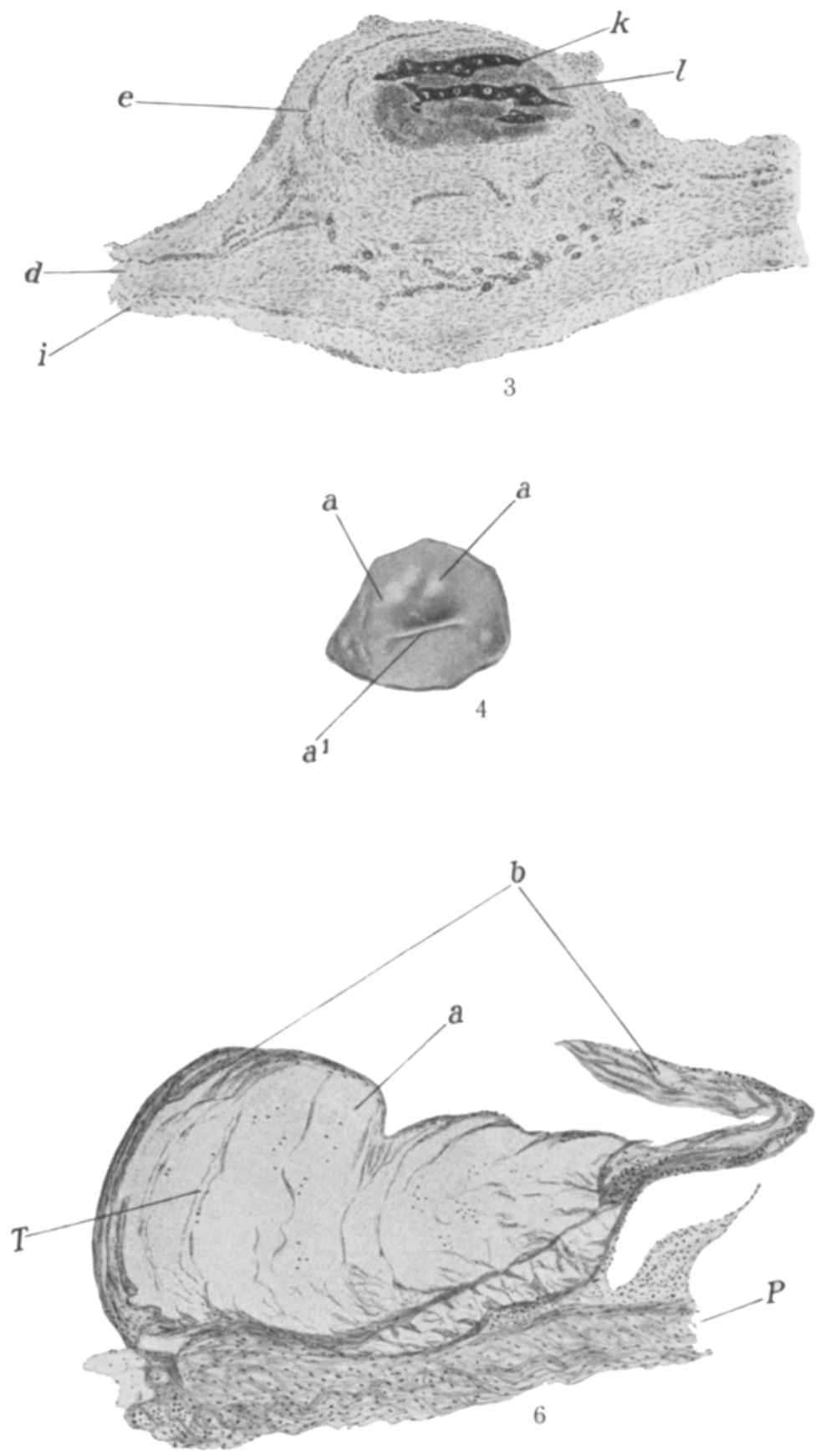
chiv f. Ohrenheilkunde 89. Bd.

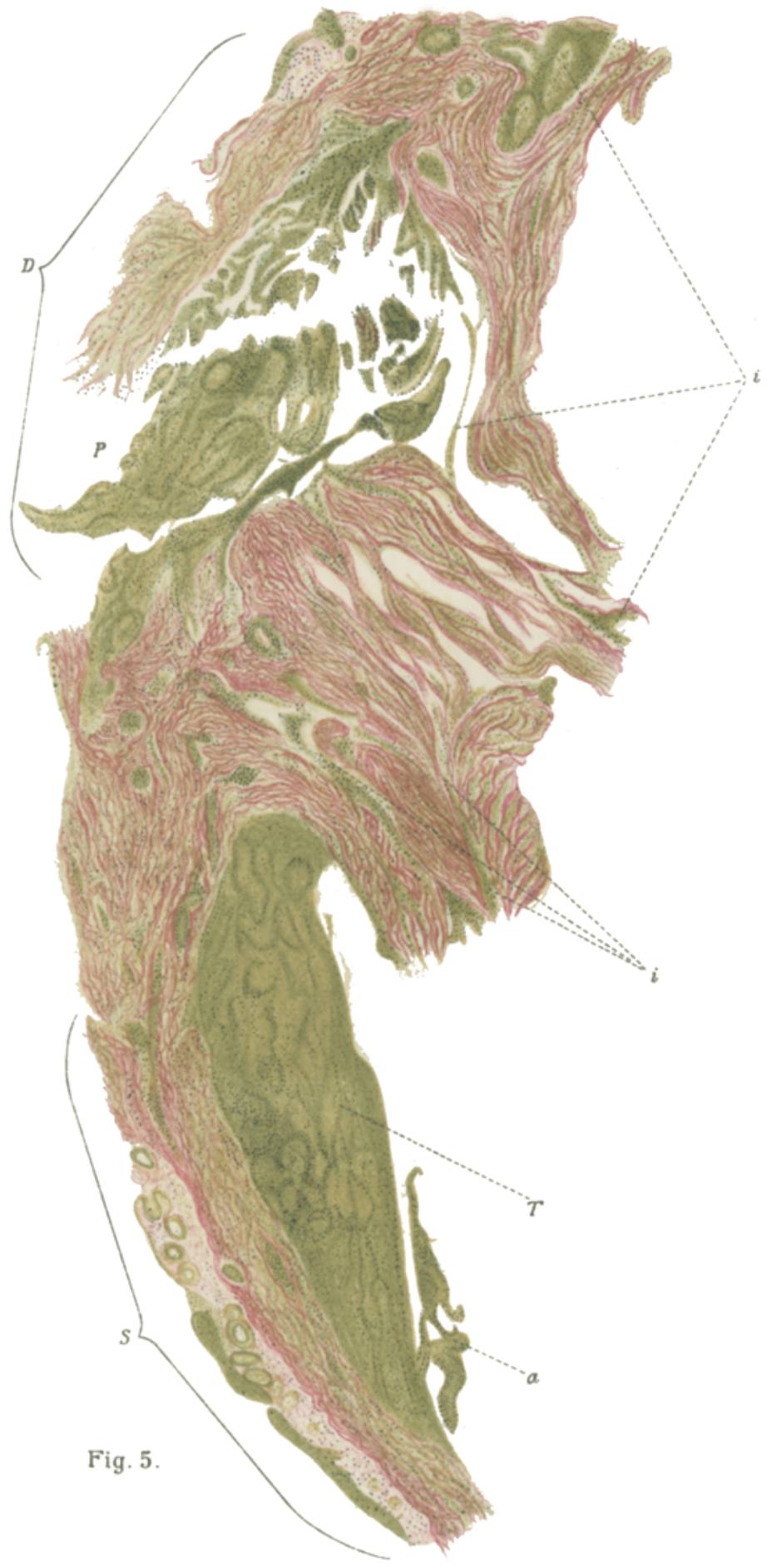


Tafel VIII.

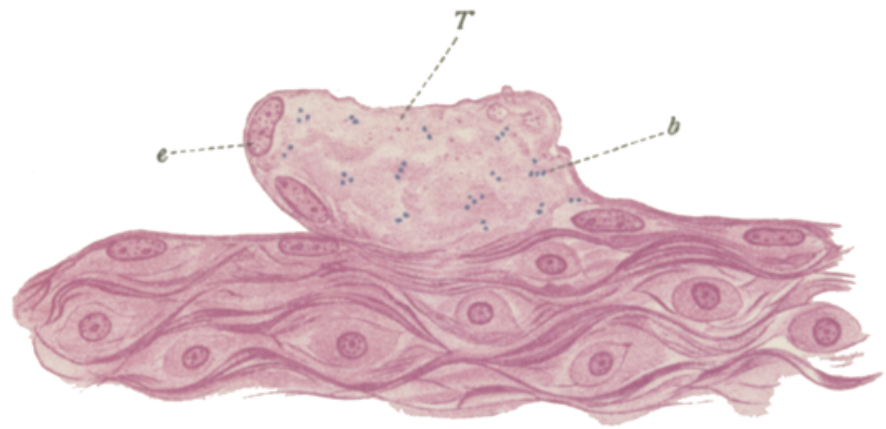

Fig. 7.

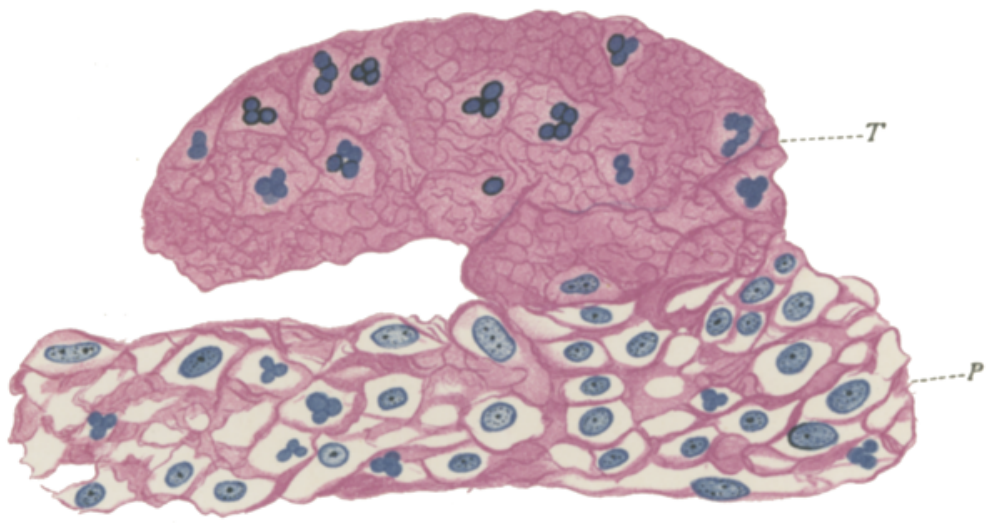

Fig. 8.

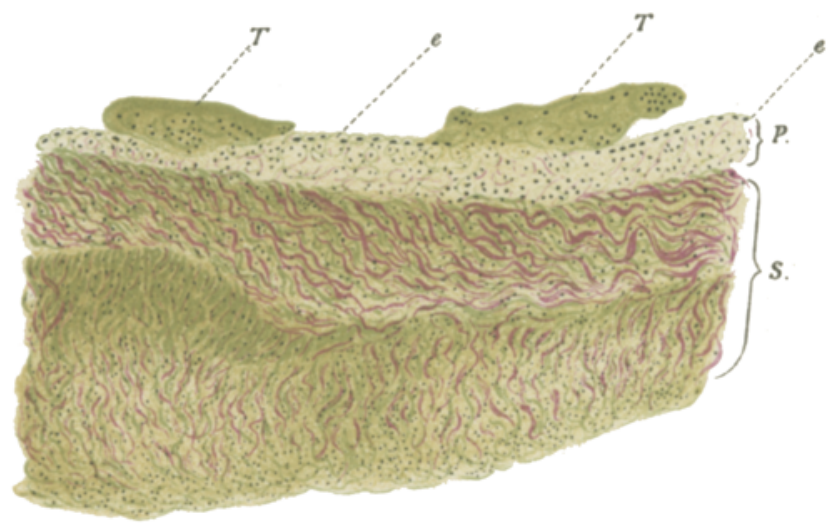

Fig. 9. 
Weitere Beiträge z. Histologie u. Pathologie d. Meningitis usw. 237

\section{Erklärung der Abbildungen auf Tafel VI-IX.}

Abb. I. Ausgeheilte Pachymeningitis externa und interna, (Hund 4.

Serie I. 20 Tage post infectionem.)

$e=$ Pachymeningitis externa

$d=$ Dura

$i=$ Pachymeningitis interna.

Abb. II. Mächtige knäuelartige Dura-Meningealnarbe nach Duraverletzung. (Katze 3. Serie I. 14 Tage post infectionem.)

$d=$ Dura

$m=$ weiche Hirnhäute

$e=$ neugebildete mit Endothelien ausgekleidete Hohlräume

$y=$ Gazefäserchen.

Abb. III. Auf der Duraaußenfläche eingeheilte Knochensplitter mit umgebendem Leukocytenwall und Bakterien. (Hund 5. Serie I. 6 Wochen post infectionem.)

$e=$ Pachymeningitis externa

$k=$ KnochenmeiBelsplitter

$l=$ Leukocytenwall

$d=$ Dura

$i=$ Pachymeningitis interna.

Abb. IV. Makroskopisches Bild einer zirkumskripten Pachymeningitis interna $(a)$ mit scharf abbrechendem Rande $\left(a_{1}\right)$. (Hund 3. Serie II.)

Abb. V. Fall F. K. - Sinuswand $(S)$ mit parietalem Thrombus $(T)$.

Auf dem letzteren aufsitzende, im Lumen frei flottierende Exkreszenz $(a)$. Kleinhirndura $(D)$ mit Punktionskanal $(P)$. Entzündliche Infiltration $(I)$.

Abb. VI. Fall F. K. - Frischer roter Thrombus $(T)$, aufsitzend auf älterer Pachymeningitis interna $(P)$.

$a=$ rote Blutkörperchen

$b=$ Fibrin.

Abb. VII. Fall F. K. - Frischer Blutplättchenthrombus $(T)$ init Bakterien (b). Endothelien der Sinuswand aufgekippt $(e)$.

Abb. VIII. Fall F. E. - Gemischter knopfförmiger Thrombus $(T)$. $P=$ Pachymeningitis interna.

Abb. IX. Fall F. E. - Diskontinuierlich entstandene parietale

Thrombose.

$S=$ Sinuswand

$P=$ Pachymeningitis interna

$T=$ Thromben

$e=$ Endothel. 